UNIVERSIDADE DE SÃO PAULO

FACULDADE DE MEDICINA DE RIBEIRÃO PRETO

PROGRAMA DE PÓS-GRADUAÇÃO EM GENÉTICA

FLÁVIA PORTO PELÁ

Associação do polimorfismo INS-VNTR com a susceptibilidade ao diabetes mellitus tipo 1, tipo 2 e gestacional na população urbana brasileira. 
FLÁVIA PORTO PELÁ

\section{Associação do polimorfismo INS-VNTR com a susceptibilidade ao diabetes mellitus tipo 1, tipo 2 e gestacional na população urbana brasileira.}

Dissertação apresentada à Faculdade de Medicina de Ribeirão Preto da Universidade de São Paulo para obtenção do título de Mestre em Ciências.

Área de Concentração: Genética

Orientador: Prof. Dr. Eduardo Antonio Donadi

RIBEIRÃO PRETO 
AUTORIZO A REPRODUÇÃO E DIVULGAÇÃO TOTAL OU PARCIAL DESTE TRABALHO, POR QUALQUER MEIO CONVENCIONAL OU ELETRÔNICO, PARA FINS DE ESTUDO E PESQUISA, DESDE QUE CITADA A FONTE.

PELÁ, FLÁVIA P.

ASSOCIAÇÃO DO POLIMORFISMO INS-VNTR COM A SUSCEPTIBILIDADE AO DIABETES MELLITUS TIPO 1, TIPO 2 E GESTACIONAL NA POPULAÇÃO URBANA BRASILEIRA. Ribeirão Preto, 2012.

Número de páginas: 115.

Dissertação de Mestrado apresentada à Faculdade de Medicina de Ribeirão Preto da Universidade de São Paulo.

Área de Concentração: Genética.

Orientador: Donadi, Eduardo Antonio

1. Diabetes mellitus tipo 1; 2. Diabetes mellitus tipo 2; 3. Diabetes mellitus gestacional; 4. Polimorfismo INS-VNTR;

5. Insulina. 


\section{FOLHA DE APROVAÇÃO}

\section{FLÁVIA PORTO PELÁ}

\section{Associação do polimorfismo INS-VNTR com a susceptibilidade ao diabetes mellitus}

tipo 1, tipo 2 e gestacional na população urbana brasileira.

Dissertação apresentada à Faculdade de Medicina de Ribeirão Preto da Universidade de São Paulo para obtenção do título de Mestre em Ciências.

Área de Concentração: Genética

Aprovado em:

Banca Examinadora

Prof. Dr.

Instituição: Assinatura:

Prof. Dr.

Instituição: Assinatura:

Prof. Dr.

Instituição: Assinatura: 
A minha mãe, selma, pela abdicação e amor incondicional, Ao men filho, Guilherme, pela vivêncía da maternidade a qual resume amor, encanto, proteção e delicadeza em único lastro. 
A Deus, por ser o grande pai que caminha ao lado do filho nos desafios do dia a dia, mostrando que paciência e sabedoria são atributos que se conquistam com reflexão e discernimento de cada intercorrência da Vida.

Ao prof. Dr. Eduardo A. Donadi, por toda dedicação para realização deste projeto de pesquisa, pela contribuição em meu processo de formação profissional, pelo seu jeito peculiar de orientar quando estamos desorientados e, principalmente, pela confiança.

Ao prof. Dr. Celso T. Mendes Junior, pela incrível dedicação e acessibilidade em me ensinar a realizar as análises estatísticas.

Aos prof. Dr. Ademilson Espencer e prof. Dr. Aguinaldo Simões, pelos exemplos de dedicação à Coordenação do Programa de Pós-graduação em Genética e ao Departamento de Genética, respectivamente.

Aos demais pesquisadores que compõem o grupo de execução do projeto temático "Transcriptoma do Diabetes mellitus" financiado pela agência de fomento FAPESP. À Dra. Diane Meyre Rassi pela contribuição na etapa da seleção e coleta das amostras. Ao prof. Dr. Milton César Foss, à prof. Dra. Maria Cristina Foss-Freitas e a Dra. Patrícia Moreira pela supervisão clínica e seleção dos pacientes. A prof. Dra. Elza Tiemi Sakamoto-Hojo e o prof. Dr. Geraldo Passos, pela contribuição científica.

Agradeço às colegas do Laboratório de Imunogenética Molecular do Departamento de Genética, aos colegas do Laboratório do Anexo A e do Laboratório de HLA dispostos a auxiliarem sempre que possível diante das intermináveis PCRs, revelações, fotos, listas de pacientes.

Agradeço aos professores pela formação acadêmico-científica.

Agradeço aos funcionários da secretaria do Departamento de Genética, em particular, Susie, Silvia e Maria Aparecida pela prontidão e atenção despendida ao longo desses anos.

Ao CNPq, FAPESP, e FAEPA pela contemplação financeira imprescindíveis para a realização deste projeto. 
Aos membros da banca examinadora pela prontidão, contribuições, críticas e sugestões.

\section{Em especial}

Ao meu filho lindo, Guilherme, pela alegria e sorrisos diários.

A minha mãe, Selma, pelo exemplo de vida, pelo companheirismo e amor incondicional.

Aos meus irmãos, Daniel e Luiz Fernando, que apesar de "chatos" são os melhores e mais lindos.

Ao meu pai, Luiz, pela atenção e paciência em realizar toda a minha logística de transporte rs.

As minhas avós, Omphalia e Carolina, por todo carinho e atenção especiais de vovós.

Aos amigos Juliana Martinez, Priscila Grupinioni, Beatriz Pinto, Thaísa Nogueira, Marcelo Puga , Flávia Balieiro, Paula Froner, Patrícia Froner, Anna Carolina Jode. 


\section{RESUMO}

Pelá, F.P. ASSOCIAÇÃO DO POLIMORFISMO INS-VNTR COM A SUSCEPTIBILIDADE AO DIABETES MELLITUS TIPO 1, TIPO 2 E GESTACIONAL NA POPULAÇÃO URBANA BRASILEIRA. 2012. $115 \mathrm{f}$. Dissertação (Mestrado) - Faculdade de Medicina de Ribeirão Preto, Universidade de São Paulo, Ribeirão Preto, 2012.

O diabetes mellitus (DM) é definido como doença metabólica, caracterizado pela hiperglicemia, causada pela disfunção da secreção de insulina, atividade da insulina ou ambas. É classificado em quatro classes clínicas i) diabetes mellitus tipo 1 (DM1), ii) diabetes mellitus tipo 2 (DM2), iii) diabetes mellitus gestacional (DMG), iv) outros tipos específicos. Dentre os genes conhecidos por influenciarem o mecanismo de produção e liberação de insulina no organismo humano, o gene da insulina (INS) é o mais bem caracterizado nas classes clínicas do DM. A região promotora do gene INS tem sido alvo de estudo em diversas amostras populacionais do mundo, devido a sua capacidade de modular os níveis de expressão de insulina no timo e no pâncreas, de acordo, com a classe alélica que compõe o genótipo do indivíduo. Localizada a 596pb acima do sítio de transcrição do gene da insulina, é estruturada em alelos minissatélites distribuídos in tandem (ACAGGGGTGTGGGG). O alelo classe I (30 - 60 repetições) tem sido associado com predisposição ao DM1, enquanto o alelo classe III (120 - 170 repetições) tem efeito de proteção ao DM1, no entanto, esse alelo tem apresentado correlação ao DM2, à obesidade em crianças e jovens e, aumento de riscos cardiovasculares. O presente trabalho tem como objetivo analisar o polimorfismo da região promotora do gene da insulina sobre os fenótipos do DM e a possível influência desse em características demográficas, clínicas e laboratoriais desses pacientes. Foram analisados 189 pacientes com DM1, 116 pacientes com DM2, 68 pacientes com DMG e 339 indivíduos controle da região de Ribeirão Preto, SP. O DNA genômico foi extraído por salting-out, seguido da amplificação e digestão enzimática do fragmento referente a região promotora do gene INS, o qual contém na sequência downstream, o polimorfismo -23HphI, cujo desequilíbrio de ligação $\left(\mathrm{r}^{2} \approx 1\right)$ com o polimorfismo INS$V N T R$, permite inferir os genótipos por intermédio da análise do polimorfismo -23HphI. Observamos que o alelo classe $I$ e o genótipo classe $I$ : classe $I$ estão relacionados à predisposição ao DM1, enquanto o alelo classe III, predominantemente em homozigose, está associado à proteção ao DM1. Em relação ao DM2, o genótipo classe I : classe III foi associado à susceptibilidade a doença e, nenhum genótipo foi correlacionado ao DMG. De acordo com os dados demográficos, clínicos e laboratoriais, variáveis como 
gênero e pigmentação da pele têm influenciado na frequência do polimorfismo INSVNTR em pacientes com DM1, como por exemplo, a maior frequência de homens com genótipo classe I : classe I no conjunto DM1. Em contrapartida, nesse mesmo grupo de pacientes, o genótipo classe III : classe III evidenciou maior susceptibilidade ao desenvolvimento de retinopatia ( $p=0,0020 ; O R=0,05333 ; 95 \%$ I.C. 0,007839 - 0,3629). Em pacientes com DM2, a comparação entre gêneros evidenciou maior frequência do genótipo classe III : classe III em mulheres. E, em relação ao DMG, os genótipos de classe I : classe I e classe I : classe III estavam associados ao menor nível de glicose no plasma sanguíneo em relação as pacientes que exibiam o genótipo classe III : classe III. Esse é o primeiro estudo de associação do polimorfismo INS-VNTR comparando as três principais classes clínicas de DM oriundas de uma mesma amostra geográfica, sendo evidenciado um perfil genotípico padrão de susceptibilidade de acordo com o tipo de DM.

Palavras-chave: INS-VNTR, -23HphI, diabetes mellitus tipo 1, diabetes mellitus tipo 2, diabetes mellitus gestacional, insulina, população brasileira. 


\begin{abstract}
Pelá, F.P. ASSOCIATION OF THE INS-VNTR POLYMORPHISM WITH SUSCEPTIBILITY TO TYPE 1, TYPE 2 AND GESTATIONAL DIABETES MELLITUS IN THE URBAN BRAZILIAN POPULATION. 2012. $115 \mathrm{f}$. Thesis (Master Degree) - Faculty of Medicine of Ribeirão Preto, University of São Paulo, Brazil, 2012.
\end{abstract}

Diabetes mellitus (DM) is defined as a metabolic disorder characterized by hyperglycemia caused by impaired insulin secretion, insulin activity or both. It is classified into four clinical classes i) type 1 diabetes mellitus (T1DM), ii) type 2 diabetes mellitus (T2DM), iii) gestational diabetes mellitus (GDM), iv) other specific types. Among the genes known to influence the mechanism of production and release of insulin, the insulin gene (INS) has been well characterized in disease susceptibility. The INS promoter has been studied in different worldwide populations due to its ability to modulate expression levels of insulin in the thymus and pancreas, in accordance with the type of diabetes. The major polymorphic site is located 596bp upstream from the translation initiation site of the INS gene and it is structured into minisatellite alleles (ACAGGGGTGTGGGG). The shorter class $I$ alleles $(30-60$ repeats) confers predisposition to DM1 and the longer class III (120 - 170 repeats) confers protection to DM1; however, the latter allele has also shown to be correlated with DM2, obesity in children and juvenile individuals, and increased cardiovascular risks. This study aims to analyze the association of a polymorphic site at promoter region of the INS gene with diabetes phenotypes, with the purpose of evaluating this region as a possible genetic marker of the disease, and the possible influence on demographic, clinical and laboratory features in a sample of the urban Brazilian population. We analyzed 189 T1DM patients, 116 T2DM patients, 68 GDM patients and 339 healthy individuals from the region of Ribeirão Preto, SP. DNA extraction was performed using a salting-out procedure, followed by amplification and restriction enzyme digestion of the fragment relating to INS gene promoter, which contains another polymorphism, $-23 \mathrm{HphI}$, which is in perfect linkage disequilibrium $\left(\mathrm{r}^{2} \approx 1\right)$ with the INS-VNTR, making it an useful genetic marker. We observed that the class I allele and class I : class I genotype are associated with predisposition to T1DM, whereas, class III allele, predominantly in homozygosity, is associated to T1DM protection. In relation to T2DM, the class I : class III genotype has been associated with susceptibility to disease. Finally, no genotype was correlated with GDM. Data stratification according to demographical, 
clinical and laboratory variables, indicated that gender, skin color seemed to influence the frequency of the INS-VNTR polymorphism; i. e., the class I : class I genotype was more frequent in male T1DM patients. On the other hand, the presence of the class III : class III genotype was associated with susceptibility the development of retinopathy $(p=0,0020 ; O R=0,05333 ; 95 \%$ I.C. 0,007839 - 0,3629). In T2DM patients, a trend association was observed between the class III : class III genotype with female diabetic patients. In relation to GDM, the genotypes class I : class I and class I : class III were associated with decreased glucose levels in relation to patients exhibiting the class III : class III genotype. This is the first study of the INS-VNTR polymorphism encompassing the major types if DM patients from the same geographical region, which showed a differential pattern of susceptibility according to the underlying type of DM.

Keywords: INS-VNTR, -23HphI, Type 1 diabetes mellitus, Type 2 diabetes mellitus, Gestational diabetes mellitus, Brazilian population. 


\section{LISTA DE ILUSTRAÇÕES}

Figura 1: Genes de susceptibilidade ao diabetes mellitus tipo 1, classificados de acordo com o risco de susceptibilidade (Odds ratio) à doença, em estudos avaliando o genoma

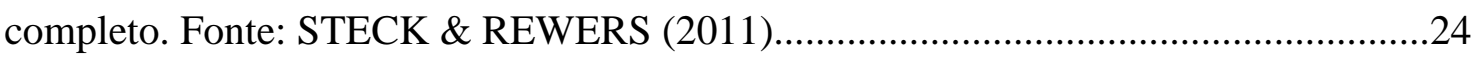

Figura 2: Representação diagramática do cromossomo 11p15.5, incluindo o conjunto de genes TH-INS-IGF2 (Tyrosine Hydroxylase - Insulin - Insulin-like growth factor 2) e mostrando os dez sítios polimórficos presentes na região de susceptibilidade ao DM1 (região conhecida como IDDM2). Os retângulos abertos, fechados e hachurados representam, respectivamente, íntrons, éxons e regiões não transcritas, e o triângulo identifica o sítio INS-VNTR. Fonte: BENNET et al. (1996) .26

Figura 3: Estrutura do gene da insulina com a indicação dos polimorfismos mais relevantes e as enzimas de digestão utilizadas para distinguir as variantes polimórficas. Fonte: Adaptado de PUGLIESE \& MICELI (2002). . .40

Figura 4: Produto de amplificação referente à região promotora do gene da insulina...55 Figura 5: Padrão de bandas obtido pela reação de digestão com a enzima HphI, na região promotora do gene da insulina.

Figura 6: Distribuição das frequências alélicas do SNP -23HphI nas populações de países como Brasil, Reino Unido, Índia, Japão, Zimbabue, Quênia, Cazaquistão e Espanha. .88 


\section{LISTA DE TABELAS}

Tabela 1: Sequências dos iniciadores utilizados na reação em cadeia da polimerase....54

Tabela 2: Condições de amplificação do DNA para tipificação do polimorfismo INSVNTR (quantidade para uma reação)

Tabela 3: Programa utilizado no termociclador GENE Amp* PCR system 9700 para a amplificação do fragmento em análise .55

Tabela 4: Condições para a digestão enzimática do produto de amplificação para avaliar o polimorfismo INS-VNTR (quantidade para uma reação) .56

Tabela 5: Características demográficas, clínicas e laboratoriais dos pacientes com diabetes mellitus tipo 1, tipo 2 e gestacional e dos indivíduos saudáveis .63

Tabela 6: Frequência alélica, frequência genotípica, número de heterozigotos observados e esperados, aderência ao Equilíbrio de Hardy-Weinberg do polimorfismo INS-VNTR na amostra populacional em estudo .73

Tabela 7: Teste exato do Equilíbrio de Hardy-Weinberg quando em deficiência de heterozigotos na amostra populacional em estudo .74

Tabela 8: Teste exato do Equilíbrio de Hardy-Weinberg quando em excesso de heterozigotos na amostra populacional em estudo .74

Tabela 9: Associações dos alelos e genótipos do polimorfismo INS-VNTR com as características fenotípicas dos tipos de diabetes mellitus.

Tabela 10: Análise comparativa entre as variações genotípicas do polimorfismo INSVNTR e as características demográficas, clínicas e laboratoriais dos indivíduos amostrados .83

Tabela 11: Comparação das frequências alélicas do SNP -23HphI entre população brasileira e demais populações mundiais 


\section{SUMÁRIO}

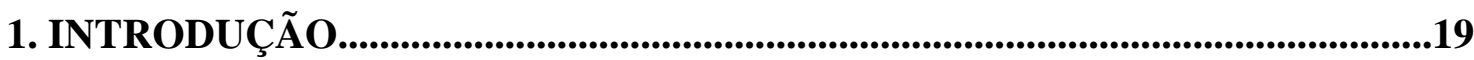

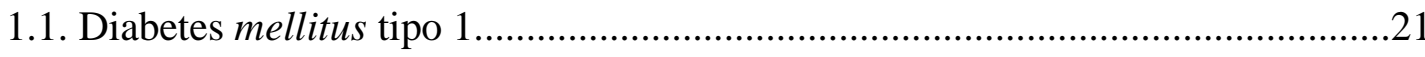

1.1.1 Patogenia do diabetes mellitus tipo 1......................................................22

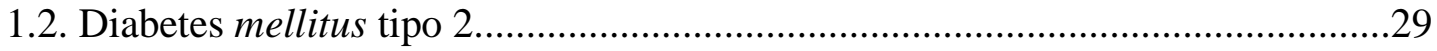

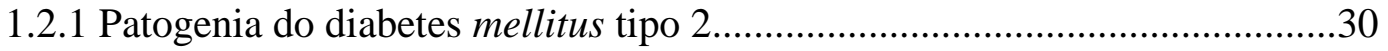

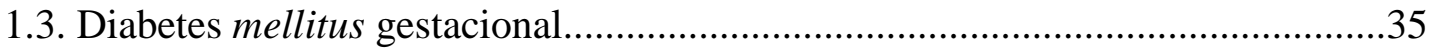

1.3.1 Patogenia do diabetes mellitus gestacional................................................37

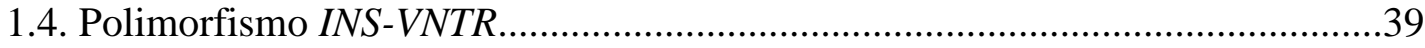

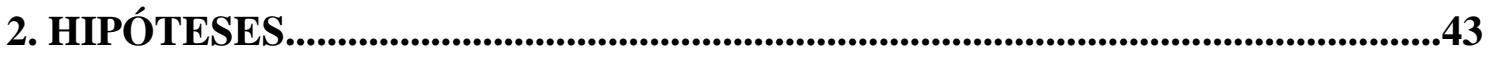

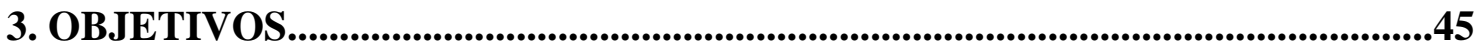

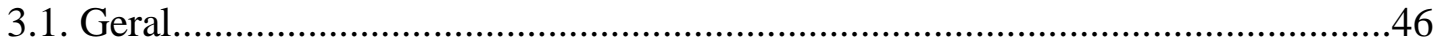

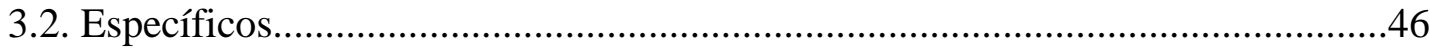

4. DELINEAMENTO EXPERIMENTAL ...........................................................47

5. MATERIAIS E MÉTODOS....................................................................................49

5.1. Casuística e Amostragem Populacional................................................................50

5.2. Extração e purificação do DNA genômico pelo método salting-out....................52

5.3. Reação em cadeia da polimerase (PCR) ..........................................................53

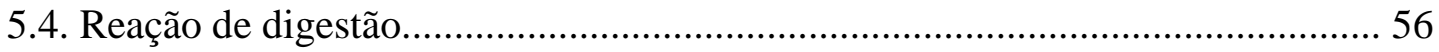

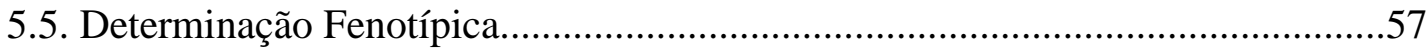

5.6. Análise Estatística

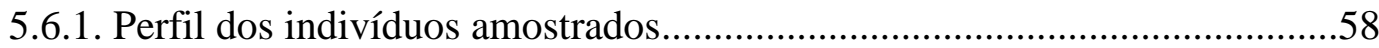

5.6.2 Estimativas das frequências alélicas e genotípicas.....................................58

5.6.3. Aderência ao equilíbrio de Hardy-Weinberg..............................................58

5.6.4. Associação do locus INS-VNTR aos tipos de diabetes mellitus 59

5.6.5. Associação das classes genotípicas às características demográficas, clínicas

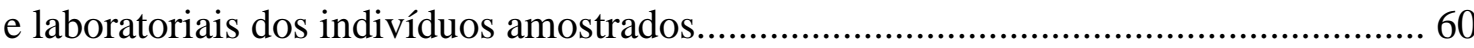

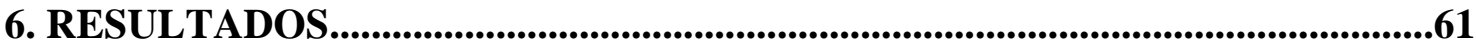

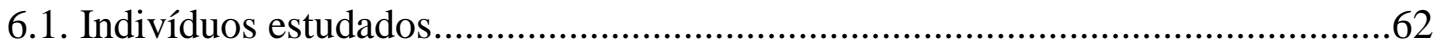

6.2. Frequências alélicas e Equilíbrio de Hardy-Weinberg......................................71

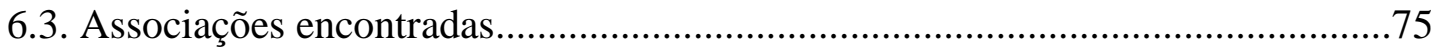

6.3.1 Associação diagnóstico dos tipos de diabetes mellitus e os genótipos INSVNTR. 
6.3.2. Associação das características clínicas dos tipos de diabetes mellitus e os genótipos INS-VNTR

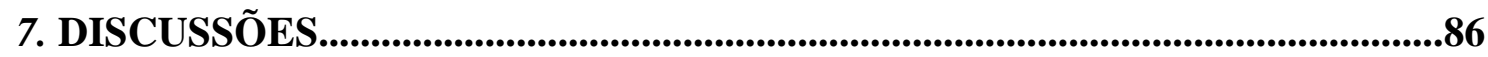

7.1. Distribuiçãa das frequências alélicas..................................................................87

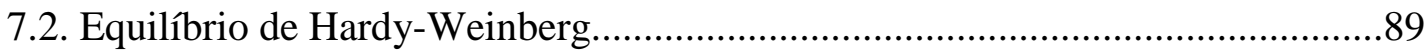

7.3. Associações encontradas 91

7.3.1. Associações entre o polimorfismo INS-VNTR e os fenótipos das classes clínicas do diabetes mellitus.

7.3.2. Associações entre o polimorfismo INS-VNTR e as características demográficas, clínicas e laboratoriais referentes a cada classe clínica do diabetes

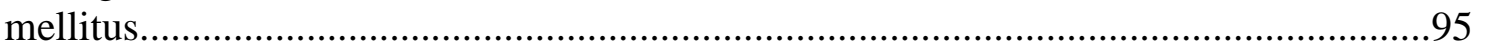

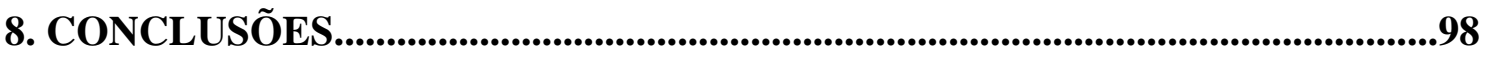

9. REFERÊNCIAS BIBLIOGRÁFICAS....................................................100

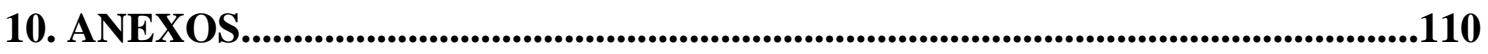




\section{LISTA DE SÍMBOLOS}

ADA - American diabetes association

ADMA - Asymmetric dimethylarginine

Akt - serine/threonine protein kinase Akt

APK7 - Mitogen-activated protein kinase 7

anti-GAD - antidescarboxilase do ácido glutâmico

ATP6V1H - ATPase, $H+$ transporting, lysosomal 50/57kDa, V1 subunit $H$

BB - inbred BioBreeding

CAP - Células apresentadoras de antígenos

CDKAL1 - CDK5 regulatory subunit associated protein 1-like 1

CDKN2A-CDKN2B - cyclin-dependent kinase inhibitor $2 A$ - cyclin-dependent kinase inhibitor $2 B$

CT - colesterol total

CTLA-4 - Cytotoxic T-Lymphocyte Antigen-4

Cav2 - Caveolin 2

COX11 - Cytochrome c oxidase assembly homolog

DDAH2 - Dimethylarginine dimethylaminohydrolase

DM - Diabetes mellitus

DM1 - Diabetes mellitus tipo 1

DM2 - Diabetes mellitus tipo 2

DMG - Diabetes mellitus gestacional

ERBB3 - v-erb-b2 erythroblastic leukemia viral oncogene homolog 3

ERK5-Mitogen-activated protein kinase

FFAR1 - Free fatty acid receptor 1

FTO - Fat mass and obesity associated

GAD - ácido glutâmico descarboxilase

GJ - Glicemia de jejum

GJA1 - Gap junction protein, alpha 1 
GLP-1 - Glucagon-like peptide-1

GPP - Glicemia pós-prandial

GWAS - Genome wide association studies

HAPO - Hyperglycemia and Adverse Pregnacy Outcomes

HbA1 - Hemoglobina glicada

HDL - lipoproteínas de alta densidade

HHEX - Hematopoietically-expressed homeobox protein HHEX

HLA - Human Leukocyte Antigen

IADPSG - International Association of Diabetes and Pregnancy Study Groups

IDDM1 - Insulin dependent diabetes mellitus region 1

IDDM2 - Insulin dependent diabetes mellitus region 2

IFIH1 - Interferon induced with helicase C domain 1

IFN- $\gamma$ - Interferon $\gamma$

IL-1 - Interleucina 1

IL2RA - Interleukin 2 receptor, alpha

INS - gene da insulina

INS-VNTR - Insulin variable nucleotide tandem repeats

Insig1 - Insulin induced gene 1

IMC - índice de massa corporal

IRS-1 - Insulin receptor substrate 1

IRS-2 - Insulin receptor substrate 2

KCNQ1 - Potassium voltage-gated channel, KQT-like subfamily, member 1

KCNJ2 - Potassium inwardly-rectifying channel, subfamily J, member 2

LDL - Lipoproteínas de baixa densidade

LPS - Lipossacarídeos

MafA - mammalian homologue of avian MafA/l-Maf

MBK1-MiniBrain Kinase (Drosophila) homologe 
MHC - Major Histocompatibility Complex

miRNAs - microRNAs

MODY - Maturity-onset diabetes of the young

Mtpn - Myotrophin

NOD - non-obese diabetic

NDUFA5 - NADH dehydrogenase (ubiquinone) 1 alpha subcomplex, 5

NDUFA10 - NADH dehydrogenase (ubiquinone) 1 alpha subcomplex, 10

Onecut-2 - One cut domain family member 2

OMS - Organização Mundial da Saúde

$p 27^{\text {Kip1 }}$ - Cyclin-dependent kinase inhibitor

PAS - pressão arterial sistólica

PAD - pressão arterial diastólica

PDK-1 - Pyruvate dehydrogenase kinase isozyme 1

PDX-1 - Pancreas-duodenum homebox-1

pGH - hormônio placentário de crescimento humano

PI3K - Phosphoinositide 3-kinase

PPARG $\gamma$ - Peroxisome proliferator-activated receptor gamma

PTPN22 - Protein tyrosine phosphatase, non-receptor type 22

SNPs - single nucleotide polymorphisms

T2D-Db-T2D-Db an integrated data resource on type 2 diabetes

TCF7L2 - Transcription factor 7-like 2

TGL - triglicerídeos

TLR4 - Toll-like receptor 4

TNF - fator de necrose tumoral

TOTG - Teste oral de tolerância à glicose 
INTRODUÇÃO 


\section{INTRODUÇÃO}

O diabetes mellitus (DM) acomete cerca de 366 milhões de habitantes em todo o mundo, sendo no Brasil, cerca de 12,4 milhões de pacientes diagnosticados com a doença. Países em desenvolvimento têm ampliado a incidência de novos casos. As justificativas são alterações na qualidade de vida desses habitantes os quais passam por transformação cultural na dieta, ingerindo alimentos mais calóricos e de fácil acesso (fast food) e, dedicam-se cada vez menos tempo às atividades físicas (INTERNATIONAL DIABETES FEDERATION, 2011).

Definida como doença metabólica, o diabetes é caracterizado pela hiperglicemia, causada pela disfunção da secreção de insulina, atividade da insulina ou ambas. A hiperglicemia crônica no diabetes está associada, em longo prazo, com disfunção e falência de diferentes órgãos e tecidos como fígado, nervos, coração, rim, retina (AMERICAN DIABETES ASSOCIATION, 2011), sendo as complicações do diabetes responsáveis pela morte precoce de $99 \%$ dos pacientes brasileiros (MINISTÉRIO DA SAÚDE, 2006).

A classificação do DM proposta pela Organização Mundial da Saúde (OMS) e pela Associação Americana de Diabetes (ADA) (2011) inclui quatro classes clínicas: diabetes mellitus tipo 1 (DM1), diabetes mellitus tipo 2 (DM2), diabetes mellitus gestacional (DMG), que apresentam perfis de doença oligogênica ou poligênica, e outros tipos específicos como Maturity-onset diabetes of the young (MODY), cujas causas estão relacionadas a alterações monogênicas associadas às funções das células $\beta$ (OLIVEIRA et al, 2002). Há ainda duas categorias referidas como pré-diabetes, correspondentes à glicemia de jejum alterada e a tolerância à glicose diminuída, as quais são consideradas fatores de risco para o desenvolvimento do DM e de doenças cardiovasculares (AMERICAN DIABETES ASSOCIATION, 2011). 


\subsection{Diabetes mellitus tipo 1 (DM1)}

O diabetes mellitus tipo 1 (DM1) é definido pela hiperglicemia e hipoinsulinemia, causadas pela destruição autoimune de células $\beta$ pancreáticas, responsáveis pela produção de insulina. Nesse contexto, o sistema imune não mantém a tolerância aos autoantígenos das células $\beta$, frequentemente regulados por moléculas do MHC (sigla em inglês MHC - Major Histocompatibility Complex) e outras moléculas imunoregulatórias, permitindo inflamação crônica das ilhotas pancreáticas e, consequentemente, impondo ao paciente a necessidade do uso de insulina exógena para regular o metabolismo da glicose no organismo (NOKOFF et al., 2012).

Dentre os fatores que predispõem à susceptibilidade ou proteção ao desenvolvimento do DM1 estão variações gênicas ou alélicas, com destaque para o locus IDDM1 (insulin dependent diabetes mellitus region 1), que compreende à região do complexo principal de histocompatibilidade (Major Histocompatibility Complex MHC) e o locus IDDM2 (insulin dependent diabetes mellitus region 2) com ênfase ao polimorfismo na região promotora do gene da insulina INS-VNTR (insulin variable nucleotide tandem repeats). Ainda, fatores ambientais como a exposição a determinados vírus que alterariam a resposta imune, a modificação da dieta infantil com adição precoce de leite bovino e cereais, a higiene em excesso que acarreta deficiência da imunoregulação do organismo da criança também agem como fatores etiopatogênicos adicionais (DEVENDRA et al., 2004).

O DM1 corresponde a 5-10\% dos indivíduos diagnosticados (HALIMI \& BENHAMOU, 2004). Dentre os principais sintomas da doença estão a poliúria, polidipsia, polifagia e perda involuntária de peso, fadiga, fraqueza, letargia, prurido cutâneo e vulvar, balanopostite e infecções de repetição (MINISTÉRIO DA SAÚDE, 2006) . 
A avaliação do DM1 é feita rotineiramente por exames clínicos/laboratoriais, incluindo a hemoglobina glicada (HbA1), glicemia de jejum (GJ), glicemia pós-prandial (GPP), lipoproteínas de baixa e alta densidade (LDL e HDL), triglicerídeos (TGL), pressão arterial sistólica e diastólica (PAS e PAD), colesterol total (CT), índice de massa corporal (IMC). Exames de autoanticorpos circulantes como antidescarboxilase do ácido glutâmico (anti-GAD), anti-ilhotas e anti-insulina estão presentes em 85-90\% dos indivíduos, por ocasião da detecção da hiperglicemia em jejum (AMERICAN DIABETES ASSOCIATION, 2011).

\subsubsection{Patogenia do diabetes mellitus tipo 1}

O DM1 é doença de evolução lenta com desenvolvimento progressivo ao longo dos anos, caracterizando a fase pré-clínica da doença. Estudos apontam que, no período da manifestação da doença, as células secretoras de insulina estão em número muito diminuídos, estando em alguns casos, praticamente ausentes (VELD, 2011). Isso remete à própria dificuldade de avaliar o início do processo inflamatório nas células $\beta$ pancreáticas em seres humanos, tornando então o modelo animal, especialmente, em camundongos NOD (non-obese diabetic) e BB (inbred BioBreeding), modelos chave para a compreensão dos impactos genéticos, ambientais e patogênicos no desenvolvimento espontâneo da doença (DRIVER et al., 2011).

Em camundongos NOD, aproximadamente na terceira semana de vida, iniciase a infiltração nas células pancreáticas por células dendríticas $\mathrm{CD}_{11 \mathrm{c}^{+}}$e macrófagos ER-MP23 ${ }^{+}$. Concomitantemente, linfócitos $\mathrm{T} \mathrm{CD}^{+}$carreando moléculas MHC de classe II acopladas com autoantígenos são detectados próximos à região das ilhotas pancreáticas, provavelmente, ativados nos nódulos linfáticos do pâncreas, acarretando alta reatividade contra as células $\beta$, caracterizando a pré-insulite. Além disso, lesões nas 
ilhotas pancreáticas conduzem à liberação de autoantígenos, acarretando então, o espalhamento do epítopo e o aumento da infiltração das ilhotas pelas células mononucleares (BLUESTONE, HEROLD \& EISENBARTH, 2010). Essa resposta próinflamatória estimula vários tipos celulares a secretarem radicais livres, como óxido nítrico, que são tóxicos às células $\beta$ pancreáticas (FERNADES et al., 2005).

Em humanos com DM1, ocorre infiltrado celular composto por linfócitos T $\mathrm{CD}^{+}$e T CD8 ${ }^{+}$, linfócitos B e células apresentadoras de antígenos (CAP), e ainda, são detectados vários autoanticorpos específicos para antígenos das ilhotas pancreáticas e citocinas pró-inflamatórias (FERNADES et al., 2005). Durante o processo de insulite, linfócitos $\mathrm{T} C D 8^{+}$reconhecem o autoantígeno pancreático ligado à molécula de HLA de classe I e promovem a destruição das células $\beta$ por citólise pela liberação de perforina e granzina e, por fim, induzindo apoptose celular. Nessa etapa, os linfócitos T CD4 ${ }^{+}$ atuam determinando reações inflamatórias e secreção de citocinas, especialmente, interleucina 1 (IL-1), interferon $\gamma$ (IFN- $\gamma$ ) e fator de necrose tumoral (TNF), culminando com a morte das células $\beta$. Linfócitos B também atuam apresentando autoantígenos, particularmente, insulina e ácido glutâmico descarboxilase (glutamic acid decarboxylase - GAD), entre outros (VELD, 2011).

Estudos genéticos evidenciam que a predisposição para o desenvolvimento do DM1 estão associados, principalmente, com o sistema HLA (Human Leukocyte Antigen - HLA), contribuindo em até $40 \%$ a $50 \%$ para o desenvolvimento da doença. A região promotora do gene da insulina - INS-VNTR (Insulin linked variable number tandem repeats) e o gene CTLA-4 (Cytotoxic T-Lymphocyte Antigen-4) também contribuem com a susceptibilidade ao DM1. Estudos do genoma completo (GWAS- Genome wide association studies) relatam a influência de outros genes de susceptibilidade ao DM1, incluindo PTPN22 (protein tyrosine phosphatase, non-receptor type 22), IL2RA 
(interleukin 2 receptor, alpha), IFIH1 (interferon induced with helicase C domain 1), ERBB3( v-erb-b2 erythroblastic leukemia viral oncogene homolog 3), entre outros (STECK \& REWERS, 2011). A Figura 1 ilustra a participação desses genes como fatores de risco ao DM1.

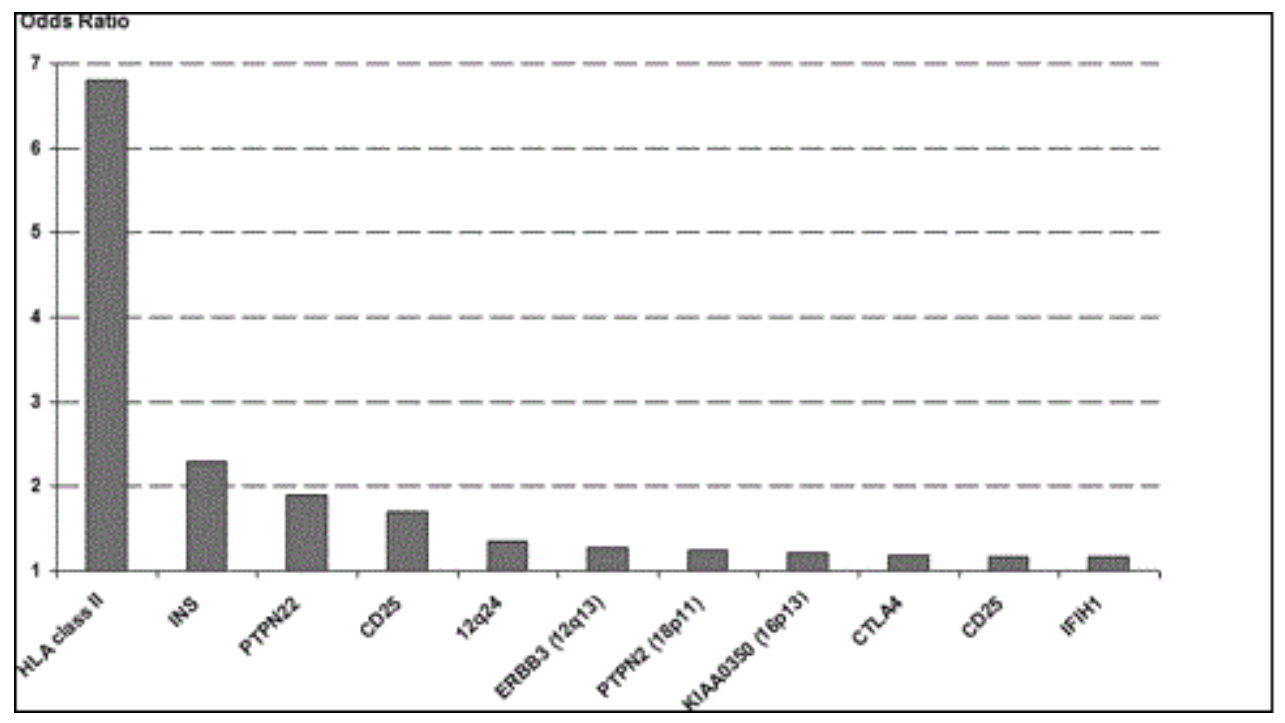

Figura 1 - Genes de susceptibilidade ao diabetes mellitus tipo 1, classificados de acordo com o risco de susceptibilidade (Odds ratio) à doença, em estudos avaliando o genoma completo. Fonte: STECK \& REWERS (2011).

O principal locus de susceptibilidade ao DM1 é o MHC de classe II, situado no braço curto do cromossomo 6 (6p21), cujos haplótipos de alto risco ao desenvolvimento da doença são: $D R B 1 * 03-D Q A 1 * 05: 01-D Q B 1 * 02: 01$ (DR3) e $D B 1 * 04-D Q A 1 * 03: 01-D Q B 1 * 03: 02$ (DR4) (NOBLE et al., 1996). Tais genótipos codificam proteínas responsáveis por apresentarem peptídeos da insulina, GAD, IA-2, ZnT8 para células T CD4. A classe II do MHC também é responsável por expressar alelos de proteção ao DM1, sendo os principais alelos DRB1*15:01, *14:01 ou *07:01 e $D Q B 1 * 06: 02, * 05: 03$ ou *03:03 os quais reduzem o risco de desenvolver a doença (BLUESTONE, HEROLD \& EISENBARTH, 2010). 
Estudos recentes mostram outros alelos do MHC, associados com susceptibilidade ao DM1, independentemente do $H L A-D R / D Q$, como os alelos $H L A$ de classe I. O grupo de alelos $H L A * A 24$, por exemplo, tem sido relacionado por induzir o DM1 precocemente; o grupo $H L A * A 30$ por conferir alto risco ao DM1 e o grupo de alelos $H L A * A 1$, baixo risco ao desenvolvimento da doença (NEJENTSEV et al., 2007).

Em relação ao INS-VNTR, o principal sítio de susceptibilidade à doença está relacionado com o número de repetições de sequencias de nucleotídeos in tandem. $\mathrm{O}$ alelo classe I é considerado como fator de risco ao desenvolvimento do DM1, caracterizado pela repetição do minissatélite em 30-60 unidades, possui frequência na população global de 50-60\% e sua presença em homozigose confere de 3 a 5 vezes mais riscos de predisposição à doença. $\mathrm{O}$ alelo classe III é caracterizado pela repetição do minissatélite em 120-160 unidades, sendo considerado alelo de proteção e a homozigose deste é mais frequente nos indivíduos saudáveis (ANJOS et al., 2004).

O fato de o INS-VNTR estar localizado fora da região gênica codificadora de proteína indica que sua atividade esteja relacionada com a regulação da expressão da insulina, e, indiretamente, com a seleção negativa de timócitos, propiciando o surgimento de linfócitos T autorreativos na periferia. Estudos de Pugliese et al., 1997, e Anjos et al., 2004, verificaram que a transcrição do gene INS no timo em presença do alelo classe III é superior em relação ao do alelo classe I, sendo postulado que o tipo de classe do INS-VNTR deva influenciar no mecanismo de seleção dos linfócitos $\mathrm{T}$ autorreativos para insulina. A Figura 2 ilustra os principais sítios de variabilidade gênica encontrados na região do IDDM2. 


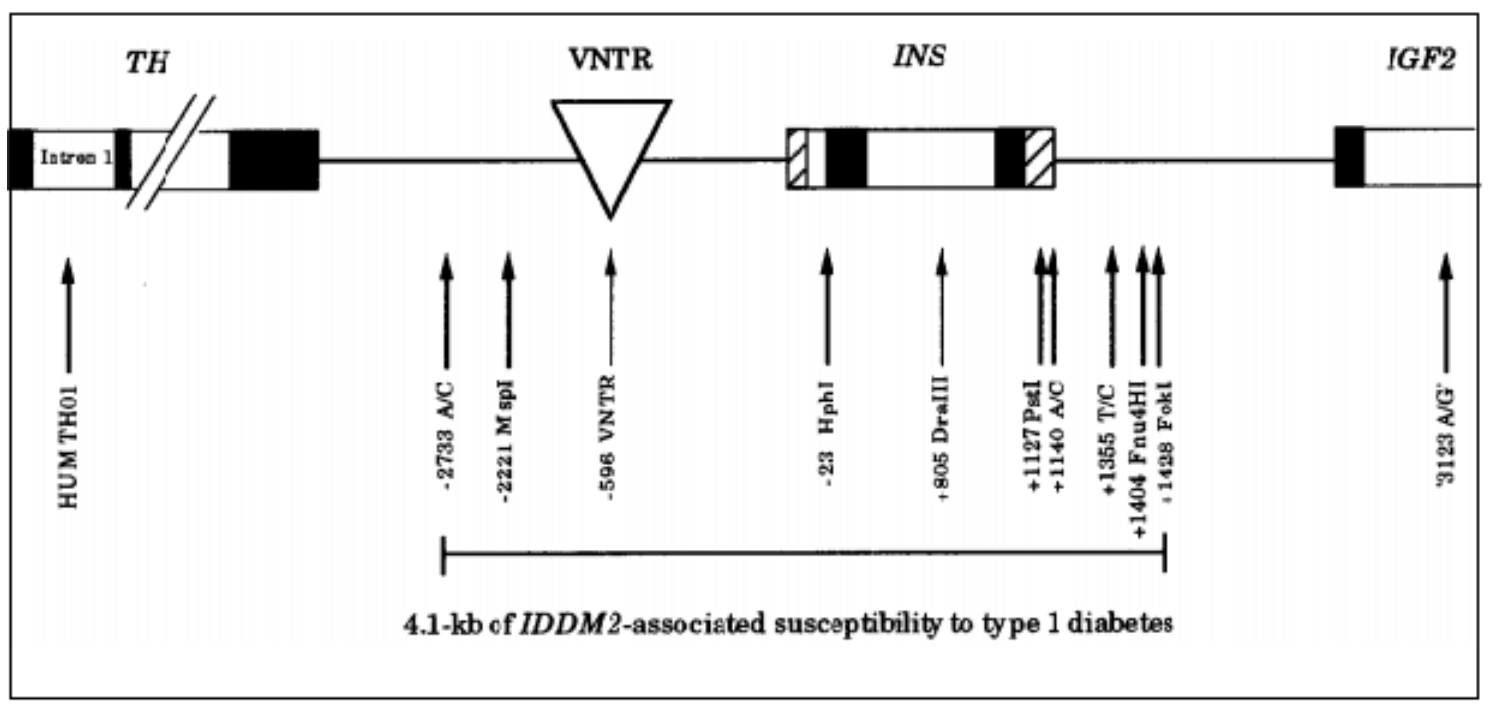

Figura 2 - Representação diagramática do cromossomo 11 p15.5, incluindo o conjunto de genes TH-INS-IGF2 (Tyrosine Hydroxylase - Insulin - Insulin-like growth factor 2) e mostrando os dez sítios polimórficos presentes na região de susceptibilidade ao DM1 (região conhecida como IDDM2). Os retângulos abertos, fechados e hachurados representam, respectivamente, íntrons, éxons e regiões não transcritas, e o triângulo identifica o sítio INS-VNTR. Fonte: BENNET et al. (1996).

O gene CTLA-4 codifica receptores expressos por células T ativadas, os quais apresentam função de regulação negativa de células T, uma vez ativadas. Em processo de resposta imune normal, o reconhecimento do antígeno pelas células $\mathrm{T}$ auxiliares é mediado pela interação do CD28, expresso em quase todas as células T, com proteínas B7 presentes na superfície das células apresentadoras de antígenos. A ligação entre CD28 e B7 é essencial para o início da resposta imune de células T naive. Em alguns casos, as células T encontram autoantígenos e iniciam a expressão de moléculas CTLA4 como mecanismo de proteção, visando a inibição de sinais para as células T (LEUNG \& LINSLEY, 1994).

Mutações e polimorfismos identificados no gene CTLA-4 têm demonstrado alterações na função da proteína codificada, podendo influenciar na progressão de doenças autoimunes (ANJOS et al., 2004, LING et al., 2001, UEDA et al., 2003). Dentre as principais regiões polimórficas estão a região promotora do gene CTLA-4 
(5'UTR), SNP na região codificadora e poliadenilação na região 3' não traduzida (3' UTR). Quanto à influência desses polimorfismos na progressão do DM1, os estudos de associação enfatizam a importância do alelo $A 49 G$ cuja homozigose $G: G$ favorece a proliferação de células $\mathrm{T}$ e influenciam, negativamente, a ativação das células $\mathrm{T}$ em resposta a moléculas IL2. Tal alelo, em diferentes populações, confere risco para a progressão do DM1, enquanto o alelo $A$ confere proteção (PHILIP \& ISABEL, 2011). Quanto ao marcador microssatélite $(A T) n$ na 3'UTR este possui forte desequilíbrio de ligação com $A 49 G$, o que permite sua associação com a susceptibilidade ao DM1.

Estudos de expressão gênica diferencial têm identificado grupos gênicos envolvidos na patogenia do DM1. Stechova et al. (2012) avaliaram o perfil de expressão gênica diferencial em pacientes com DM1, familiares de primeiro grau do paciente com presença de autoanticorpos e com ausência de autoanticorpos, e ainda, indivíduos controle. A principal diferença de expressão encontrada foi entre parentes de primeiro grau em ausência de autoanticorpos e indivíduos saudáveis, sendo evidenciadas alterações de expressão de 17 genes envolvidos no sistema imune. Rassi et al.(2008) reportaram o perfil de expressão gênica de pacientes DM1 de acordo com regiões de susceptibilidade. As modulações foram observadas em torno da região cromossômica 1p13, com 2 genes modulados os quais estariam envolvidos na ação da insulina. Na região cromossômica $2 \mathrm{q} 33$, foram modulados 3 genes os quais atuariam no controle negativo da expressão de moléculas do MHC de classe II. Na região cromossômica $6 q$ 21-24, 7 genes foram modulados sendo suas atividades relacionadas ao processo metabólico de glicoproteínas, regulação da apoptose e produção de imunoglobulinas. $\mathrm{Na}$ região cromossômico 11p15, 2 genes foram encontrados associados com regulação negativa da produção de insulina. 
Além dos genes que contribuem com o desenvolvimento do DM1, diversos fatores que regulam a transcrição gênica também têm sido implicados na patogenia do DM1, particularmente, a regulação pós-transcricional, mediada pelos microRNAs (miRNAs). Pesquisas descrevem a participação dos miRNAs na patogênese do diabetes e nas complicações associadas à doença, principalmente, por atuarem sobre genes envolvidos em processos biológicos de produção, secreção e ação da insulina (BAROUKH et al., 2007, KLOOSTERMAN et al, 2007, POY et al, 2004), no metabolismo dos lipídios, nas complicações vinculadas ao DM1 e, indiretamente, no controle glicêmico (POY et al, 2007).

Os miRNAS miR-375, miR-124a e let-7b atuam na regulação da expressão do gene Mtpn (Myotrophin), alterando a atividade de secreção da insulina e o desenvolvimento das células $\beta$ pancreáticas (POY et al, 2007). A indução da expressão de miR-29a e de miR-29b pode atuar no processo biológico de transporte de glicose, tendo como alvos os genes Insig1(Insulin induced gene 1) e Cav2 (Caveolin 2) (HE et al., 2007). A baixa expressão de miR-143 tem atuação na repressão dos genes ERK5 (Mitogen-activated protein kinase), MBK1 (MiniBrain Kinase (Drosophila) homologe) MAPK7(Mitogen-activated protein kinase 7), reduzindo a atividade de diferenciação dos adipócitos. Consequentemente, a alta expressão do miR-143 permite maior produção de células de gordura, favorecendo o diabetes (ESAU et al., 2004). A baixa expressão de miR-1, por intermédio da regulação pós-transcricional dos genes $K C N J 2$ (Potassium inwardly-rectifying channel, subfamily J, member 2) e GJA1 (Gap junction protein, alpha 1), favorece alterações fisiológicas cardíacas como hipertrofia (YANG et al., 2007). 


\subsection{Diabetes mellitus tipo 2 (DM2)}

O DM2 é caracterizado pela progressiva deterioração funcional das células $\beta$ pancreáticas e aumento da resistência à insulina em tecidos periféricos, como fígado e músculo esquelético, e ainda, incapacidade de secretar insulina suficiente para manter os níveis glicêmicos de jejum e pós-prandial, definindo o quadro hiperglicêmico no paciente (FREEMAN, 2010).

Considerado o principal problema de saúde pública, face o aumento de risco de doenças cardíacas, derrames e complicações microvasculares como cegueira, insuficiência renal, neuropatia periférica. A mudança do estilo de vida, incluindo alterações de hábitos alimentares e a diminuição de atividade física têm sido indicativos de causa do aumento da doença, sendo possível caracterizá-la como pandêmica. Atualmente, cerca de $90 \%$ - 95\% dos pacientes são do tipo DM2 (AMERICAN DIABETES ASSOCIATION, 2012).

O DM2 é considerado doença de evolução lenta, assintomática até a manifestação de sintomas clássicos como perda de peso, polidpsia, poliúria, polifagia e fraqueza. Por estar vinculada a danos vasculares e neurológicos na fase pré-clínica, o diagnóstico precoce é fundamental para redução dessas complicações, sendo imprescindível a avaliação de fatores de risco para o DM2 os quais remetem à idade do paciente, histórico familiar de diabetes, presença dos componentes da síndrome metabólica, incluindo excesso de peso (IMC $>25 \mathrm{~kg} / \mathrm{m}^{2}$ ), dislipidemia (HDL-colesterol baixo ou triglicérides elevados), hipertensão arterial, doença cardiovascular, microalbuminúria, diabetes gestacional prévio com ocorrência de macrossomia fetal, histórico de abortos de repetição ou mortalidade perinatal, sedentarismo, uso de drogas hiperglicemiantes (corticosteroides, tiazídicos, beta-bloqueadores) (GROSS et al., 2000). 
O diagnóstico do DM2 é realizado pelo teste oral de tolerância à glicose (TOTG) em que a sobrecarga de glicose é avaliada pela medida da glicemia plasmática venosa de jejum e 2 horas após a sobrecarga de $75 \mathrm{~g}$ de glicose. Os níveis de glicemia para o diagnóstico da doença devem ser superiores a $126 \mathrm{mg} / \mathrm{dL}$ para o jejum e superior a 200mg/dL, após a sobrecarga de glicose (GOMES et al., 2009).

O tratamento da doença envolve o procedimento educacional de compreensão do DM2, a modificação de hábitos alimentares, inclusão de prática de exercícios físicos quando na ausência de sintomas de risco como cetoacidose, hipoglicemia e hiperglicemia, arritmia. Quando o controle glicêmico não foi atingido, há a introdução de medicamentos (GROSS et al., 2000).

\subsubsection{Patogênese do diabetes mellitus tipo 2}

O desenvolvimento do DM2 é marcado pela gradual perda de sensibilidade à insulina, diminuição da secreção de insulina pelas células $\beta$, aumento da secreção de glucagon pelas células $\alpha$ pancreáticas e o comprometimento efetor das incretinas. A progressão do DM2 remete à influência de fatores ambientais e genéticos os quais definem o quadro clínico da doença.

O mecanismo biológico de secreção de insulina pelas células $\beta$ pancreáticas atualmente é bem compreendido. Para a ocorrência da exocitose de grânulos de insulina, é necessário que haja o aumento de íons cálcio $\left(\mathrm{Ca}^{+2}\right)$ no interior da célula por meio dos canais de $\mathrm{Ca}^{+2}$, o que remete a uma diferença de potencial na superfície da membrana. A abertura dos canais de $\mathrm{Ca}^{+2}$ é controlada pelo canal de $\mathrm{K}^{+}$sensível à molécula de ATP $\left(\mathrm{K}_{\mathrm{ATP}}\right)$. Em baixos níveis plasmáticos de glicose, esse canal é aberto e ocorre a saída de $\mathrm{K}^{+}$pelo poro da membrana plasmática que se mantém polarizada, impedindo a abertura do canal de $\mathrm{Ca}^{+2}$, a entrada de íons cálcio e, consequentemente, a secreção de insulina. 
O aumento de glicose no plasma sanguíneo induz a captação aumentada de glicose e o aumento do metabolismo das células $\beta$, que favorece a produção de ATP e queda de MgADP. Esse mecanismo implica na diferença elétrica próxima ao canal de $\mathrm{K}_{\mathrm{ATP}}$, promovendo a entrada de íons $\mathrm{Ca}^{+2}$ pelos canais de $\mathrm{Ca}^{+2}$ e a secreção de insulina (ASHCROFT \& RORSMAN, 2012).

Hormônios e neurotransmissores também são capazes de modular a secreção de insulina sem influenciar os níveis plasmáticos de íons cálcio. $\mathrm{O}$ foco dos estudos atuais são as incretinas, em particular a GLP-1 (Glucagon-like peptide-1), a qual sendo liberada por células L do intestino em resposta à presença de glicose e outros nutrientes na luz intestinal é capaz de potencializar a secreção de insulina por meio de cAMP, presente no meio intracelular (ASHCROFT \& RORSMAN, 2012).

A exposição da membrana celular a ácidos graxos livres promove a extensão dos canais de $\mathrm{Ca}^{+2}$ ao longo da membrana celular, favorecendo disfunção das células $\beta$ pancreáticas, pois a entrada excedente de íons $\mathrm{Ca}^{+2}$ não será proporcional à secreção de insulina. Dessa forma, as células $\beta$ se encontram em disfunção e incapazes de suprir a produção de insulina necessária para manter o nível plasmático glicêmico normal. Além disso, o potencial elétrico típico do estímulo pela glicose é mantido na membrana plasmática, delineando, então, o quadro de resistência à insulina.

Os fatores genéticos exercem forte influencia no desenvolvimento do DM2, sendo atualmente descritos, no banco de dados T2D-Db (T2D-Db an integrated data resource on type 2 diabetes), em torno de 320 genes de susceptibilidade à doença para $\mathrm{o}$ organismo humano (T2D-Db, 2012). Nos últimos cinco anos, estudos de ligação e avaliação do genoma completo caracterizaram, aproximadamente, 40 novos genes com predominância de variações nucleotídicas pontuais (SNPs - single nucleotide 
polymorphisms). A diversidade de SNPs em regiões não-codificadoras desses genes, individualmente, apresenta efeito irrisório no mecanismo da doença, no entanto, em conjunto, a somatória da expressão simultânea de diversos genes pode contribuir com a susceptibilidade ao DM2 (BONNEFOND et al., 2010; MCCARTHY, 2010). Abaixo, são listados alguns desses genes.

O gene TCF7L2 (Transcription factor 7-like 2) aumenta em 1,7 vezes o risco ao DM2. Estudos funcionais sugerem que o gene esteja envolvido na secreção da insulina, pois quando reprimido, promove redução na secreção do hormônio (SHU et al., 2008).

As variantes do gene KCNQ1 (Potassium voltage-gated channel, KQT-like subfamily, member 1) estão associadas com a secreção da insulina e ao metabolismo dos lipídios. A presença do alelo $C$ reduz o estímulo à produção de insulina na primeira fase da glicose, induz elevado nível de LDL e colesterol total, enquanto o alelo $T$ promove a redução de produção de insulina na segunda fase da glicose (VAN VLIETOSTAPTCHOUK et al., 2012).

O gene DDAH2 (Dimethylarginine dimethylaminohydrolase) afeta a sensibilidade à insulina quando os níveis de ADMA (Asymmetric dimethylarginine) estão aumentados. Os indivíduos que apresentam o genótipo $G: G$ possuem menor sensibilidade à insulina do que os indivíduos cujo genótipo apresenta pelo menos um alelo $C$ (ANDREOZZI et al., 2012).

Observações recentes têm sugerido que ativação da cascata de sinalização de lipossacarídeos (LPS) ligados ao Toll-like receptor 4 (TLR4) exercem efeitos deletérios sobre a função das células $\beta$ pancreáticas. Amyot et al. (2012) relataram que lipossacarídeos reduzem a expressão do gene da insulina, devido à diminuição da 
expressão do mRNA do gene PDX-1 (Pancreas-duodenum homebox-1) e do gene MafA (mammalian homologue of avian MafA/l-Maf).

Como exposto, há grande diversidade de genes influenciando no desenvolvimento do DM2, a maioria deles está envolvido na alteração da função, desenvolvimento e regulação da massa de células $\beta$ (BONNEFOND et al., 2010; MCCARTHY, 2010). Outros grupos de genes estão associados indiretamente ao DM2, envolvidos com predisposição à obesidade, altos níveis de colesterol total, LDL, baixo nível de HDL, dentre outros fatores, cujas atividades acarretam alterações no processo de secreção da insulina.

O SNP rs8050136, presente no gene FTO (Fat mass and obesity associated) está associado com maior índice de massa corporal, maior índice de gordura corporal e maior porcentagem de gordura, favorecendo o aumento de resistência à insulina e, consequentemente, indireta predisposição ao DM2 (PECIOSKA et al., 2010).

$\mathrm{O}$ gene PPARG $\gamma$ (Peroxisome proliferator-activated receptor gamma) apresenta funções diversas em processos biológicos fundamentais como a regulação de genes que modulam a sensibilidade à insulina, a diferenciação dos adipócitos, inflamação e aterosclerose (HAMZA et al., 2009). A presença do polimorfismo Pro12Ala tem sido associado à susceptibilidade ao DM2 em algumas populações (GUO et al., 2011).

Os SNPs presentes no gene FFARI(Free fatty acid receptor 1) demonstram associação indireta com o DM2, relacionados com o número de sítios polimórficos encontrados no gene. $\mathrm{O}$ alelo $C$ do SNP rs1573611 está associado com maior índice de massa corporal e de gordura corporal, ao passo que o alelo $G$ do SNP rs2301151 indica 
elevado nível de colesterol total, e o alelo A do SNP rs16970264 com menor nível de colesterol total e LDL (WALKER et al. 2011).

Diversidade de estudos de expressão gênica diferenciada tem identificado grupos gênicos envolvidos na patogenia do DM2. Olsson et al. (2011) verificaram a baixa expressão de 21 genes envolvidos no mecanismo de fosforilação oxidativa quando comparado ilhotas pancreáticas de pacientes DM2 com doadores controle. Esses genes podem estar envolvidos no comprometimento da secreção da insulina, entre eles estão NDUFA5 (NADH dehydrogenase (ubiquinone) 1 alpha subcomplex, 5), NDUFA10 (NADH dehydrogenase (ubiquinone) 1 alpha subcomplex, 10), COX11 (Cytochrome c oxidase assembly homolog) e ATP6V1H (ATPase, H+ transporting, lysosomal 50/57kDa, V1 subunit $H)$.

Mao et al. (2011) realizaram estudo de expressão gênica diferencial analisando genes de dois grupos étnicos, o de origem Caucasiana e o de origem Afro-Americana. Amostras de sangue periférico de pacientes DM2 dessas duas origens étnicas e de indivíduos controle, também das duas origens étnicas, foram coletadas para análise em microarrays. Os resultados apontam uma diferença de expressão gênica entre os grupos étnicos. Os Afro-Americanos apresentaram 574 genes diferencialmente expressos entre pacientes e controle, sendo significante a baixa expressão de genes envolvidos na via de sinalização de imunodeficiência primária. Os Caucasianos apresentaram 200 genes diferencialmente expressos, sendo significante a baixa expressão de genes envolvidos na sinalização do sistema complemento. Essa avaliação da patogenia entre grupos étnicos valida a importância de diagnósticos e medicamentos personalizados.

Além da variabilidade genética, diversos fatores pós-transcricionais também estão associados com a patogenia do DM2. Poy et al. (2004) demonstraram a influência 
do miR-375 na regulação da secreção da insulina. Em células $\beta$ adultas, miR-375 está reprimido na presença de excesso de glicose. Baixos níveis de miR-375 induzem a secreção de insulina e reprimem outros genes alvo como Mtpn e PDK-1(Pyruvate dehydrogenase kinase isozyme 1), enquanto a superexpressão de miR-375 atenua a transcrição do gene da insulina (FERNANDEZ-VALVERDE et al., 2011).

Karolina et al. (2011) descreveram a participação do miR-144 na regulação pós-transcricional do gene IRS-1 (Insulin receptor substrate 1) em pacientes com DM2, posto que níveis elevados de miR-144 no sangue periférico estiveram associados com baixo nível de mRNA e de proteínas do gene $I R S-1$.

O miR-9 está envolvido no mecanismo de exocitose de grânulos de insulina. A sua superexpressão promove a diminuição da taxa transcricional do gene Onecut-2 (One cut domain family member 2), consequentemente, diminuindo a atividade de secreção de grânulos de insulina (PLAISANCE et al., 2006).

Em conjunto, muitos miRNAs relatados em associação com o DM2 estão envolvidos com a atividade das células $\beta$.

\subsection{Diabetes mellitus gestacional (DMG)}

O DMG é caracterizado como qualquer grau de redução da tolerância à glicose, cujo início ou detecção ocorre durante a gravidez (AMERICAN DIABETES ASSOCIATION, 2011).

Estudos populacionais demonstram que a incidência da doença varia conforme a idade, origem étnica, prevalência associada à epidemia global de obesidade e diabetes, e ainda, conforme os critérios utilizados para o diagnóstico (JENUN et al, 2012). Tal faixa de incidência varia de 1-22\% na população global (GALTIER, 2010), sendo que, 
no Brasil, cerca de 7\% das gestantes são acometidas pela doença (SCHMIDT et al., 2000).

Considerado uma das intercorrências mais frequente na gestação, o GDM favorece o aumento de riscos perinatais e maternos. Dentre as complicações para o feto estão macrossomia, tocotraumas, hipoglicemia neonatal, hiperbilirrubinemia neonatal, síndrome do desconforto respiratório do recém-nascido, hipocalcemia, prematuridade e óbito fetal, além do aumento de susceptibilidade ao diabetes mellitus. Para as mães, estudos demonstram aumento do número de cesáreas, aumento da incidência de obesidade, hipertensão, síndrome metabólica e maior predisposição para a progressão para o DM2 (FRANCISCO et al., 2011).

O estudo Hyperglycemia and Adverse Pregnacy Outcomes (HAPO), 2008, expôs o fato de não existirem pontos de glicemia limites para advertir quanto aos riscos para a parturiente e o feto, já que até em resultados de glicemias normais, riscos são possíveis (METZGER et al., 2010). A International Association of Diabetes and Pregnancy Study Groups (IADPSG), em 2009, avaliou diferentes resultados de estudos, objetivando uniformizar os critérios de diagnóstico para o DMG. Em 2010, foi publicado que o teste de tolerância oral com sobrecarga de $75 \mathrm{~g}$ de glicose é o teste de escolha para o diagnóstico do DMG, sendo aplicado a todas as gestantes entre a $24^{\mathrm{a}}$ e a $28^{a}$ semana de gestação com análise das glicemias de jejum, 1hora após a sobrecarga e 2 horas após a sobrecarga de $75 \mathrm{~g}$ de glicose. O diagnóstico de DMG é definido pela ocorrência de um ou mais valores maiores ou iguais aos valores de referência do TOTG $75 \mathrm{~g}$, ou seja, glicemia de jejum $\geq 92 \mathrm{mg} / \mathrm{dL}$, de uma hora após a sobrecarga $\geq 180$ $\mathrm{mg} / \mathrm{dL}$ e de duas horas após a sobrecarga $\geq 153 \mathrm{mg} / \mathrm{dL}$. Estes valores de corte foram estabelecidos pela IADPSG e correspondem a 1,75 do desvio padrão da média dos valores de glicemia (METZGER et al., 2010). No Brasil, a Sociedade Brasileira de 
Diabetes, em 2009, definiu que o diagnóstico do diabetes gestacional é realizado pelo TOTG com sobrecarga de $75 \mathrm{~g}$ de glicose com a evidência de pelo menos uma das taxas glicêmicas alteradas (GOMES et al., 2009).

O tratamento do DMG está vinculado à dieta alimentar, prática de exercícios físicos e, quando não há contra-indicações, a terapia medicamentosa deve ser instituída para o controle glicêmico.

\subsubsection{Patogênese do diabetes mellitus gestacional}

A patogenia do DMG não está bem definida. Diferentes informações como efeitos de hormônios placentários, escassez de micronutrientes, excesso de ácidos graxos livres, diminuição da expressão de receptores de insulina, dentre outros aspectos, modulam o quadro clínico da doença.

A gestação é naturalmente caracterizada pela resistência à insulina após a $20^{\circ}$ semana. Nesse período, há aumento da concentração de hormônio placentário de crescimento humano (pGH), aumento da concentração do TNF, alta concentração de progesterona e aumento de cortisol livre no plasma materno (FREEMARK, 2010).

O TNF atua inibindo a captação de insulina mediada pela glicose nos músculos esqueléticos e tecidos adiposos. Esses efeitos são mediados, em parte, pela redução da fosforilação de receptores da insulina e de substratos como IRS-1, IRS-2 (Insulin receptor substrate 2), PI3K (Phosphoinositide 3-kinase) e Akt (serine/threonine protein kinase Akt). Além disso, o TNF em associação com o pGH promovem a baixa regulação da expressão de adiponectina no desenvolvimento de pré-adipócitos. A alta concentração de progesterona reduz a ligação da insulina ao receptor GLUT-4 o que interfere no modo do transporte de glicose no músculo esquelético e tecidos adiposos. De forma similar, o cortisol inibe a captação de insulina, e ainda, estimula a 
gliconeogênese hepática (FREEMARK, 2006). Quando essas alterações metabólicas reduzem a secreção de insulina de modo a não manter os níveis glicêmicos normais a gestante é diagnosticada com o diabetes gestacional.

A base genética da patogenia do DMG ainda é pouco esclarecida. Diversos grupos demonstram a participação de genes associados ao DM1 e ao DM2 na alteração metabólica descrita no DMG, incluindo a participação dos genes $H L A-D R 3$ e $H L A-D R 4$ (FREINKEL et al., 1986), KCNQ1 (KWAK et al., 2010), PPAR (ARCK et al., 2010), FTO, CDKAL1 (CDK5 regulatory subunit associated protein 1-like 1), HHEX (Hematopoietically-expressed homeobox protein HHEX), TCF7L2 (transcription factor 7-like 2), CDKN2A-CDKN2B (cyclin-dependent kinase inhibitor $2 A$ - cyclin-dependent kinase inhibitor 2B) (CHO et al., 2009), dentre outros. Alguns desses genes já foram mencionados em parágrafos anteriores referentes ao DM1 e DM2. A seguir, mencionaremos os demais genes ainda não citados.

Chao et al. (2009) relataram forte associação dos SNPs rs7756992 e rs7754840 presentes no gene $C D K A L 1$ e $r s 10811661$ presente no gene $C D K N 2 A-C D K N 2 B$ com o DMG, sendo esses responsáveis pelo comprometimento das células $\beta$, inviabilizando a secreção adequada de insulina. Esse mesmo grupo verificou a associação do SNP rs1111875 presente no gene $H H E X$ que influencia a capacidade de compensação da secreção de insulina na gestação.

A presença do alelo $T$ referente ao SNP rs7903146 presente no gene TCF7L2 aumenta de forma significativa o risco da gestante desenvolver o DMG. Esse gene tem sido correlacionado ao comprometimento de secreção de insulina e, indiretamente, na proliferação das células $\beta$ pancreáticas, afetando a via WNT de sinalização (SHAAT et al., 2007). 
Zhao et al. (2010) analisaram a expressão diferencial de tecidos placentários e de sangue periférico de pacientes diagnosticadas com DMG e relataram 5197 genes no sangue e 243 genes na placenta com perfil de expressão alterado. O procedimento de análise de enriquecimento funcional desses genes identificou na placenta a via cytokinecytokine receptor interaction como sendo a de maior significância, enquanto, nas células sanguíneas as vias foram natural killer cell mediated cytotoxicity, T-cell receptor signalling pathway e B-cell receptor signalling pathway, evidenciando a influência do sistema imune na modulação do DMG.

Até o momento, há um único estudo relatando o envolvimento dos miRNAs na modulação do DMG. Zhao et al. (2011) observaram baixa expressão do miR-29a, miR132 e miR-222 em soro de pacientes DMG em comparação com gestantes controle, avaliadas no início do segundo trimestre de gestação. O resultado propõe que o miR-29a seja um regulador negativo de glicose no soro pois, a sua baixa expressão favorece a transcrição do gene Insigl (Insulin induced gene 1) que aumenta o nível de glicose no soro. O miR-132 pode ter atuação na produção de proteínas chave no mecanismo de exocitose da insulina. O miR-222 pode estar envolvido na regulação do ciclo celular através do controle de $p 27^{\text {Kipl }}$ (Cyclin-dependent kinase inhibitor). Apesar do possível envolvimento desses miRNAs no DMG, o grupo aponta a necessidade de estudos adicionais para melhor compreensão do mecanismo de atuação desses na patogenia do DMG.

\subsection{O polimorfismo INS-VNTR}

Como já mencionado, o sítio polimórfico INS-VNTR está localizado na região promotora do gene da insulina, no cromossomo 11p15.5. É composto por sequências consenso de 14-15 pares de base (pb), ACAGGGGTCTGGGG, repetidas in tandem, as quais se encontram a 360pb acima do códon de iniciação da região codificadora do gene 
da insulina. Essa sequência é rica em guanina, o que favorece in vivo e in vitro a formação de estruturas de DNA não usuais, provavelmente, pelo quarteto de guanina no final de sequência (PUGLIESE \& MICELI, 2002).

As variações alélicas do polimorfismo INS-VNTR se dividem em três classes, compostas por variações numéricas da sequência minissatélite. O alelo classe I corresponde à variação de 30 a 60 repetições, o de classe II de 60 a 120 repetições e o classe III, de 120 a 170 repetições, sendo rara a presença do alelo de classe II em populações Caucasianas e Africanas (BENNET et al., 1996).

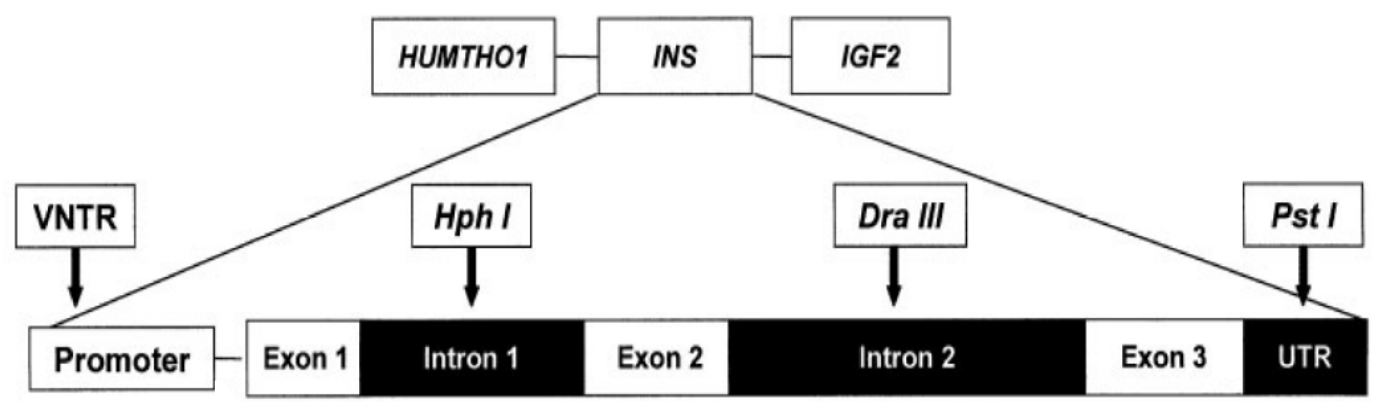

Figura 3 - Estrutura do gene da insulina com a indicação dos polimorfismos mais relevantes e as enzimas de digestão utilizadas para distinguir as variantes polimórficas. Fonte: Adaptado de PUGLIESE \& MICELI (2002).

Os efeitos das frequências alélicas do INS-VNTR, bem como, as variações de único nucleotídeo na sequência consenso no processo de transcrição da insulina demonstraram diferenças no nível de expressão da proteína. $O$ fato de a região promotora do gene INS ter forte afinidade para o fator de transcrição Pur-1 favorece a transcrição da insulina em células que normalmente não expressam a proteína (KENNEDY et al., 1995). Essa regulação transcricional do gene da insulina favoreceu o uso do INS-VNTR como marcador genético para estudos do diabetes mellitus (BENNET et al., 1996).

A maioria dos estudos com células pancreáticas humanas e de camundongos confirma a associação do alelo classe III com menor expressão de RNA mensageiro 
para a insulina no pâncreas (LUCASSEN et al., 1995) e confere maior expressão de RNA mensageiro no timo do indivíduo. Tal contexto, permitiu, em estudos posteriores, correlacionar a presença desse alelo com proteção contra o desenvolvimento de DM1 (BENNET et al., 1996), pois níveis elevados de insulina no timo podem aumentar a tolerância à proteína, inviabilizando a produção de autoanticorpos (PUGLIESE et al., 1995). Como corolário, o alelo classe I apresenta níveis de expressão de insulina contrários à expressão do alelo classe III.

No DM1, análises genéticas familiares demonstraram haver interação do polimorfismo INS-VNTR com genes $H L A-D R$ e $H L A-D Q$. Um modelo plausível dessa interação seria a presença de alelos classe I do polimorfismo INS-VNTR, principalmente em homozigose, os quais diminuiriam a expressão de insulina no timo. A apresentação de peptídeos da insulina pelas moléculas codificadas pelos alelos de susceptibilidade HLA-DR3, DR4, DQA1 * 03:01-DQB1 * 03:02/DQA1 * 05:01-DQB1 * 02:01 estimulariam a resposta imunológica à insulina, uma vez que a proteína está hiporrepresentada no timo, durante a fase de expressão gênica promíscua, por ocasião da seleção negativa. Nesse contexto, o surgimento de linfócitos T autorreativos contra a insulina pode propiciar o início da insulite no pâncreas e a progressão para DM1 (PUGLIESE et al., 1995).

A ação dos alelos do polimorfismo INS-VNTR na modulação da expressão de insulina no timo especulou a possibilidade desse minissatélite ter ação no pâncreas, em relação à resistência à insulina, podendo contribuir com susceptibilidade ao DM2. Estudos da frequência do INS-VNTR em pacientes com DM2 em populações do Reino Unido, Dinamarca evidenciaram que o alelo de classe III não confere susceptibilidade ao DM2 (HANSEN et al., 2004; MITCHELL et al., 2004). Em relação ao estudo do polimorfismo na população Framingham (Massachusets - USA), os resultados apoiam 
a hipótese de que o INS-VNTR seja fator de risco genético para o DM2 na presença do genótipo de classe III em dupla dose (MEIGS et al., 2004). Assim, a origem da população em estudo pode evidenciar fatores genéticos de susceptibilidade distintos para o desenvolvimento do DM2.

A alteração metabólica para o desenvolvimento do DM2 está também associada com predisposição genética à obesidade, que também pode apresentar disfunções nas células $\beta$ pancreáticas. Stunff et al (2001) estudaram a possível correlação entre o INS-VNTR e a obesidade, os resultados apontaram que na fase precoce da obesidade alelos do INS- VNTR foram associados a diferentes efeitos na secreção de insulina, sendo o alelo classe I mais frequente em jovens obesos.

Rodriguez et al. (2004) estudaram peso e composição corporal, pressão sanguínea e nível plasmáticos de triglicerídeos em associação com os genótipos de IGF2-INS-TH. Os resultados do grupo apontaram que o alelo classe III do INS-VNTR está associado com baixa expressão de insulina no pâncreas e pode predispor o indivíduo a características de síndromes metabólicas como elevada pressão sanguínea, excesso de gordura, elevado nível de triglicerídeos os quais favorecem o desenvolvimento de DM2, síndrome do ovário policístico e doenças cardíacas.

No GDM, poucos são os estudos que abordam a frequência do INS-VNTR na progressão da doença. Litou et al. (2006) analisaram a frequência do polimorfismo INSVNTR na população de gestantes gregas com DMG e, apesar de não significativa, verificaram aumento do alelo de classe III na amostra de pacientes DMG. Shaat et al. (2004) estudaram a influência do gene INS-VNTR em pacientes com DMG de origem Árabe e Escandinávia, não encontrando diferenças significantes nos dois grupos populacionais. 
HIPÓTESES 


\section{Hipóteses}

O polimorfismo INS-VNTR tem sido considerado como marcador de susceptibilidade para o desenvolvimento do diabetes melllitus tipo 1 em populações Caucasianas, uma vez que o alelo classe I em homozigose está associado com baixa produção de insulina no timo, favorecendo processo ineficiente de seleção negativa e perda de tolerância à insulina. As associações entre o polimorfismo INS-VNTR e a progressão do diabetes mellitus tipo 2 e diabetes mellitus gestacional ainda não estão bem estabelecidas, havendo poucos relatos em diferentes populações acerca desse assunto. Considerando que não existem estudos do polimorfismo INS-VNTR em pacientes com os três principais tipos de diabetes em nenhuma população mundial, nossa primeira hipótese está relacionada com "Associação do polimorfismo INS-VNTR com diabetes mellitus tipo 1, diabetes mellitus tipo 2 e diabetes mellitus gestacional em pacientes urbanos de uma mesma população brasileira."

A nossa segunda hipótese é "De acordo com a classe genotípica do polimorfismo INS-VNTR, há influencia dos alelos quanto ao possível desencadeamento de complicações típicas ao quadro clínico do diabetes mellitus." Pois, estudos de associação evidenciam papel efetor distinto de cada alelo no desencadeamento de complicações do quadro clínico do diabetes mellitus, como a influência na predisposição a obesidade, principalmente em crianças e jovens, quando em presença do alelo classe I, preferencialmente em homozigose, no desenvolvimento fetal acelerado, aumento de riscos cardiovasculares e doenças metabólicas, em presença do alelo classe III. 
OBJETIVOS 


\section{Objetivos}

\subsection{Objetivo geral:}

Avaliar o polimorfismo INS-VNTR do gene da insulina em pacientes com diabetes mellitus (DM1, DM2 e DMG) da população urbana brasileira e a possível influência das frequências desse polimorfismo nas variáveis demográficas, clínicas e laboratoriais observadas nos pacientes com diabetes.

\subsection{Objetivos específicos:}

- Caracterizar alelos e genótipos do polimorfismo INS-VNTR de pacientes diabéticos mellitus do tipo 1 , diabéticos mellitus do tipo 2, diabéticas mellitus gestacional e indivíduos saudáveis da população urbana brasileira.

- A partir dos resultados de frequências alélicas e genotípicas do polimorfismo INS-VNTR verificar adesão ao equilíbrio de Hardy-Weinberg e comparar os resultados com demais estudos populacionais.

- Verificar o efeito do polimorfismo INS-VNTR quanto ao fenótipo dos indivíduos amostrados da população urbana brasileira.

- Avaliar a influência do polimorfismo INS-VNTR sobre as características demográficas, clínicas e laboratoriais dos pacientes diabéticos. 
DELINEAMENTO EXPERIMENTAL 


\section{Delineamento Experimental}

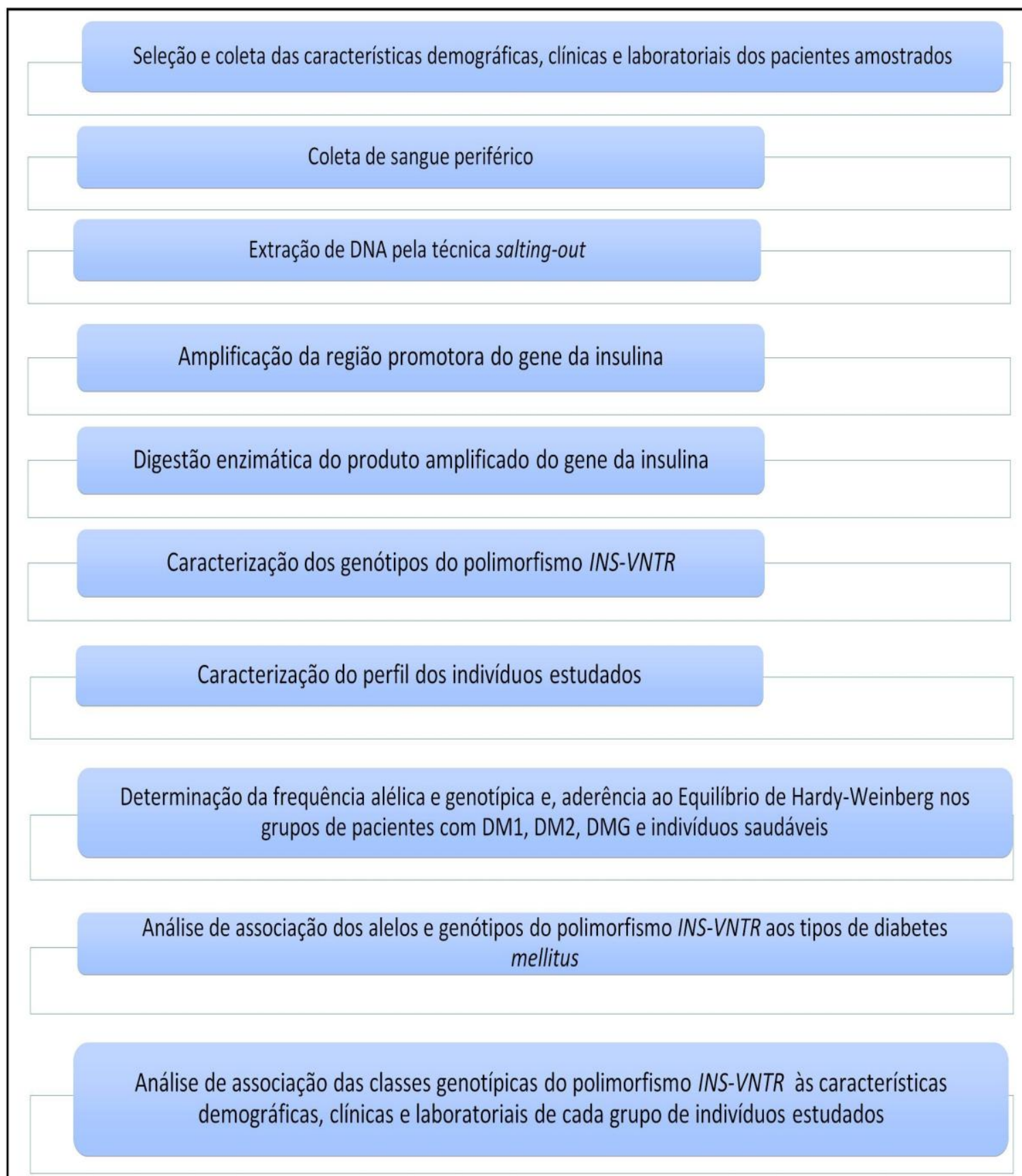


MATERIAIS E MÉTODOS 


\section{Materiais e Métodos}

\subsection{Casuística e Amostragem Populacional}

Visando analisar a associação do polimorfismo INS-VNTR na população urbana brasileira foram genotipadas 189 amostras de pacientes diabéticos do tipo 1, 116 de pacientes diabéticos tipo 2, 68 de pacientes diabéticas gestacional e 339 de indivíduos saudáveis. As amostras dos pacientes diagnosticados com diabetes mellitus (DM) foram obtidas nos ambulatórios da Divisão de Endocrinologia do Hospital das Clínicas da Faculdade de Medicina de Ribeirão Preto, da Universidade de São Paulo (HCFMRP-USP) e da Unidade Básica de Saúde-Posto Cuiabá da Faculdade de Medicina de Ribeirão Preto, da Universidade de São Paulo (USP), enquanto as amostras dos indivíduos saudáveis foram obtidas no Hemocentro de Ribeirão Preto. Todos indivíduos assinaram termo de consentimento livre e esclarecido (ANEXO 1), concordando em participar do estudo, aprovado pelo Comitê de Ética em Pesquisa do HCFMRP-USP (Processo $\left.n^{\circ} 12542 / 2011\right)$ (ANEXO 2).

Foram colhidos $20 \mathrm{~mL}$ de sangue periférico em tubos vaccumtainer, contendo EDTA 5\% (Becton \& Dickinson, EUA) para extração de DNA genômico e RNA total.

Para seleção dos pacientes DM foram avaliados prontuários médicos que validam o diagnóstico da doença de acordo com o protocolo estabelecido pela Associação Americana de Diabetes (ADA) e ausência de outras doenças autoimunes subjacentes. A etapa de seleção dos pacientes foi realizada com a colaboração do Prof. Dr. Milton César Foss e da Prof. Dr ${ }^{\mathrm{a}}$ Maria Cristina Foss Freitas ambos responsáveis pela Divisão de Endocrinologia da Faculdade de Medicina de Ribeirão Preto, Universidade de São Paulo (USP), Brasil, do departamento de Clínica Médica, e ainda, da Dr ${ }^{\mathrm{a}}$ Patrícia Moreira médica da Divisão de Endocrinologia da Faculdade de Medicina de Ribeirão Preto e da pós-doutoranda Dr ${ }^{\mathrm{a}}$ Diane Meyre Rassi. 
Dos pacientes diabéticos tipo 1 e diabéticos tipo 2, foram obtidos dos prontuários médicos informações referentes à idade, sexo, peso, estatura, tempo de doença, a existência de complicações da doença como nefropatia, neuropatia, retinopatia, hipertensão, dislipidemia e obesidade, nível glicêmico de jejum e hemoglobina glicada, preferencialmente, na data de realização da coleta, e ainda, os medicamentos de uso contínuo. Das pacientes diabéticas gestacionais, foram obtidas informações acerca da idade, peso, estatura, tempo gestacional, número de gestações, incidência do DMG em outra gestação, exame de TOTG (Teste Oral de Tolerância a Glicose), complicações ao longo da gestação e medicamentos em uso. Dado o período entre a coleta das amostras e o tempo de análise, foi possível obter dados de nascimento dos recém-nascidos das pacientes diabéticas gestacionais, incluindo sexo, peso, estatura e APGAR.

A genotipagem dos alelos do polimorfismo INS-VNTR foi determinada a partir da extração de DNA genômico de cada amostra de sangue periférico dos pacientes seguido a realização da técnica de PCR-RFLP, usando a enzima de digestão $H p h I$, cujo alvo é o SNP -23HphI que está em perfeito desequilíbrio de ligação $\left(\mathrm{r}^{2} \approx 1\right)$ com o polimorfismo em questão (Bennett\& Todd, 1996).

O levantamento dos resultados de frequências alélicas e genotípicas permitiram determinar parâmetros de diversidade genética, verificar o equilíbrio de HardyWeinberg, comparar os resultados com demais estudos populacionais referentes às frequências do polimorfismo INS-VNTR, avaliar a influência do polimorfismo INSVNTR quanto ao fenótipo dos pacientes e o papel efetor dos genótipos quanto às características demográficas, clínicas e laboratoriais dos pacientes. 


\subsection{Extração e purificação do DNA genômico pelo método Salting-out}

\section{Reagentes e Soluções:}

Tampão de lise I (Tampão de lise dos glóbulos vermelhos): 0,32 M sacarose; $10 \mathrm{mM}$ Tris $\mathrm{HCl} ; 5 \mathrm{mM} \mathrm{MgCl} 2 ; 0,75 \%$ Triton-X-100 ; (pH a 7,6).

Tampão de lise II (desproteinização): 20 mM Tris-HCl; 4 mM Na 2 EDTA; $100 \mathrm{mM} \mathrm{NaCl} ;(\mathrm{pH}$ a 7,4).

A extração do DNA genômico foi realizada utilizando $10 \mathrm{~mL}$ de sangue venoso de cada amostra de paciente que estava armazenado em tubo vaccumtainer, contendo 5\% EDTA sob refrigeração. O material foi homogeneizado e transferido para tubo de 50mL, no qual houve a adição da solução tampão de lise I. Após a homogeneização, seguiu-se com a centrifugação por 10 minutos a 600 x g para lise das hemácias e formação de botão de glóbulos brancos. Com a separação das fases, o sobrenadante foi descartado e houve a adição de 4,5 mL de tampão de lise II, 1,1mL de perclorato de sódio e $125 \mu \mathrm{L}$ SDS. Essa solução foi levada ao vórtex e, posteriormente, centrifugada por 10 minutos a $600 \mathrm{x}$ g. Nesta etapa, o sobrenadante era recolhido para outro tubo de $50 \mathrm{~mL}$, no qual foi adicionado $7,5 \mathrm{~mL}$ de isopropanol de forma a ocorrer a precipitação do DNA. O DNA precipitado era então coletado e transferido para tubo de $1,5 \mathrm{~mL}$, no qual foi adicionado $1 \mathrm{~mL}$ de álcool $70 \%$. Este material foi centrifugado por 10 minutos a 30.000 x g para formação de botão do material genômico. Após desprezar o álcool $70 \%$, foram adicionados $300 \mu \mathrm{L}$ de $\mathrm{H}_{2} \mathrm{O}$ miliQ autoclavada para homogeneização do material genômico. Finaliza-se a etapa de extração do DNA com o armazenamento em freezer $-20^{\circ} \mathrm{C}$.

A quantificação e pureza das extrações foram obtidas por meio da avaliação das absorbâncias e cálculo das razões, usando um espectrofotômetro NanoDrop ND1000 (NanoDrop Products, Wilmington, DE). 
A extração do DNA genômico e análise de controle de qualidade do mesmo foram realizados no laboratório de Imunologia Molecular do Hospital das Clínicas de Ribeirão Preto, Faculdade de Medicina de Ribeirão Preto, Universidade de São Paulo (USP), Brasil.

\subsection{Reação em cadeia da polimerase (PCR)}

\section{Reagentes e Soluções}

DNA polimerase (Taq): concentração de $5 \mathrm{U} / \mu \mathrm{L}$ em solução estoque sendo utilizada para cada reação apenas 2,5U (BIOTOOLS - B \& M Labs, AS).

Tampão de estocagem da DNA polimerase: $10 \mathrm{mM}$ de Tris/ $\mathrm{HCl}(\mathrm{pH} 8,0), 50$

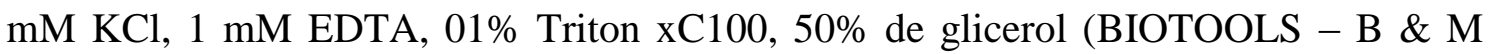
Labs, AS).

Tampão de reação da DNA polimerase: Tris/ $\mathrm{HCl} 75 \mathrm{mM} \mathrm{pH} \mathrm{9.0;} \mathrm{KCl} 50$ $\mathrm{mM} ;(\mathrm{NH} 4)_{2} \mathrm{SO}_{4} 20 \mathrm{mM}$ e $2 \mathrm{mM} \mathrm{MgCl} 2$. (BIOTOOLS - B \& M Labs, AS).

dNTP solução estoque: presença de quatro soluções liofilizadas referentes a cada base nucleica, dATP, dTTP, dCTP, dGTP, contendo em cada frasco uma concentração de $25 \mu \mathrm{M}$ (Amersham Biosciences).

dNTP solução trabalho: após eluição com água mili-Q autoclavada da solução estoque de cada dNTP foi realizada uma solução trabalho contendo uma concentração $2 \mathrm{mM}$.

Iniciadores (Primers) solução estoque: os primers liofilizados (Foward e Reverse) (Tabela 1) foram eluídos para uma concentração de $0.5 \mathrm{nM}$.

Iniciadores (Primers) solução trabalho: A partir da solução estoque se fez uma solução trabalho de concentração $10 \mu \mathrm{M}$. 
Tabela 1: Sequências dos iniciadores utilizados na reação em cadeia da polimerase.

\begin{tabular}{cc}
\hline Primers (-23 HphI) & Sequências \\
\hline Forward & AGC AGG TCT GTT CCA AGG \\
Reverse & CTT GGG TGT GTA GAA GAA GC-3’ \\
\hline
\end{tabular}

\section{Procedimento}

As reações de PCR foram realizadas em volume final de $25 \mu \mathrm{L}$, sendo que todos os reagentes, com exceção do DNA, foram misturados em reação MIX de forma a garantir a homogeneidade das reações. Cada amostra de DNA genômico foi diluída para garantir 100ng de material em cada frasco. A quantidade de cada reagente específico para a amplificação da região promotora da insulina, a qual contém o SNP-23HphI, encontra-se na Tabela 2.

Tabela 2: Condições de amplificação do DNA para tipificação do polimorfismo INS-VNTR (quantidade para uma reação).

\begin{tabular}{ccccccc}
\hline Polimorfismo & $\begin{array}{c}\text { Água mili-Q } \\
\text { DEPC } \\
\text { autoclavada }\end{array}$ & $\begin{array}{c}\text { Tampão } \\
\text { de PCR }\end{array}$ & dNTPs & $\begin{array}{c}\text { DNA } \\
\text { polimerase }\end{array}$ & Primers & $\begin{array}{c}\text { DNA } \\
\text { (100ng) }\end{array}$ \\
\hline $\mathbf{- 2 3 H p h I}$ & $15 \mu 1$ & $2,5 \mu \mathrm{l}$ & $2 \mu \mathrm{l}$ & $0,5 \mu 1$ & $2 \mu 1$ & $1 \mu 1$ \\
\hline
\end{tabular}

Cada reação de PCR foi realizada em microtubo de $200 \mu \mathrm{L}$, sendo que para cada conjunto de reações foram utilizadas três controles negativos, contendo apenas água mili-Q DEPC autoclavada ao invés de DNA genômico. O programa utilizado no termociclador GENE Amp* PCR system 9700 (Applied Biosystem) para a amplificação do fragmento de $360 \mathrm{pb}$ é descrito na Tabela 3. 
Tabela 3: Programa utilizado no termociclador GENE Amp* PCR system 9700 para a amplificação do fragmento em análise.

\begin{tabular}{ccc}
\hline Ciclos & Temperatura & Tempo \\
\hline 1 & $96^{\circ} \mathrm{C}$ & $2 \mathrm{~min}$ \\
30 & $94^{\circ} \mathrm{C}$ & $1 \mathrm{~min}$ \\
& $62^{\circ} \mathrm{C}$ & $1 \mathrm{~min}$ \\
& $72^{\circ} \mathrm{C}$ & $1 \mathrm{~min}$ \\
1 & $72^{\circ} \mathrm{C}$ & $10 \mathrm{~min}$ \\
\hline
\end{tabular}

A Figura 4 representa o gel de agarose $2 \%$ do produto amplificado que possui $360 \mathrm{pb}$ e os marcadores moleculares de 50pb (Promega, Madison, EUA) e $\varphi$ X174 (Sigma, Saint Louis, EUA). O fragmento é referente a região promotora do gene da insulina, o qual contém na sequência downstream o polimorfismo -23HphI cujo desequilíbrio de ligação $\left(\mathrm{r}^{2} \approx 1\right)$ com o polimorfismo INS-VNTR permite inferir os genótipos dos pacientes em estudo através da análise do polimorfismo -23HphI.

Figura 4: Produto de amplificação referente à região promotora do gene da insulina.

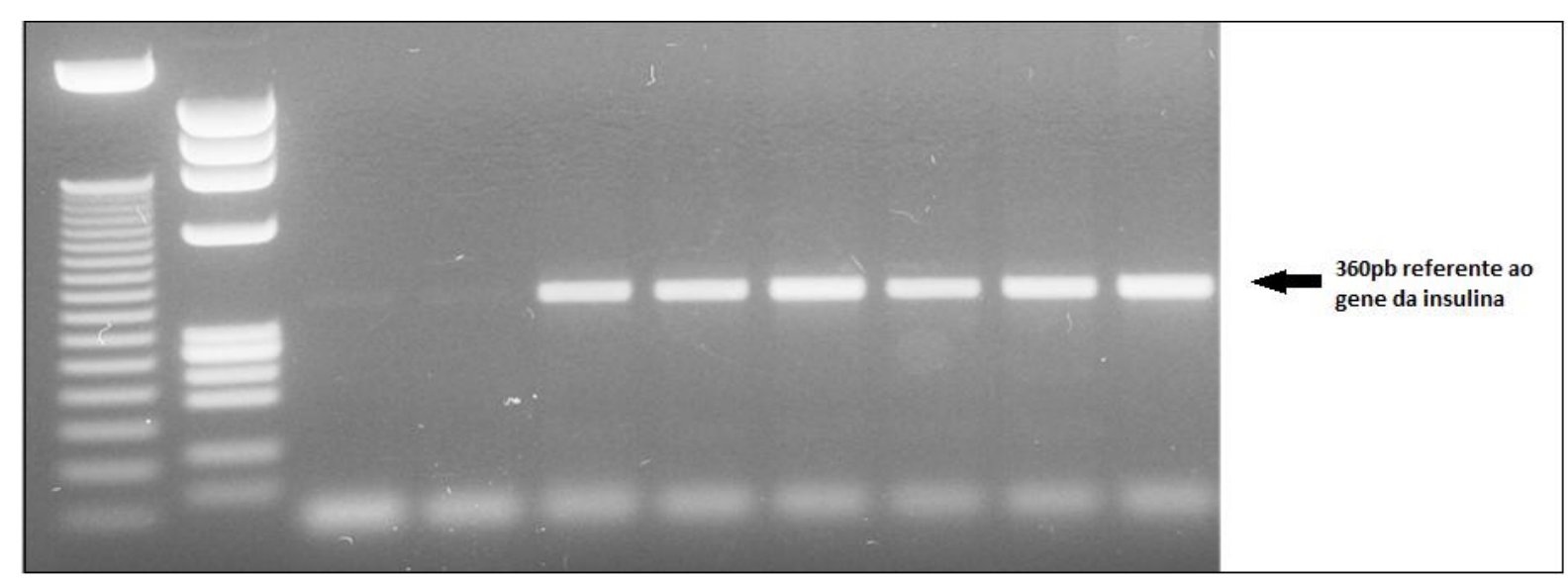

As amplificações da região promotora do gene da insulina foram realizadas no laboratório de Imunogenética Molecular do Departamento de Genética e laboratório de Biologia Molecular, Faculdade de Medicina de Ribeirão Preto, Universidade de São Paulo (USP), Brasil. 


\subsection{Reação de digestão}

O uso da enzima -23HphI deveu-se ao fato de o polimorfismo do tipo SNP $23 H p h I$ encontrar-se em desequilíbrio de ligação $\left(\mathrm{r}^{2} \approx 1\right)$ com o polimorfismo INS$V N T R$, fato que favorece a análise do minissatélite na região promotora do gene da insulina, pois ao obtermos o genótipo do SNP -23HphI, podemos inferir o genótipo do polimorfismo INS-VNTR.

\section{Reagentes e Soluções}

Mistura de reação: 2,5U da enzima HphI (Fermentas, Burlington, Canadá) na concentração de $10 \mathrm{U} / \mu \mathrm{L}, 1 \mu \mathrm{L}$ de tampão de reação $10 \mathrm{X}$ (Fermentas) e $9 \mu \mathrm{L}$ de Água mili-Q autoclavada.

\section{Procedimento}

As reações foram realizadas em volume final de $15,25 \mu \mathrm{L}$, sendo que todos os reagentes, com exceção do produto amplificado, foram misturados em uma reação MIX de forma a garantir a homogeneidade das reações. O volume do produto amplificado adicionado em cada tubo de polipropileno de $1,5 \mathrm{~mL}$ foi de $5 \mu \mathrm{L}$. A quantidade de cada reagente específico para a reação de restrição SNP-23HphI encontra-se na Tabela 4.

Tabela 4: Condições para a digestão enzimática do produto de amplificação para avaliar o polimorfismo INS-VNTR (quantidade para uma reação).

\begin{tabular}{cc}
\hline Reagentes & Volume $(\boldsymbol{\mu L})$ \\
\hline Água mili-Q autoclavada & 9 \\
Buffer 10X & 1 \\
Enzima HphI & 0,25 \\
\hline
\end{tabular}

Para a digestão, as amostras foram incubadas em banho-maria a $37^{\circ} \mathrm{C}$ em um intervalo de 4 horas e 30 minutos. Após incubação, os tubos foram retirados do banhomaria e realizou-se um choque térmico com água e gelo e, posteriormente, os tubos 
foram recolocados em banho-maria em temperatura de $65^{\circ} \mathrm{C}$ por 30 minutos para inativação da enzima.

\subsection{Determinação Fenotípica}

A descrição dos cortes da enzima HphI são:

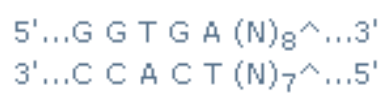

A Figura 5 representa o gel de agarose 2\%, referente ao padrão de bandas após digestão enzimática do DNA amplificado. A presença das bandas de 129pb e 191pb caracterizam indivíduo homozigoto para o alelo $A$, inferindo para o polimorfismo INSVNTR indivíduo de classe I : classe I. A presença das bandas de $129 \mathrm{pb}$ e $231 \mathrm{pb}$ caracterizam o indivíduo homozigoto para o alelo $T$, inferindo para o polimorfismo INS-VNTR indivíduo de classe III : classe III. Por fim, a presença das bandas $129 \mathrm{pb}$, $191 \mathrm{pb}$ e $231 \mathrm{pb}$ caracterizam o indivíduo heterozigoto de classe I : classe III.

Figura 5: Padrão de bandas obtido pela reação de digestão com a enzima HphI, na região promotora do gene da insulina.

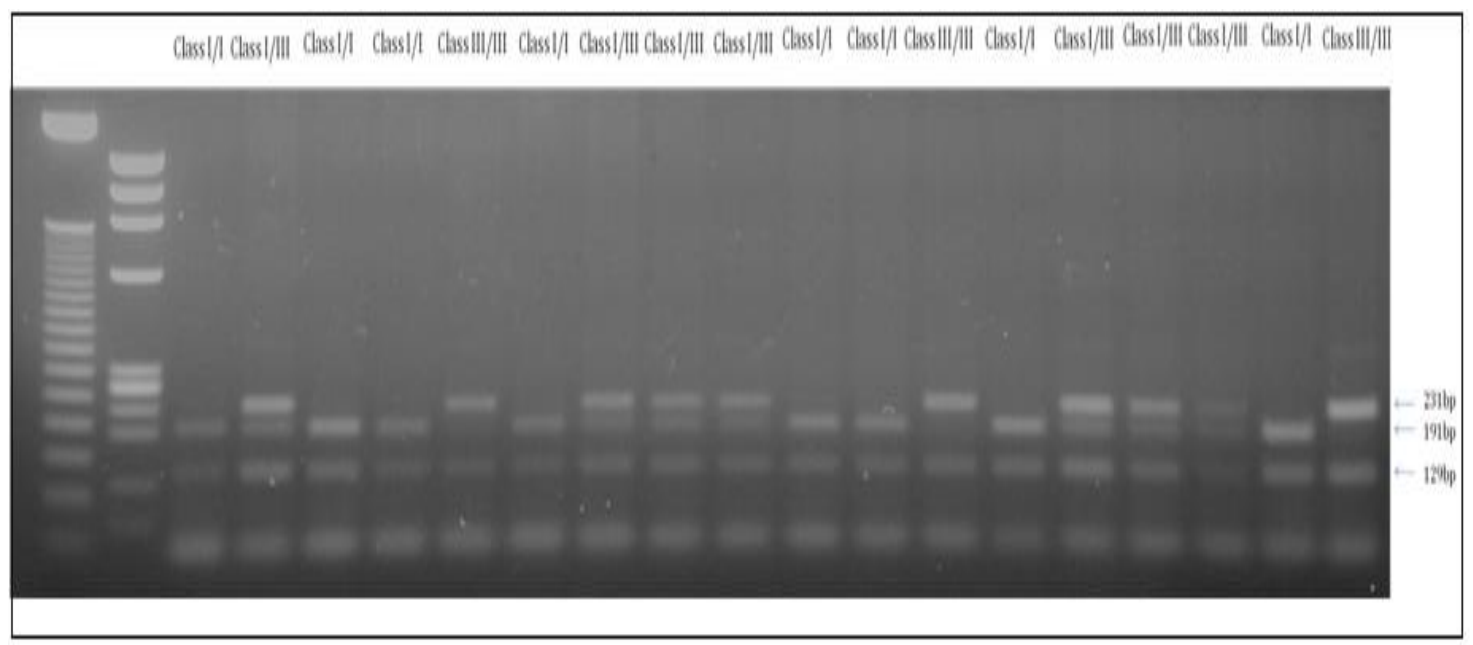




\subsection{Análise Estatística}

\subsubsection{Perfil dos indivíduos amostrados}

A caracterização do perfil dos indivíduos amostrados de acordo com os dados demográficos, clínicos e laboratoriais dos indivíduos foi realizada empregando-se testes como o teste exato de Fisher por meio do programa GraphPad Instat 3.06 (Graphpad Software, 2003) e RXC fazendo uso do algoritmo Metropolis, one-way ANOVA seguido Kruskal-Wallis (KWT) e teste T não pareado por meio do programa GraphPad Instat 3.06 (Graphpad Software, 2003).

\subsubsection{Estimativas das frequências alélicas e genotípicas}

As frequências alélicas (xi) e genotípicas (Xii) do polimorfismo INS-VNTR em cada amostra foram estimadas por contagem direta, utilizando-se o programa GENEPOP 4.0 (ROUSSET, 2008). Considerando-se a representação da frequência relativa de um genótipo $\mathrm{A}_{\mathrm{i}} \mathrm{A}_{\mathrm{j}}$ como sendo $\mathrm{X}_{\mathrm{ij}}$, temos que a frequência do alelo $i$ é dada por:

$$
x i=X i i+\Sigma \frac{X i j}{2}
$$

Em que $\Sigma_{\mathrm{j} \neq \mathrm{i}} \mathrm{X}_{\mathrm{ij}}$ indica a somatória de frequências de todos os genótipos que apresentam o alelo $i$, exceto quando $\mathrm{i}=\mathrm{j}(\mathrm{NEI}, 1987)$.

\subsubsection{Aderência ao equilíbrio de Hardy-Weinberg}

Segundo o teorema de Hardy-Weinberg, as frequências genotípicas esperadas no equilíbrio foram estimadas a partir da expansão do seguinte binômio:

$$
(x i+x j)^{2}=x i^{2}+2 x i x j+x j^{2}
$$

Em que:

$\mathrm{xi}^{2}$ é a frequência esperada dos homozigotos do alelo $\mathrm{i}$;

2 xixj é a frequência esperada do heterozigoto ij; 
$\mathrm{xj}^{2}$ é a frequência esperada dos homozigotos para o alelo $\mathrm{j}$.

A aderência das frequências genotípicas observadas às proporções teóricas de Hardy-Weinberg foi verificada com o emprego do programa GENEPOP 4.0 (ROUSSET, 2008). Foram realizados três testes baseados na hipótese nula de união aleatória dos gametas: teste exato de probabilidade, teste para detecção da deficiência e para detecção do excesso de heterozigotos.

No teste exato de probabilidade, o valor de $p(p \mathrm{HWE})$ corresponde à soma de probabilidades de todas as tabelas com probabilidade menor ou igual ao observado.

O segundo e o terceiro são testes mais sensíveis do que o de probabilidade e utilizam uma hipótese alternativa (H1) de excesso ou de deficiência de heterozigotos, respectivamente.

\subsubsection{Associação do locus INS-VNTR aos tipos de diabetes mellitus}

Para verificação da existência de associações entre alelos, genótipos e um determinado tipo de diabetes mellitus foi utilizado o teste exato de Fisher. A magnitude dessa associação foi calculada por meio do Odds ratio e seu intervalo de confiança de 95\% com limite inferior e superior. Todos esses dados foram obtidos empregando-se o programa RXC e GraphPad Instat 3.06 (Graphpad Software, 2003).

O Odds ratio corresponde à razão entre a probabilidade de um indivíduo apresentar um determinado fenótipo quando possuir um determinado alelo/genótipo e a probabilidade de um indivíduo não apresentar o fenótipo quando possuir um determinado alelo/genótipo. Esse parâmetro é apropriado para estudos de associação. Exemplificando, o Odds ratio igual a 10 significa que o fenótipo considerado ocorre com frequência dez vezes maior em indivíduos que apresentem o alelo/genótipo em questão do que em indivíduos que não os apresentam. 
5.6.5. Associação das classes genotípicas às características demográficas, clínicas e laboratoriais dos indivíduos amostrados.

A análise de possíveis associações entre as classes genotípicas e uma determinada característica demográfica, clínica ou laboratorial dentro de um determinado tipo de diabetes mellitus foi realizada a partir do teste exato de Fisher, empregando o programa GraphPad Instat 3.06 (Graphpad Software, 2003) e o RXC, esse último, quando havia a necessidade de tabelas de contingência com matrizes distintas a 2x2, para dados predominantemente de presença ou ausência de sintomas, sexo, cor. Para os dados de idade, tempo de doença, peso, estatura, glicemia de jejum, hemoglobina glicada, peso e estatura fetal foram utilizados testes de comparação oneway ANOVA, seguidos de pós-testes, como teste Kruskal-Wallis (KWT), Dunn's, Mann-Whitney Wilcoxon (MWW) e Tukey HSD (Tukey honestly significantly different) (HSD), de acordo com o tipo de distribuição paramétrica ou não paramétrica. Esses testes foram realizados utilizando-se o programa GraphPad Instat 3.06 (Graphpad Software, 2003). 
RESULTADOS 


\section{RESULTADOS}

\subsection{Indivíduos estudados}

Dados acerca das características demográficas, clínicas e laboratoriais dos pacientes foram utilizadas para descrever o perfil de cada classe clínica do diabetes mellitus.

Os pacientes diabéticos mellitus tipo 1 e diabéticos mellitus tipo 2 foram caracterizados em relação à idade, sexo, ancestralidade (cor da pele), peso, estatura, tempo de doença, presença ou ausência de nefropatia, neuropatia, retinopatia, hipertensão, dislipidemia e obesidade, resultados de exames de glicemia em jejum e hemoglobina glicada e medicamentos em uso.

As pacientes com diabetes gestacional foram caracterizadas de acordo com a idade, ancestralidade (cor da pele), peso, estatura, tempo gestacional, número de gestações, presença ou não do diabetes gestacional em outra gestação, complicações, resultado do exame de glicemia em jejum, medicamentos em uso, presença ou não de macrossomia fetal, obesidade, nefropatia, neuropatia, retinopatia, dislipidemia e hipertensão, sexo do recém-nascido (RN), APGAR do RN, peso do RN e estatura do RN.

Em relação aos controles, foram coletados dados de idade, sexo, peso, estatura e ancestralidade (cor da pele). 
Tabela 5: Características demográficas, clínicas e laboratoriais dos pacientes com diabetes mellitus tipo 1, tipo 2 e gestacional e dos indivíduos saudáveis.

\begin{tabular}{|c|c|c|c|c|c|c|}
\hline & \multicolumn{3}{|c|}{ Diabetes mellitus } & \multirow{2}{*}{$\begin{array}{c}\text { Recém- } \\
\text { nascidos das } \\
\text { pacientes } \\
\text { com DMG }\end{array}$} & \multirow{2}{*}{$\begin{array}{c}\text { Indivíduos } \\
\text { saudáveis } \\
\text { (controle - CTRL) }\end{array}$} & \multirow{2}{*}{$\begin{array}{l}p \text { - valores de comparação entre: } \\
\text { DM1 vs. DM2 vs. DMG vs. CTRL }\end{array}$} \\
\hline & DM1 & DM2 & DMG & & & \\
\hline Sexo & $(n=188)$ & $(n=91)$ & $(\mathrm{n}=68)$ & $(\mathrm{n}=45)$ & $(n=316)$ & $\begin{array}{l}\text { DM1 vs. DM2 vs. DMG vs. CTRL } \\
\qquad p=0,000020^{*} \text { (MET) }\end{array}$ \\
\hline Homens / Mulheres & $89 / 99$ & $34 / 57$ & $0 / 68$ & $16 / 29$ & $176 / 140$ & $\begin{array}{l}\text { DM1 vs. DM2 } p=0.1244 \quad(\text { FET }) \\
\text { DM1 vs. DMG } p<0.0001 *(\mathrm{FET}) \\
\text { DM1 vs. CTRL } p=0.0797 \quad(\mathrm{FET}) \\
\text { DM2 vs. DMG } p<0.0001 *(\mathrm{FET}) \\
\text { DM2 vs. CTRL } p=0.0028^{*}(\mathrm{FET}) \\
\text { DMG vs. CTRL } p<0.0001 *(\mathrm{FET})\end{array}$ \\
\hline Idade (anos) & $(n=167)$ & $(\mathrm{n}=89)$ & $(n=64)$ & - & $(n=270)$ & \\
\hline Média & 25.035 & 56.595 & 31.437 & - & 39.770 & $p<0.0001 *(\mathrm{KWT})$ \\
\hline Mediana & 23 & 60 & 31 & - & 41 & \\
\hline Intervalo & $7-79$ & $27-85$ & $16-43$ & - & $1-72$ & \\
\hline $\begin{array}{l}\text { Ancestralidade (cor } \\
\text { da pele) }\end{array}$ & $(n=178)$ & $(\mathrm{n}=82)$ & $(n=65)$ & & $(\mathrm{n}=255)$ & $p=0296290(\mathrm{MET})$ \\
\hline $\begin{array}{l}\text { Branco / Negro/ } \\
\text { Amarelo/ Mulato }\end{array}$ & $\begin{array}{l}153 / 8 / 2 / \\
15\end{array}$ & $65 / 8 / 8 / 1$ & $\begin{array}{l}49 / 8 / 0 / \\
8\end{array}$ & & $201 / 27 / 1 / 26$ & \\
\hline
\end{tabular}




\section{Continuação}

\begin{tabular}{|c|c|c|c|c|c|c|}
\hline Peso & $(\mathrm{n}=106)$ & $(\mathrm{n}=75)$ & $(\mathrm{n}=61)$ & $(n=45)$ & $(\mathrm{n}=310)$ & DM1 vs. DM $2 p<0.001 *($ KWT $)$ \\
\hline (quilogramas) & & & & & & DM1 vs. DMG $p<0.001 *(\mathrm{KWT})$ \\
\hline Média & 63,462 & 80,976 & 86,173 & 3,592 & 69,464 & DM1 vs. CTRL $p<0.001^{*}$ (KWT) \\
\hline Intervalo & $24,5-119,3$ & $47,6-139,7$ & $55-130$ & $\begin{array}{c}2,720- \\
4,975\end{array}$ & $12-110$ & $\begin{array}{l}\text { DM2 vs. DMG } p>0.05 \quad(\text { KWT }) \\
\text { DM2 vs. CTRL } p<0.001 *(\text { KWT })\end{array}$ \\
\hline Mediana & 61,75 & 80,4 & 88,0 & 3,622 & 70 & DMG vs. CTRL $p<0.001 *(\mathrm{KWT})$ \\
\hline Estatura (metros) & $(\mathrm{n}=77)$ & $(\mathrm{n}=92)$ & $(\mathrm{n}=59)$ & $(n=45)$ & $(n=310)$ & DM1 vs. DM2 $p>0.05(\mathrm{KWT})$ \\
\hline Média & 1,596 & 1,606 & 1,598 & 0,497 & 1,66 & DM1 vs. DMG $p>0.05(\mathrm{KWT})$ \\
\hline Intervalo & $1,21-1,88$ & $1,45-1,80$ & $1,47-1,75$ & $0,45-0,53$ & $0,9-1,95$ & $\begin{array}{l}\text { DM1 vs. CTRL } p<0.001 *(\mathrm{KWT}) \\
\text { DM2 vs. DMG } p>0.05(\mathrm{KWT})\end{array}$ \\
\hline Mediana & 1,60 & 1,585 & 1,59 & 0,5 & 1,68 & $\begin{array}{l}\text { DM2 vs. CTRL } p<0.01 *(\mathrm{KWT}) \\
\text { DMG vs. CTRL } p<0.001 *(\mathrm{KWT})\end{array}$ \\
\hline APGAR & $(\mathrm{n}=0)$ & $(\mathrm{n}=0)$ & $(\mathrm{n}=0)$ & $(n=45)$ & $(\mathrm{n}=0)$ & \\
\hline Média & - & - & - & $8,58 / 9,73$ & - & \\
\hline Intervalo & - & - & - & $5-10 / 8-10$ & - & \\
\hline Mediana & - & - & - & $9 / 10$ & - & \\
\hline
\end{tabular}




\section{Continuação}

\begin{tabular}{|c|c|c|c|c|}
\hline & \multicolumn{3}{|c|}{ Diabetes mellitus } & \multirow{2}{*}{$\begin{array}{c}p \text { - valores de comparação entre: } \\
\text { DM1 vs. DM2 vs. DMG }\end{array}$} \\
\hline & DM1 & DM2 & DMG & \\
\hline Tempo de doença (anos) & $(n=110)$ & $(n=73)$ & $(\mathrm{n}=0)$ & \\
\hline Média & 13,172 & 13,739 & - & \\
\hline Intervalo & $2-39$ & $1-34$ & - & $p=0,9776($ Teste T não pareado $)$ \\
\hline Mediana & 11 & 14 & - & \\
\hline $\begin{array}{l}\text { Tempo de gestação } \\
\text { (semanas) }\end{array}$ & $(\mathrm{n}=0)$ & $(\mathrm{n}=0)$ & $(n=62)$ & \\
\hline Média & - & - & 32 & - \\
\hline Intervalo & - & - & $18-40$ & \\
\hline Mediana & - & - & 34 & \\
\hline Número de gestações & $(\mathrm{n}=0)$ & $(\mathrm{n}=0)$ & $(n=62)$ & \\
\hline Média & - & - & 2,91 & - \\
\hline Intervalo & - & - & $1-10$ & \\
\hline Mediana & - & - & 2 & \\
\hline $\begin{array}{c}\text { Diabetes em outra } \\
\text { gestação (P / A) }\end{array}$ & - & - & $13 / 48$ & - \\
\hline
\end{tabular}




\section{Continuação}

\begin{tabular}{|c|c|c|c|c|}
\hline Exames & & & & \\
\hline Glicemia de jejum & $(n=100)$ & $(n=84)$ & $(n=65)$ & \multirow[b]{2}{*}{ DM1 vs. DM2 $p>0.05(\mathrm{KWT})$} \\
\hline$(\mathrm{mg} / \mathrm{dL})$ & & & & \\
\hline Média & 183,794 & 168,821 & 95,190 & \multirow{2}{*}{$\begin{array}{l}\text { DM1 vs. DMG } p<0.001 *(\mathrm{KWT}) \\
\text { DM2 vs. DMG } p<0.001 *(\mathrm{KWT})\end{array}$} \\
\hline Intervalo & $23-505$ & $45-388$ & $59-274,4$ & \\
\hline Mediana & 178,5 & 132,5 & 90 & \\
\hline $\begin{array}{l}\text { Hemoglobina glicada } \\
\qquad(\%)\end{array}$ & $(\mathrm{n}=109)$ & $(n=73)$ & $(\mathrm{n}=0)$ & \multirow{4}{*}{$p=0.9827$ (Teste T não pareado) } \\
\hline Média & 9,549 & 9,556 & - & \\
\hline Intervalo & $5,7-15,1$ & $5,5-17,4$ & - & \\
\hline Mediana & 9,2 & 8,8 & - & \\
\hline \multicolumn{5}{|l|}{ Sintomas } \\
\hline Nefropatia & $19 / 95$ & $30 / 52$ & $0 / 68$ & DM1 vs. DM2 vs. DMG $p=0,000000 *(\mathrm{MET})$ \\
\hline & $(\%=16,52)$ & $(\%=36,58)$ & $(\%=0)$ & DM1 vs. DM2 $p=0.0024 *(\mathrm{FET})$ \\
\hline & & & & DM1 vs. DMG $p<0.0001 *(\mathrm{FET})$ \\
\hline & & & & DM2 vs. DMG $p<0.0001 *(\mathrm{FET})$ \\
\hline
\end{tabular}




\section{Continuação}

\begin{tabular}{|c|c|c|c|c|}
\hline $\begin{array}{c}\text { Neuropatia } \\
\text { (P/ A) }\end{array}$ & $\begin{array}{c}8 / 106 \\
(\%=7,01)\end{array}$ & $\begin{array}{c}26 / 56 \\
(\%=31,70)\end{array}$ & $\begin{array}{c}0 / 68 \\
(\%=0)\end{array}$ & $\begin{array}{l}\text { DM1 vs. DM2 vs. DMG } p=0,000050 *(\mathrm{MET}) \\
\text { DM1 vs. DM2 } p<0.0001 *(\mathrm{FET}) \\
\text { DM1 vs. DMG } p<0.0262(\mathrm{FET}) \\
\text { DM2 vs. DMG } p<0.0001 *(\mathrm{FET})\end{array}$ \\
\hline $\begin{array}{c}\text { Retinopatia } \\
\text { (P/ A) }\end{array}$ & $\begin{array}{c}12 / 102 \\
(\%=10,52)\end{array}$ & $\begin{array}{c}29 / 53 \\
(\%=35,36)\end{array}$ & $\begin{array}{c}0 / 68 \\
(\%=0)\end{array}$ & $\begin{array}{c}\text { DM1 vs. DM2 vs. DMG } p=0,000000^{*}(\mathrm{MET}) \\
\text { DM1 vs. DM2 } p<0.0001 *(\mathrm{FET}) \\
\text { DM1 vs. DMG } p=0.0040 *(\mathrm{FET}) \\
\text { DM2 vs. DMG } p<0.0001 *(\mathrm{FET})\end{array}$ \\
\hline $\begin{array}{l}\text { Hipertensão } \\
\text { (P / A) }\end{array}$ & $\begin{array}{c}21 / 95 \\
(\%=18,42)\end{array}$ & $\begin{array}{c}64 / 19 \\
(\%=78,04)\end{array}$ & $\begin{array}{c}5 / 63 \\
(\%=7,35)\end{array}$ & $\begin{array}{c}\text { DM1 vs. DM2 vs. DMG } p=0,000010 *(\mathrm{MET}) \\
\text { DM1 vs. DM2 } p<0.0001 *(\mathrm{FET}) \\
\text { DM1 vs. DMG }<0.0001 *(\mathrm{FET}) \\
\text { DM2 vs. DMG } p<0.0001 *(\mathrm{FET})\end{array}$ \\
\hline $\begin{array}{c}\text { Dislipidemia } \\
\text { (P/ A) }\end{array}$ & $\begin{array}{c}22 / 93 \\
(\%=19,29)\end{array}$ & $\begin{array}{c}56 / 26 \\
(\%=68,29)\end{array}$ & $\begin{array}{c}6 / 62 \\
(\%=8,82)\end{array}$ & $\begin{array}{c}\text { DM1 vs. DM2 vs. DMG } p=0,000050 *(\mathrm{MET}) \\
\text { DM1 vs. DM2 } p<0.0001 *(\mathrm{FET}) \\
\text { DM1 vs. DMG } p=0.0879(\mathrm{FET}) \\
\text { DM2 vs. DMG } p<0.0001 *(\mathrm{FET})\end{array}$ \\
\hline $\begin{array}{c}\text { Obesidade } \\
\text { (P/ A) }\end{array}$ & $\begin{array}{c}12 / 102 \\
(\%=9,64)\end{array}$ & $\begin{array}{c}38 / 43 \\
(\%=46,34)\end{array}$ & $\begin{array}{c}18 / 50 \\
(\%=26,47)\end{array}$ & $\begin{array}{l}\text { DM1 vs. DM2 vs. DMG } p=0,000670 *(\mathrm{MET}) \\
\text { DM1 vs. DM2 } p<0.0001^{*}(\mathrm{FET}) \\
\text { DM1 vs. DMG } p=0.0070 *(\mathrm{FET}) \\
\text { DM2 vs. DMG } p=0.0114 *(\mathrm{FET})\end{array}$ \\
\hline
\end{tabular}




\section{Continuação}

\begin{tabular}{|c|c|c|c|c|}
\hline $\begin{array}{c}\text { Macrossomia Fetal } \\
\qquad(\mathbf{P} / \mathbf{A})\end{array}$ & $\begin{array}{l}0 / 114 \\
(\%=0)\end{array}$ & $\begin{array}{c}0 / 82 \\
(\%=0)\end{array}$ & $\begin{array}{c}6 / 22 \\
(\%=27,9)\end{array}$ & $\begin{array}{l}\text { DM1 vs. DM2 vs. DMG } p=0,000850 *(\mathrm{MET}) \\
\text { DM1 vs. DMG } p<0.0001 *(\mathrm{FET}) \\
\text { DM2 vs. DMG } p=0.0002 *(\mathrm{FET})\end{array}$ \\
\hline Medicamentos & $(\mathrm{n}=107)$ & $(\mathrm{n}=78)$ & $(n=61)$ & \\
\hline Insulina NPH & $\begin{array}{c}64 \\
(\%=59,81)\end{array}$ & $\begin{array}{c}73 \\
(\%=93,58)\end{array}$ & $\begin{array}{c}19 \\
(\%=31,14)\end{array}$ & $\begin{array}{c}\text { DM1 vs. DM2 vs. DMG } p=0,000150 *(\mathrm{MET}) \\
\text { DM1 vs. DM2 } p<0.0001 *(\mathrm{FET}) \\
\text { DM1 vs. DMG } p=0.0004^{*}(\mathrm{FET}) \\
\text { DM2 vs. DMG } p<0.0001 *(\mathrm{FET})\end{array}$ \\
\hline Insulina Regular & $\begin{array}{c}79 \\
(\%=73,83)\end{array}$ & $\begin{array}{c}57 \\
(\%=73,07)\end{array}$ & $\begin{array}{c}18 \\
(\%=29,5)\end{array}$ & $\begin{array}{c}\text { DM1 vs. DM2 vs. DMG } p=0,016520^{*}(\mathrm{MET}) \\
\text { DM1 vs. DM2 } p=1.0000(\mathrm{FET}) \\
\text { DM1 vs. DMG } p<0.0001^{*}(\mathrm{FET}) \\
\text { DM2 vs. DMG } p<0.0001^{*}(\mathrm{FET})\end{array}$ \\
\hline Insulina Ultra-rapid & $\begin{array}{c}24 \\
(\%=22,42)\end{array}$ & $\begin{array}{c}0 \\
(\%=0)\end{array}$ & $\begin{array}{c}0 \\
(\%=0)\end{array}$ & $\begin{array}{c}\text { DM1 vs. DM2 vs. DMG } p=0,000000 *(\mathrm{MET}) \\
\text { DM1 vs. DM2 } p<0.0001 *(\mathrm{FET}) \\
\text { DM1 vs. DMG } p<0.0001 *(\mathrm{FET})\end{array}$ \\
\hline Insulina Lantus & $\begin{array}{c}18 \\
(\%=16,82)\end{array}$ & $\begin{array}{c}0 \\
(\%=0)\end{array}$ & $\begin{array}{c}0 \\
(\%=0)\end{array}$ & $\begin{array}{c}\text { DM1 vs. DM2 vs. DMG } p=0,000130 *(\mathrm{MET}) \\
\text { DM1 vs. DM2 } p<0.0001 *(\mathrm{FET}) \\
\text { DM1 vs. DMG } p=0.0002 *(\mathrm{FET})\end{array}$ \\
\hline
\end{tabular}




\section{Continuação}

\begin{tabular}{|c|c|c|c|c|}
\hline Insulina Aspart & $\begin{array}{c}7 \\
(\%=6,54)\end{array}$ & $\begin{array}{c}0 \\
(\%=0)\end{array}$ & $\begin{array}{c}0 \\
(\%=0)\end{array}$ & $\begin{array}{l}\text { DM1 vs. DM2 vs. DMG } p=0,029440 *(\text { MET }) \\
\text { DM1 vs. DM2 } p=0.0470 *(\text { FET }) \\
\text { DM1 vs. DMG } p=0.0219(\text { FET })\end{array}$ \\
\hline Metformina & $\begin{array}{c}11 \\
(\%=10,28)\end{array}$ & $\begin{array}{c}72 \\
(\%=92,3)\end{array}$ & $\begin{array}{c}4 \\
(\%=6,55)\end{array}$ & $\begin{array}{c}\text { DM1 vs. DM2 vs. DMG } p=0,000000 *(\mathrm{MET}) \\
\text { DM1 vs. DM2 } p<0.0001 *(\mathrm{FET}) \\
\text { DM1 vs. DMG } p=0.4156(\mathrm{FET}) \\
\text { DM2 vs. DMG } p<0.0001 *(\mathrm{FET})\end{array}$ \\
\hline Glifage XR & $\begin{array}{c}18 \\
(\%=16,82)\end{array}$ & $\begin{array}{c}6 \\
(\%=7,69)\end{array}$ & $\begin{array}{c}0 \\
(\%=0)\end{array}$ & $\begin{array}{c}\text { DM1 vs. DM2 vs. DMG } p=0,010710 *(\mathrm{MET}) \\
\text { DM1 vs. DM2 } p=0.0788(\mathrm{FET}) \\
\text { DM1 vs. DMG } p=0.0001 *(\mathrm{FET}) \\
\text { DM2 vs. DMG } p=0.0302 *(\mathrm{FET})\end{array}$ \\
\hline
\end{tabular}

$\mathrm{O}$ asterisco $(*)$ caracteriza os resultados que apresentaram significância estatística com $p$-valor $\leq 0,05$. A representação (P/A) denomina a presença (P) ou ausência (A). As comparações entre os quatro grupos (DM1, DM2, DMG, CTRL) foram realizadas através de análises por one-way ANOVA seguida de múltiplas comparações por teste Kruskal-Wallis test (KWT), Dunn's, teste T não pareado ou por teste exato que aplica Metropolis algorithm (MET) para obter um estimativa imparcial do exato valor de para uma dada Tabela de contigência RxC (no caso de reveladas diferenças significativas por esta ultima análise, comparações pós teste pair-wise foram feitas com teste exato de Fisher (FET)). 
Como esperado, os resultados estatísticos apontam diferenças significativas quanto as informações clínicas, laboratoriais e demográficas entre os três principais tipos de diabetes mellitus.

O perfil dos pacientes com DM1 foi composto por indivíduos de ambos os sexos com frequências similares, com prevalência de faixa etária em torno dos 25 anos, maioria brancos, sendo que, considerando os valores da média do peso e estatura para calcular a média do IMC (Índice de massa corporal) temos o resultado de um conjunto de indivíduos levemente acima do peso $(\mathrm{IMC}=24,9)$. Os resultados intrinsecamente relacionados ao DM1, apontam que esse o conjunto de pacientes tem o diagnóstico da doença há aproximadamente 13 anos, sendo que, de acordo com exames de glicemia de jejum e hemoglobina glicada, esses pacientes estão com o quadro clínico alterado uma vez que ambos os exames apresentam médias com valores superiores do limítrofe. Dentre os sintomas, observamos maior frequência de pacientes com dislipidemia. Os medicamentos rotineiramente utilizados nesses pacientes são a insulina regular e a insulina NPH, no entanto, ao avaliarmos os dados dos três grupos de pacientes diabéticos, é também utilizado no tratamento outros tipos de insulina como a Ultrarapid, Lantus e Aspart (não tivemos dados de pacientes DM2 e DMG que fizessem uso desses outros tipos de insulina).

O DM2 é caracterizado nessa amostra por ser comum a ambos os sexos, sendo mais frequente em mulheres, com idade média de 56 anos aproximadamente e maioria brancos. Diferentemente dos pacientes com DM1, os pacientes DM2 apresentam o IMC médio (IMC=31,2) de indivíduos com obesidade de grau I. Dentre os resultados diretamente relacionados ao DM2 temos que esse conjunto de pacientes tem o diagnóstico da doença há aproximadamente 13 anos, e no momento, com quadro clínico 
alterado, dado que os exames de glicemia de jejum e hemoglobina glicada estão com resultados acima dos limites considerados normais. Em relação aos sintomas, são prevalentes os casos de hipertensão seguido dos casos de dislipidemia, sendo importante ressaltar que os demais sintomas são frequentes e, em diferentes pacientes, mais de uma complicação foi diagnosticada. Os medicamentos habitualmente utilizados são insulina NPH, insulina regular e metformina, sendo comum, a associação desses medicamentos para o controle glicêmico.

As pacientes diabéticas gestacionais têm idade média de 31 anos, com idade média gestacional de 32 semanas, maioria brancos, com IMC médio (IMC=34,02) referente a indivíduos com obesidade de grau I, sendo 2,91 o número médio de gestações e 13 pacientes já apresentaram o diagnóstico do DMG em outras gestações. Apresentam o resultado de glicemia de jejum controlado, sendo mais frequentes os sintomas de obesidade e macrossomia fetal. Podemos observar que a maioria das gestantes controlam a glicemia com a readequação da dieta, no entanto, quando o uso de medicamentos foram necessários, a insulina NPH e a insulina regular foram prescritos com maior frequência. Em relação aos recém-nascidos dessas pacientes, as médias dos peso e estatura enquadram-se nos valores considerados normais para um recém-nascido, bem como, os valores do APGAR.

Os indivíduos saudáveis (controle) apresentam idade média de 39 anos, maioria brancos, com IMC médio $(\mathrm{IMC}=24,44)$ que caracteriza indivíduos com peso adequado.

\subsection{Frequências alélicas e Equilíbrio de Hardy-Weinberg}

Após coletados os resultados dos genótipos do polimorfismo INS-VNTR calculamos as frequências alélicas e genotípicas, número de heterozigotos observados e 
esperados e analisamos a probabilidade de aderência ao Equilíbrio de Hardy-Weinberg ( $p$ EHW) de cada grupo amostral em estudo. A Tabela 6 apresenta essas informações descritas.

Considerando o critério de definição para que um locus seja considerado polimórfico (frequência entre 1\% e 99\% para o alelo mais frequente), observamos que o locus INS-VNTR é considerado polimórfico na população brasileira.

As frequências genotípicas foram comparadas aos valores esperados pelo teste exato do equilíbrio de Hardy-Weinberg (Tabela 6). Apenas as amostras populacionais dos pacientes diabéticos tipo 2 (DM2) e diabéticas gestacionais (DMG) estão em equilíbrio de Hardy-Weinberg. Devido ao desvio do equilíbrio de Hardy-Weinberg, grupo de indivíduos controle, pacientes diabéticos tipo 1 e o grupo total de pacientes diabéticos, subtemos os dados ao teste de equilíbrio de Hardy-Weinberg em déficit de heterozigotos (Tabela 7) e em excesso de heterozigotos (Tabela 8). Os resultados do $p$ valor para o teste exato de equilíbrio de Hardy-Weinberg para grupos com déficit de heterozigotos evidenciam que o possível desvio no grupo de indivíduos controle, pacientes diabéticos tipo 1 e o grupo total de pacientes diabéticos foram devido ao déficit de heterozigotos analisados. Como pode ser observado, na Tabela 8, não houve nenhum resultado com $p$ valor significativo para $\alpha=0,05$ para o teste exato de equilíbrio de Hardy-Weinberg para grupos com excesso de heterozigotos. 
Tabela 6: Frequência alélica, frequência genotípica, número de heterozigotos observados e esperados, aderência ao Equilíbrio de HardyWeinberg do polimorfismo INS-VNTR na amostra populacional em estudo.

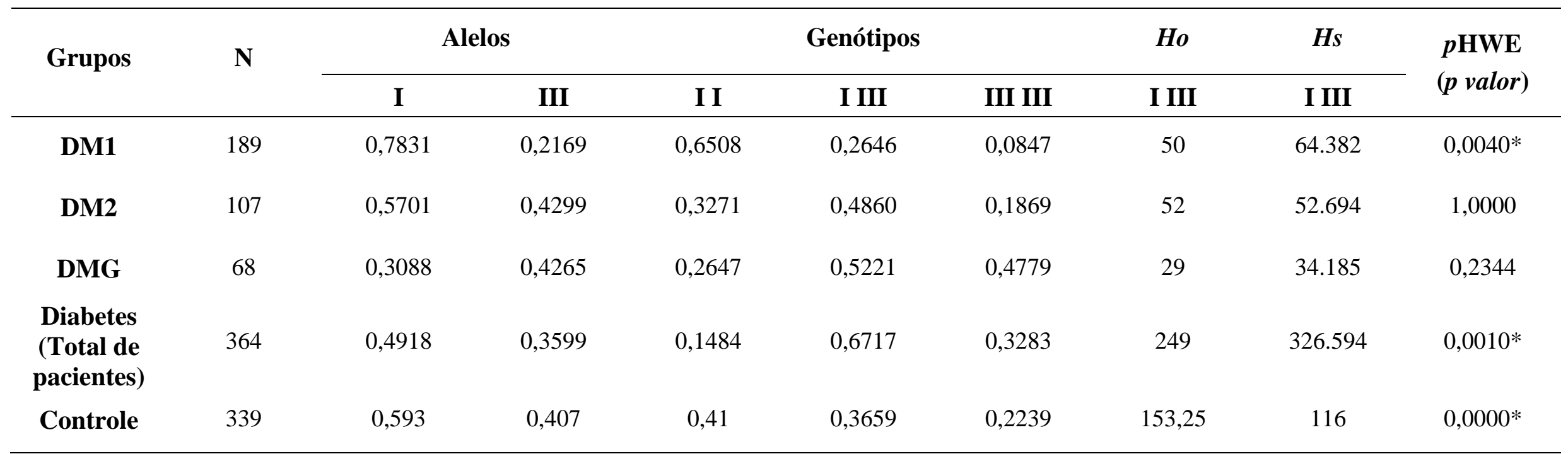

Esses resultados foram obtidos por meio do uso do software GENEPOP 4.0, sendo que, os resultados do teste de equilíbrio de Hardy-Weinberg (HWE) foram indicados com asterisco $(*)$ quando os valores foram significativos $(\alpha<0,05)$. 
Tabela 7: Teste exato do Equilíbrio de Hardy-Weinberg quando em deficiência de heterozigotos na amostra populacional em estudo.

\begin{tabular}{cc}
\hline Grupos & $p$ HWE \\
\hline DM1 & $0.0022^{*}$ \\
DM2 & 0.5242 \\
DMG & 0.1596
\end{tabular}

Diabetes $0.0005^{*}$

(Total de pacientes)

Controle $\quad 0.0000^{*}$

Esses resultados foram obtidos por meio do uso do software GENEPOP 4.0, sendo que, os resultados do teste de equilíbrio de Hardy-Weinberg quando em déficit de heterozigose (HWE) foram indicados com asterisco (*) quando os valores foram significativos $(\alpha<0,05)$.

Tabela 8: Teste exato do Equilíbrio de Hardy-Weinberg quando em excesso de heterozigotos na amostra populacional em estudo.

\begin{tabular}{cc}
\hline Grupos & $p$ HWE \\
\hline DM1 & 0.9996 \\
DM2 & 0.6362 \\
DMG & 0.9316 \\
Diabetes & 1.0000 \\
(Total de pacientes) & \\
Controle & 1.0000 \\
\hline
\end{tabular}

Esses resultados foram obtidos por meio do uso do software GENEPOP 4.0. 


\subsection{Associações encontradas}

\subsubsection{Associação diagnóstico dos tipos de diabetes mellitus e os genótipos INS- VNTR}

A análise da possível correlação existente entre alelos/genótipos do INS-VNTR e o fenótipo do indivíduo amostrado, no caso, se o alelo/genótipo pode ser considerado um marcador genético para a doença do diabetes mellitus foi realizada por meio do teste exato de Fisher, seus valores de Odds Ratio (OR) e intervalos de confiança com limites mínimo e máximo de 95\%, ressaltando que, para a análise comparativa entre genótipos e os fenótipos dos pacientes diabéticos apenas o teste exato de Fisher foi aplicado. Estão amostradas na Tabela 9 as associações encontradas a nível alélico e genotípico.

Em comparação ao grupo controle, o alelo classe I ( $p=0,0000 ; O R=2,4783$; 95\%I.C.1,8570-3,3075) e o genótipo classe I : classe I ( $p=0,0000 ;$ OR=2,5855; 95\%I.C. 1,7881-3,7385) estavam associados com susceptibilidade ao desenvolvimento do DM1, enquanto o alelo classe III ( $p=0,0000 ; O R=0,4035 ; 95 \%$ I.C.0,3023-0,5385) e o genótipo classe III : classe III ( $p=0,0000 ;$ OR=0,3044; 95\%I.C.0,1720-0,5386) conferiram proteção contra o desenvolvimento de DM1. Ainda, verificamos que no grupo de pacientes diabéticos mellitus tipo 1 em comparação aos demais grupos de pacientes com diabéticos existe significância estatística para o alelo classe I e alelo classe III e dos genótipos classe I : classe I, classe I : classe III e classe III : classe III. Esses resultados remetem ao alelo classe I associação à susceptibilidade ao DM1, predominantemente em homozigose.

Os pacientes diabéticos mellitus tipo 2 apresentaram significância estatística ao nível de 5\% para o genótipo classe I : classe III ( $p=0,0121 ;$ OR=1,7707, 95\% I.C: 1,1403-2,7496), quando comparado ao grupo amostral de indivíduos controle, isso o 
caracteriza como marcador de susceptibilidade ao DM2. Houve também significância estatística ao nível de 5\% para todos os alelos e genótipos quando comparado ao grupo amostral de pacientes diabéticos mellitus tipo 1. Como visto anteriormente, o alelo classe I está associado à progressão do DM1, sendo assim, o alelo classe III está relacionado ao DM2, com prevalência do genótipo em heterozigose. Em comparação com o grupo amostral de pacientes com diabetes mellitus gestacional não houve significância estatística ao nível de 5\%.

As pacientes com diabetes mellitus gestacional não apresentaram diferença estatística ao nível de 5\% de significância para nenhum dos alelos quando comparadas com o grupo amostral de indivíduos controle e de pacientes diabéticos mellitus tipo 2. Em comparação ao grupo amostral de pacientes diabéticos mellitus tipo 1, verifica-se significância estatística ao nível de $5 \%$ para todos os alelos e genótipos. Como visto anteriormente, a importância do alelo classe I para a progressão do DM1 torna possível inferir que o alelo de classe III esteja associado ao DMG. 
Tabela 9: Associações dos alelos e genótipos do polimorfismo INS-VNTR com as características fenotípicas dos tipos de diabetes mellitus.

\begin{tabular}{lccccc}
\hline \multicolumn{1}{c}{ Comparação } & $\begin{array}{c}\text { Alelo }- \\
\text { Genótipo }\end{array}$ & $\begin{array}{c}\text { Teste exato de } \\
\text { Fisher bicaudal } \\
(\boldsymbol{p} \text { valor })\end{array}$ & $\begin{array}{c}\text { IC 95\% limite } \\
\text { inferior }\end{array}$ & $\begin{array}{c}\text { Odds ratio }(\text { OR }) \\
\text { IC 95\% limite } \\
\text { superior }\end{array}$ \\
\hline Diabetes vs. Controle & I & $0,0023^{*}$ & 1,1299 & 1,4047 & 1,7464 \\
Diabetes vs. Controle & III & $0,0023^{*}$ & 0,5726 & 0,7119 & 0,8850 \\
Diabetes vs. Controle & I I & 0,0583 & 0,9965 & 1,3423 & 1,8083 \\
Diabetes vs. Controle & I III & 0,7529 & 0,7728 & 1,0530 & 1,4349 \\
Diabetes vs. Controle & III III & $0,0051^{*}$ & 0,3908 & 0,5733 & 0,8411 \\
\hline DM1 vs. Controle & I & $0,0000^{*}$ & 1,8570 & 2,4783 & 3,3075 \\
DM1 vs. Controle & III & $0,0000^{*}$ & 0,3023 & 0,4035 & 0,5385 \\
DM1 vs. Controle & I I & $0,0000^{*}$ & 1,7881 & 2,5855 & 3,7385 \\
DM1 vs. Controle & I III & 0,0516 & 0,4548 & 0,6737 & 0,9980 \\
DM1 vs. Controle & III III & $0,0000^{*}$ & 0,1720 & 0,3044 & 0,5386 \\
\hline
\end{tabular}




\section{Continuação}

\begin{tabular}{|c|c|c|c|c|c|}
\hline Comparação & $\begin{array}{c}\text { Alelo - } \\
\text { Genótipo }\end{array}$ & $\begin{array}{c}\text { Teste exato de } \\
\text { Fisher bicaudal } \\
\text { ( } p \text { valor })\end{array}$ & $\begin{array}{l}\text { IC } 95 \% \text { limite } \\
\text { inferior }\end{array}$ & $\begin{array}{l}\text { Odds ratio } \\
\qquad(O R)\end{array}$ & $\begin{array}{l}\text { IC } 95 \% \text { limite } \\
\text { superior }\end{array}$ \\
\hline DM2 vs. Controle & I & 0,5776 & 0,6671 & 0,9104 & 1,2426 \\
\hline DM2 vs. Controle & III & 0,5776 & 0,8048 & 1,0984 & 1,4990 \\
\hline DM2 vs. Controle & I I & 0,1123 & 0,4266 & 0,6744 & 1,0660 \\
\hline DM2 vs. Controle & I III & $0,0121 *$ & 1,1403 & 1,7707 & 2,7496 \\
\hline DM2 vs. Controle & III III & 0,3523 & 0,4377 & 0,7566 & 1,3079 \\
\hline DMG vs. Controle & I & 0,1289 & 0,5182 & 0,7499 & 1,0854 \\
\hline DMG vs. Controle & III & 0,1289 & 0,9213 & 1,3334 & 1,9299 \\
\hline DMG vs. Controle & I I & 0,1041 & 0,3548 & 0,6199 & 1,0829 \\
\hline DMG vs. Controle & I III & 0,2683 & 0,8197 & 1,3927 & 2,3660 \\
\hline DMG vs. Controle & III III & 0,6399 & 0,6537 & 1,1848 & 2,1474 \\
\hline
\end{tabular}




\section{Continuação}

\begin{tabular}{cccccc}
\hline Comparação & $\begin{array}{c}\text { Alelo } \text { - } \\
\text { Genótipo }\end{array}$ & $\begin{array}{c}\text { Teste exato de } \\
\text { Fisher bicaudal } \\
(\boldsymbol{p} \text { valor })\end{array}$ & $\begin{array}{c}\text { IC 95\% limite } \\
\text { inferior }\end{array}$ & $\begin{array}{c}\text { Odds ratio } \\
(\text { OR })\end{array}$ & $\begin{array}{c}\text { IC 95\% limite } \\
\text { superior }\end{array}$ \\
\hline DM1 vs. DM2 & I & $0,0000^{*}$ & Não se aplica & Não se aplica & Não se aplica \\
DM1 vs. DM2 & III & $0,0000^{*}$ & Não se aplica & Não se aplica & Não se aplica \\
DM1 vs. DM2 & I I & $0,0000^{*}$ & Não se aplica & Não se aplica & Não se aplica \\
DM1 vs. DM2 & I III & $0,0002^{*}$ & Não se aplica & Não se aplica & Não se aplica \\
DM1 vs. DM2 & III III & $0,0151^{*}$ & Não se aplica & Não se aplica & Não se aplica \\
\hline DMG vs. DM1 & I & $0,0000^{*}$ & Não se aplica & Não se aplica & Não se aplica \\
DMG vs. DM1 & III & $0,0000^{*}$ & Não se aplica & Não se aplica & Não se aplica \\
DMG vs. DM1 & I I & $0,0000^{*}$ & Não se aplica & Não se aplica & Não se aplica \\
DMG vs. DM1 & I III & $0,0148^{*}$ & Não se aplica & Não se aplica & Não se aplica \\
DMG vs. DM1 & III III & $0,0006^{*}$ & Não se aplica & Não se aplica & Não se aplica \\
\hline
\end{tabular}




\section{Continuação}

\begin{tabular}{cccccc}
\hline Comparação & $\begin{array}{c}\text { Alelo }- \\
\text { Genótipo }\end{array}$ & $\begin{array}{c}\text { Teste exato de } \\
\text { Fisher bicaudal } \\
(\boldsymbol{p} \text { valor })\end{array}$ & $\begin{array}{c}\text { IC 95\% limite } \\
\text { inferior }\end{array}$ & $\begin{array}{c}\text { Odds ratio } \\
(\text { OR })\end{array}$ & $\begin{array}{c}\text { IC 95\% limite } \\
\text { superior }\end{array}$ \\
\hline DMG vs. DM2 & I & 0,3807 & Não se aplica & Não se aplica & Não se aplica \\
DMG vs. DM2 & III & 0,3807 & Não se aplica & Não se aplica & Não se aplica \\
DMG vs. DM2 & I I & 0,8686 & Não se aplica & Não se aplica & Não se aplica \\
DMG vs. DM2 & I III & 0,5341 & Não se aplica & Não se aplica & Não se aplica \\
DMG vs. DM2 & III III & 0,2606 & Não se aplica & Não se aplica & Não se aplica \\
\hline
\end{tabular}

O teste exato de Fisher foi realizado por meio do uso do software GraphPad Instat 3.06 (Grafhpad Software, 2003). Os resultados com valores significativos $(\alpha<0,05)$ foram indicados com asterisco $(*)$. 


\subsubsection{Associação das características clínicas dos subtipos de diabetes mellitus e os genótipos INS-VNTR}

Os dados acerca das características demográficas, clínicas e laboratoriais dos pacientes foram utilizados para avaliar a possível influência dos genótipos do polimorfismo INS-VNTR em relação à idade, sexo, ancestralidade (cor da pele), peso, estatura, tempo de doença, glicemia, hemoglobina glicada e susceptibilidade as complicações frequentes associadas a cada tipo de diabetes mellitus.

A análise comparativa dos genótipos do polimorfismo INS-VNTR às características clínicas de cada subtipo de DM foi realizada pela aplicação de diferentes testes estatísticos como o teste exato de Fisher (FET), algoritmo Metropolis (MET), one -way ANOVA seguidos dos pós testes Kruskal-Wallis (KWT), Dunn's, Mann-Whitney Wilcoxon (MWW) e Tukey HSD (Tukey honestly significantly different) (HSD), conforme a distribuição dos dados (Tabela 10).

As frequências dos genótipos do polimorfismo INS-VNTR nos pacientes com DM1 apresentaram diferenças estatísticas significativas ao nível de 5\% em relação ao sexo $(p=0,015850)$, cor da pele $(p=0,041130)$ e retinopatia $(p=0,000010)$. Quanto ao gênero, os homens apresentaram frequência mais elevada do genótipo classe I : classe I e as mulheres frequências mais elevadas do genótipo classe III : classe III ( $p=0,01222)$. Assim, avaliando as frequências desses genótipos nos dois gêneros podemos supor que indivíduos do sexo masculino com genótipo classe I : classe I podem apresentar maior probabilidade de desenvolverem o DM1. Em relação à cor da pele, apenas brancos e mulatos se distinguiram quanto aos genótipos, classe I : classe I versus classe I : classe III ( $p=0,0266)$. Os dados de frequência referente a cada genótipo e cor demonstram que indivíduos brancos com genótipo classe I : classe I são comumente mais acometidos 
com o DM1 do que os indivíduos mulatos. Por fim, dentre os sintomas relacionados às complicações do diabetes mellitus, a retinopatia foi a única complicação com associação ao genótipo INS-VNTR no DM1, diferenciando indivíduos quanto aos genótipos, classe I : classe I versus classe III : classe III (p<0,0001; OR=0,02985; 95\% I.C. 0,005374 $0,1658)$ e entre classe I : classe III versus classe III : classe III $(p=0,0020 ;$ OR= 0,05333; 95\% I.C. 0,007839 - 0,3629). Os resultados de Odds ratio e o intervalo de confiança de $95 \%$ expõem o genótipo de classe III : classe III como fator de susceptibilidade à retinopatia no grupo DM1.

Pacientes DM2 se diferenciaram quanto aos genótipos INS-VNTR em nível estatístico com poder de $\alpha=0,05$ em relação ao sexo $(p=0,039060)$. Assim, o genótipo classe III : classe III foi mais frequente em mulheres $(p=0,0288)$ acometidas pelo DM2.

As pacientes DMG apenas apresentaram influência dos genótipos INS-VNTR em nível estatístico com poder de $\alpha=0,05$ sobre o nível de glicemia de jejum ( $p=0,0233)$. Pacientes apresentando os genótipos classe I : classe I e classe I : classe III apresentaram perfis glicêmicos semelhantes, ao passo que mulheres apresentando o genótipo classe III : classe III tiveram maior nível de glicose no plasma sanguíneo.

Em anexo 3, estão disponíveis os dados numéricos referentes à distribuição dos genótipos entre os sexo, a pigmentação da pele e ausência e presença de retinopatia em pacientes com DM1, distribuição dos genótipos entre os sexo em pacientes com DM2 e a distribuição do perfil glicêmico das pacientes com DMG. 
Tabela 10: Análise comparativa entre as variações genotípicas do polimorfismo INS-VNTR e as características demográficas, clínicas e laboratoriais dos indivíduos amostrados.

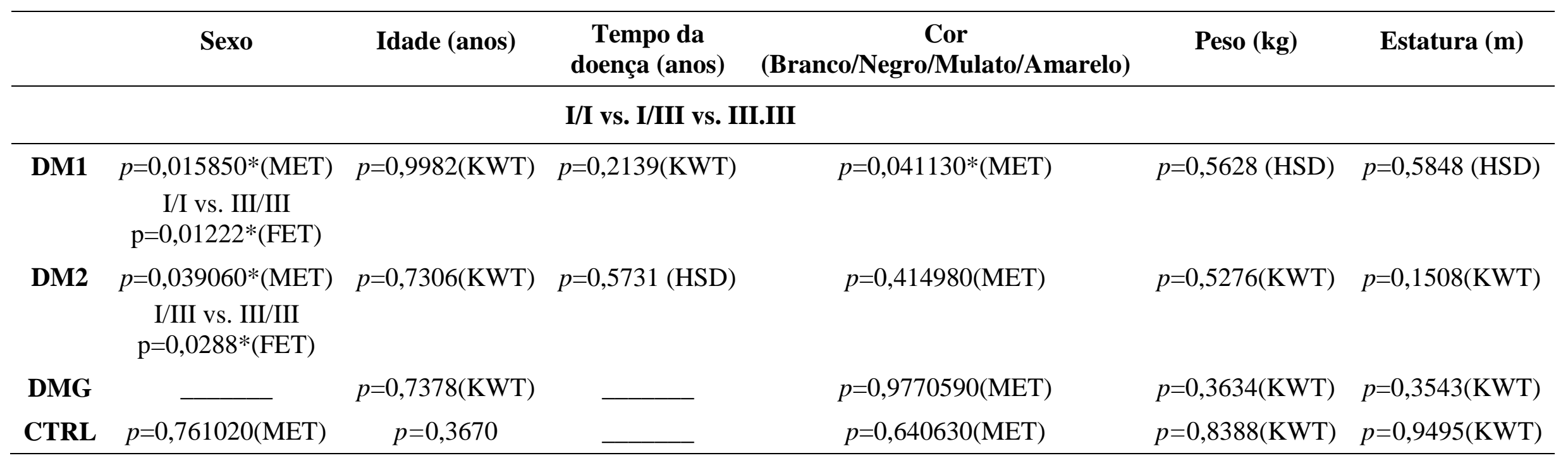




\section{Continuação}

\begin{tabular}{|c|c|c|c|c|c|c|c|}
\hline & $\begin{array}{c}\text { Peso RN } \\
(\mathbf{k g})\end{array}$ & $\begin{array}{c}\text { Estatura RN } \\
(\mathbf{m})\end{array}$ & Glicemia (mg/dL) & $\begin{array}{c}\text { Hemoglobina } \\
\text { glicada }(\%)\end{array}$ & Nefropatia & Neuropatia & Retinopatia \\
\hline \multicolumn{8}{|c|}{ I/I vs. I/III vs. III/III } \\
\hline DM1 & & $\underline{-}$ & $p=0,8755(\mathrm{KWT})$ & $p=0,0674(\mathrm{KWT})$ & $p=0,791400(\mathrm{MET})$ & $p=0,255500(\mathrm{MET})$ & $\begin{array}{c}p=0,000010 *(\mathrm{MET}) \\
\text { I/I vs. III } / \mathrm{III} \\
p<0,0001 *(\mathrm{FET}) \\
\text { I/III vs. III } / \mathrm{III} \\
p=0,0020 *(\mathrm{FET})\end{array}$ \\
\hline DM2 & & & $p=0,8966(\mathrm{KWT})$ & $p=0,5666(\mathrm{KWT})$ & $p=0,87347(\mathrm{MET})$ & $p=0,782250(\mathrm{MET})$ & $p=0,648750(\mathrm{MET})$ \\
\hline DMG & $\begin{array}{c}p=0,2763 \\
(\mathrm{KWT})\end{array}$ & $p=0.8568(\mathrm{KWT})$ & $\begin{array}{c}p=0,0233 *(\mathrm{KWT}) \\
\text { I/I vs. III } / \mathrm{III} \\
\mathrm{p}=0,0179 *(\mathrm{MWW}) \\
\mathrm{I} / \mathrm{III} \text { vs. III } / \mathrm{III} \\
\mathrm{p}=0,0159 *(\mathrm{MWW})\end{array}$ & - & 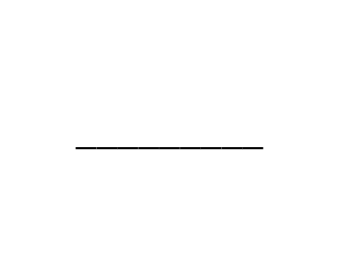 & $\longrightarrow$ & $\longrightarrow$ \\
\hline
\end{tabular}




\section{Continuação}

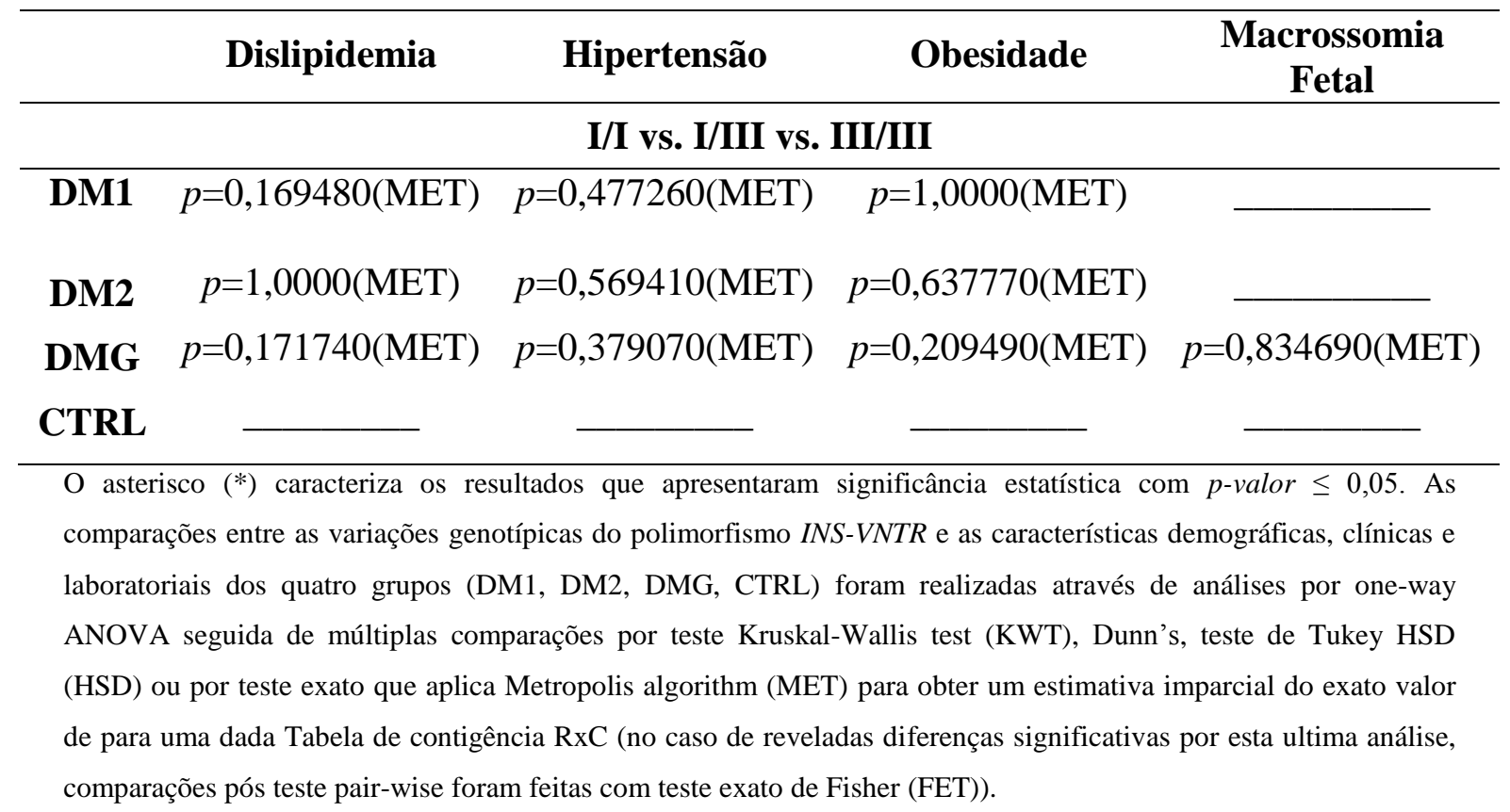


DISCUSSÃO 


\section{Discussão}

\subsection{Distribuição das frequências alélicas}

Os resultados de frequências alélicas do locus INS-VNTR na população brasileira o caracterizam como polimórfico (frequência superior a 0,01), uma vez que os alelos apresentarem variações máxima e mínima de, respectivamente, 0,7831 e 0,2169. Frequências do SNP -23HphI, variação genética que utilizamos para inferir sobre o polimorfismo INS-VNTR, depositadas no banco de dados SNP do NCBI (National Center for Biotechnology of Information) e dados coletados na literatura, demonstram que o locus INS-VNTR é também polimórfico em distintas populações mundiais, variando as frequências alélicas conforme a origem da população.

A Figura 6 mostra as frequências alélicas do SNP -23HphI nas amostras populacionais do Brasil (resultados do presente trabalho), Reino Unido ( NCBI), Japão (AWATA et al., 2007), Cazaquistão (NCBI), Índia (RAHA et al., 2011), Zimbabue (NCBI), Quênia (NCBI) e Espanha (NCBI). A Tabela 11 mostra as análises estatísticas realizadas por meio do uso do algoritmo Metropolis (MET) e do teste exato de Fisher (FET), comparando os dados de frequências alélicas entre a população brasileira e demais populações mundiais. 
Figura 6: Distribuição das frequências alélicas do SNP -23HphI nas populações de países como Brasil, Reino Unido, Índia, Japão, Zimbabue, Quênia, Cazaquistão e Espanha.

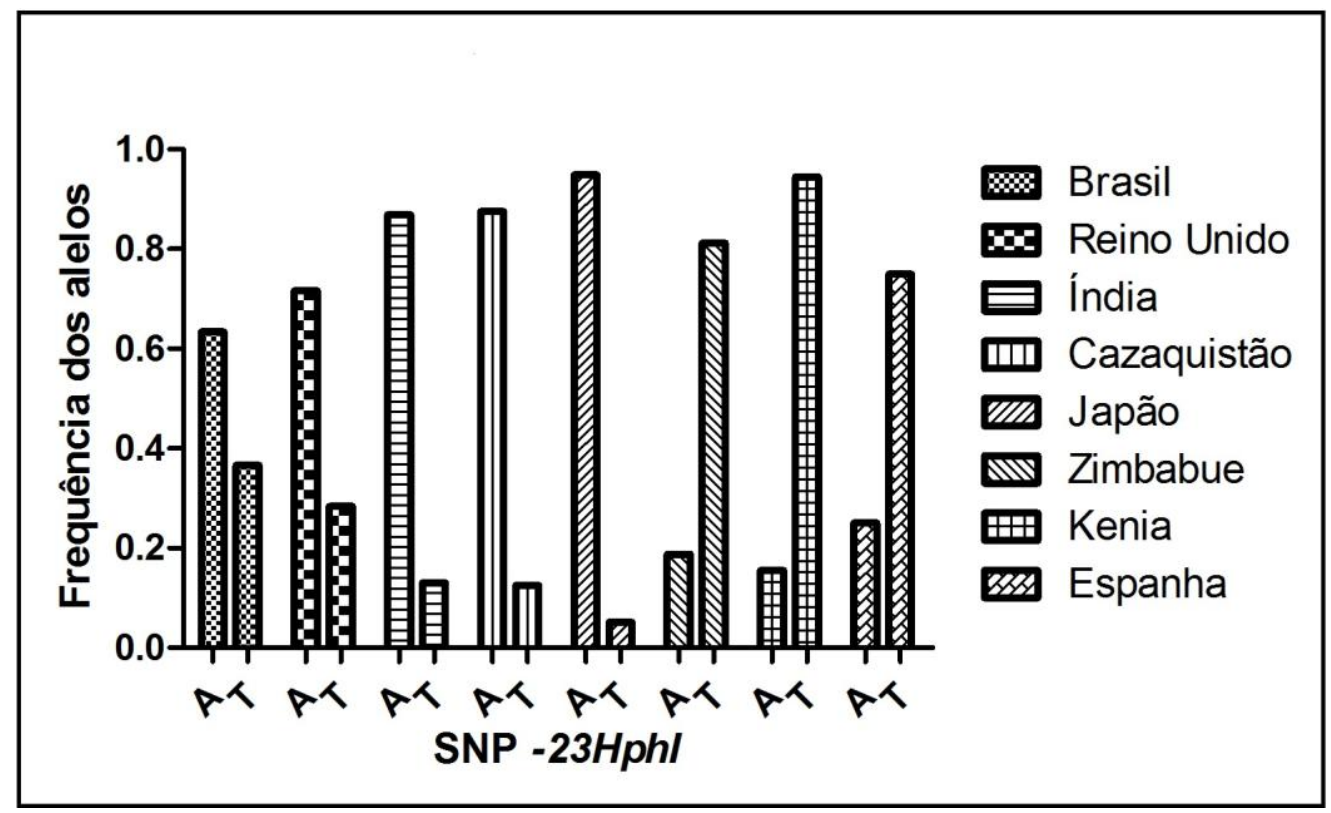

Tabela 11: Comparação das frequências alélicas do SNP -23HphI entre população brasileira e demais populações mundiais.

\begin{tabular}{|c|c|c|c|}
\hline \multirow{2}{*}{ Comparação } & \multicolumn{2}{|c|}{ Frequência alélica } & \multirow{2}{*}{$\begin{array}{c}p \text { valor de comparação entre as } \\
\text { populações: }\end{array}$} \\
\hline & $\boldsymbol{A}$ & $T$ & \\
\hline Brasil (BR) & 0,634 & 0,366 & $\begin{array}{l}\text { BR vs. RU vs. JP vs. ZW vs. EAK } \\
\text { vs. KA vs. E } p=0,000000 *(\mathrm{MET})\end{array}$ \\
\hline Reino Unido (RU) & 0,716 & 0,284 & BR VS. RU $p=0.0233 *(\mathrm{FET})$ \\
\hline Índia (IN) & 0,869 & 0,1303 & BR VS. IN $p=<0.0001 *(\mathrm{FET})$ \\
\hline Japão (JP) & 0,949 & 0,051 & BR VS. JP $p=<0.0001 *(\mathrm{FET})$ \\
\hline Zimbabue (ZW) & 0,188 & 0,812 & BR VS. ZW $p<0.0001 *(\mathrm{FET})$ \\
\hline Quênia (EAK) & 0,155 & 0,945 & BR VS. EAK $p<0.0001 *(\mathrm{FET})$ \\
\hline Cazaquistão (KA) & 0,875 & 0,125 & BR VS. K $p<0.0001 *(\mathrm{FET})$ \\
\hline Espanha $(\mathrm{E})$ & 0,25 & 0,75 & BR VS. E $p<0.0001 *(\mathrm{FET})$ \\
\hline
\end{tabular}

Esses resultados foram obtidos por meio do algoritmo Metropolis (MET) e teste exato de Fisher (FET), sendo que, os resultados que apresentaram valores significantes $(\alpha<0,05)$ foram indicados com asterisco $(*)$. 
Evidenciamos que as populações citadas apresentam frequências alélicas diferentes entre si, pois os resultados estatísticos para $\alpha<0,05$ rejeitam a hipótese nula a qual analisa a similaridade das amostras populacionais citadas quanto à frequência alélica do SNP -23HphI. É interessante observar que a frequência do alelo $A$ é mais comum nas populações brasileira, inglesa, japonesa e cazaquistanesa, enquanto que o alelo $T$ é mais frequente nas populações zimbabuana, queniana e espanhola. Devido à ausência de informação armazenada no banco de dados de SNPs do NCBI, referente às características clínicas e laboratoriais dos indivíduos amostrados, não podemos inferir qual é a influência desses alelos no desenvolvimento do diabetes mellitus. No entanto, podemos evidenciar a influência da mistura étnica, localização geográfica e processos de seleção como possíveis causas das diferentes distribuições alélicas nas populações mundiais citadas.

\subsection{Equilíbrio de Hardy-Weinberg}

Os desvios das proporções observadas em relação às esperadas, segundo o equilíbrio de Hardy-Weinberg, utilizando o teste global, foram encontrados nas amostras das populações de pacientes DM1, diabetes (total de pacientes diabéticos amostrados) e em indivíduos controle. A aplicação de testes mais sensíveis, que detectam se o desvio ocorre por déficit ou excesso de heterozigotos, indica ser o déficit de heterozigotos responsável pela ausência do equilíbrio de Hardy-Weinberg nessas amostras.

Dentre os fatores responsáveis pelo déficit de heterozigotos, podemos evidenciar a possibilidade de essas amostras não se enquadrarem às premissas do princípio de equilíbrio, sendo até mesmo provável, que tais premissas estejam, concomitantemente, se anulando, como por exemplo, a ocorrência de mistura étnica, casamentos preferenciais, endogamia, ocorrência de fluxo gênico, de processos de 
seleção natural, presença da infertilidade entre os casais, entre outros (GUO e THOMPSON, 1992 e BEIGUELMAN, 2008).

Dentre os fatores supracitados, enfatizamos a ocorrência de mistura étnica na nossa casuística. Ferreira et al., 2006 e Muniz et al., 2008 relataram alta taxa de miscigenação na população de Ribeirão Preto, cidade que predominantemente realizamos a coleta do material genético e de dados clínicos. A população de Ribeirão Preto foi caracterizada para marcadores de ancestralidade, com proporções europeia, africana e ameríndia, respectivamente, em média, 59\%, 34\% e 7\%.

Somado à mistura étnica, a ocorrência de casamentos preferenciais devido à ancestralidade e pigmentação da pele, favorece o processo de estratificação populacional que pode acarretar a deficiência de heterozigotos distribuídos na população, consequentemente, nas amostras populacionais utilizadas no presente trabalho, caracterizando assim o efeito gargalo, ou Wallund, na população.

Apesar de as amostras populacionais de pacientes com DM2 ou DMG estarem em equilíbrio de Hardy-Weinberg, isso não significa que a população em questão esteja totalmente livre da ação de fatores evolutivos. Essa preocupação decorre do fato de serem amostras populacionais associadas a um conjunto genético peculiar à doença. Como discutiremos a seguir, o polimorfismo INS-VNTR, com exceção das pacientes DMG, apresentam um genótipo INS-VNTR característico a cada tipo do DM, e isso, em um contexto genético mais amplo, pode ocasionar desvios no equilíbrio de HardyWeinberg.

Sendo assim, fatores como mistura étnica, fluxo gênico, casamento preferencial e coleta de amostras de grupos específicos de pacientes podem ter contribuído 
simultaneamente para a determinação dos desvios observados em relação às proporções esperadas segundo o modelo de equilíbrio de Hardy-Weinberg.

\subsection{Associações encontradas}

\subsubsection{Associações entre o polimorfismo INS-VNTR e os fenótipos das classes clínicas do diabetes mellitus}

O genótipo classe I : classe I do polimorfismo INS-VNTR está associado à susceptibilidade do diabetes mellitus tipo 1 na nossa amostra populacional brasileira, enquanto o alelo de classe III e o genótipo classe III : classe III estão associados ao efeito protetor contra o desenvolvimento do DM1.

É importante ressaltar esse resultado do genótipo de proteção ao DM1 em nossa população, pois Chung et al. (2010), em estudos de associação na população coreana, não encontraram o genótipo classe III : classe III em nenhum dos grupos amostrados, pacientes com DM1 e indivíduos controle, o que os levaram a caracterizar o genótipo classe I : classe III como fator de proteção, evidentemente devido a maior frequência desse nos indivíduos controle.

Nossos resultados corroboram os resultados referentes às amostras populacionais da Polônia (FENDLER et al., 2011), Romênia (GUJA et al., 2004), Japão (AWATA et al., 2007), Índia (RAHA et al., 2011) e Caucasianas (BELL et al.,1984; WALTER et al., 2003; BENNETT et al. 2004), todas avaliando pacientes com DM1 .

A contribuição do alelo classe I na progressão do DM1 consiste no fato desse induzir a baixa expressão de mRNA do gene da insulina no timo. Durante a seleção negativa, por ocasião da expressão gênica promíscua, a baixa expressão de insulina pode acarretar em aprendizado ineficaz dos timócitos. Assim, na periferia, uma vez que os linfócitos entrem em contato com insulina endógena modificada ou exógena, a 
molécula pode se tornar um autoantígeno, desencadeando assim, a doença autoimune (Pugliese et al., 1997 e Vafiadis et al.,1997). Em estudo mais recente, Sabater et al., 2005, observaram associação, no timo, entre o gene AIRE e o minissatélite INS-VNTR, em que, o gene AIRE atuaria na modulação da expressão da insulina no timo concomitantemente com o INS-VNTR. A hipótese da influência do gene AIRE no mecanismo transcricional da insulina foi sugerida dado ao fato de o gene AIRE atuar na regulação de fatores de transcrição que controlam a expressão de autoantígenos periféricos no timo, incluindo a insulina. Embora esse efeito não esteja completamente esclarecido, a correlação positiva entre o AIRE e a expressão de insulina corrobora o papel do AIRE no processo de seleção promíscua no timo, que pode culminar com o desenvolvimento da doença autoimune. Sendo assim, efeito protetor do alelo de classe III, no timo, se deve ao mecanismo reverso do alelo classe I.

Desta forma, nossos resultados apresentam concordância tanto com o mecanismo biológico já descrito na literatura como também com os resultados de demais estudos populacionais, associando o diabetes mellitus tipo 1 com o alelo classe $I$ do INS-VNTR.

Em relação à amostra populacional de pacientes diabéticos mellitus tipo 2, o genótipo classe I : classe III apresentou associação ao desenvolvimento do DM2. Nosso resultado é inédito pois em nenhum outro estudo houve associação do genótipo em heterozigose como fator de susceptibilidade ao DM2.

Em 1996, Bennett et al., associaram o alelo classe III, em específico o genótipo classe III : classe III, como fator de susceptibilidade ao DM2. Tal resultado se tornou a premissa dos posteriores estudos populacionais de associação do DM2 ao polimorfismo INS-VNTR. 
Assim como no presente trabalho, Hansen et al. (2004), Mitchell et al. (2004) e Lindsay et al. (2003) não encontraram associação do alelo classe III com o DM2, respectivamente, nas populações dinamarquesa, britânica, e também, em índios norteamericanos do grupo Pima. Esses achados indicam a influência da ancestralidade (origem étnica, distribuição geográfica) e de fatores ambientais, interferindo na susceptibilidade à doença que, tipicamente, é caracterizada como multifatorial, tendo associação com a qualidade de vida do indivíduo.

Apesar da ausência de reprodução dos dados quanto ao fenótipo da doença, o alelo classe III tem sido descrito como fator genético capaz de influenciar na capacidade de liberação de insulina pelas células $\beta$ pancreáticas. A presença do alelo classe III pode reduzir em até $20 \%$ a expressão transcricional da insulina no pâncreas quando comparado com o alelo classe I (KENNEDY et al., 1995; BENNETT et al., $1995 \mathrm{e}$ VAFIADIS et al., 1996). Esses resultados estruturam a hipótese da influência do alelo classe III na progressão do DM2 uma vez que interferem no processo de resistência à insulina, característica determinante ao diagnóstico da doença.

Atualmente, cerca de 600 genes têm sido associados com predisposição à obesidade, condição mórbida usualmente encontrada no DM2. Além dos hábitos alimentares, o ganho de peso corporal tem sido relacionado com a interação múltipla de fatores genéticos. Sabe-se que o declínio gradual da secreção de insulina promove a diminuição da liberação de ácidos graxos do tecido adiposo pela reduzida sensibilidade à lipase. $\mathrm{O}$ alelo classe $\mathrm{I}$, que promove a alta expressão de insulina no pâncreas pode estar associado a um dos principais determinantes do aumento do peso corpóreo. SANTORO et al.(2006), LE FUR et al.(2006), LE STUNFF et al. (2000) relataram efeito do alelo classe I, preferencialmente em homozigose, com predisposição à obesidade em crianças e adolescentes. Quanto a indivíduos adultos, esses resultados não 
foram reproduzidos, de modo a considerar o INS-VNTR como fator genético singular para determinação da obesidade. No entanto, considerando os três genes de susceptibilidade em conjunto, Rodriguez et al. (2006) reportaram o efeito relevante do IGF2-INS-TH, em homens adultos, na predisposição à obesidade. Desse modo, é evidente a necessidade de novos estudos para compreensão do papel biológico do INSVNTR no mecanismo desencadeador da obesidade.

Sendo assim, a associação do genótipo classe I : classe III com susceptibilidade ao DM2 na amostra da população brasileira pode ser também explicada pela associação do alelo classe III com resistência à insulina, e ainda, pela associação do alelo classe I com predisposição à obesidade. Estudos mais abrangentes, estratificando os pacientes de acordo com a presença ou não de obesidade poderão evidenciar a influência dessa variável na susceptibilidade ao DM2.

A amostra populacional de pacientes diabéticas gestacional não apresentou qualquer associação com o polimorfismo INS-VNTR. Nosso resultado é semelhante ao encontrado por Shaat et al. (2004) em estudo com amostras populacionais de mulheres diabéticas árabes e escandinavas. No entanto, Litou et al. (2006) reportaram, apesar de não significativa, maior frequência do alelo classe III nas gestantes diabéticas.

Poucos são os relatos de estudos de associação do polimorfismo INS-VNTR ao fenótipo de diabetes gestacional, sendo evidente a importância de novos estudos para comprovação do efeito do polimorfismo diante do modo de expressão da insulina durante o período gestacional. 


\subsubsection{Associações entre o polimorfismo INS-VNTR e as características demográficas, clínicas e laboratoriais referentes a cada classe clínica do diabetes mellitus}

Os estudos de associação do polimorfismo INS-VNTR existentes na literatura analisam, predominantemente, a relação entre as variáveis genotípicas e um determinado fenótipo de uma amostra populacional. Dentre os fenótipos mais analisados, estão as classes clínicas do diabetes mellitus, obesidade, composição da massa corpórea, crescimento fetal acelerado e síndrome do ovário policístico. No presente trabalho, apenas a síndrome do ovário policístico não foi reportada. A título de curiosidade, o padrão de associação dessa doença tem sido reproduzido na maioria das amostras populacionais estudadas. Yun et al. (2012), Xu et al. (2009), Haller et al. (2007) não encontraram associação entre o polimorfismo INS-VNTR na população Koreana, Han (Chinesa) e Harjumaa (Estônia), respectivamente. Ferk et al. (2008) encontraram prevalência do alelo classe III em pacientes com síndrome do ovário policístico na população Ljubljana (Eslovênia), sendo evidenciado, maior susceptibilidade à síndrome quando a paciente apresentava o genótipo classe III : classe III e obesidade. Haller et al. (2007) observaram aumento do número médio de folículos em mulheres que apresentavam o genótipo classe I : classe I, o que os levaram a sugerir a possível influência desse fenótipo no contexto da síndrome do ovário policístico. Há ainda, publicações únicas que remetem associação do INS-VNTR à um determinado fenótipo, como por exemplo, o trabalho de Krechler et al. (2009) em que evidenciaram associação do genótipo classe I : classe III ao estadiamento tumoral em paciente com câncer pancreático.

As dificuldades de concluir a influência do INS-VNTR sobre um determinado fenótipo estão relacionados à dificuldade de replicação dos resultados, como visto nas 
citações literárias apresentadas e, também, na Tabela 11 a qual expõe a diversidade do padrão de distribuição das frequências alélicas e genotípicas de acordo com a ancestralidade da amostra populacional avaliada, o que demonstra a especificidade do padrão de susceptibilidade à doença para cada amostra populacional. Ainda, poucos são os resultados acerca da associação dos sítios INS-VNTR com outras variáveis, como complicações clínicas, achados laboratoriais, dentre outras. Por fim, ausência de estudos avaliando o perfil de expressão gênica das classes genotípicas do INS-VNTR os quais colaborariam, na determinação de genes corregulados o que favorece análise quanto a influência dos sítios polimórficos sobre fenótipo.

Em relação aos nossos resultados de análises de associações entre o polimorfismo INS-VNTR e as características demográficas, clínicas e laboratoriais referentes a cada classe clínica do diabetes mellitus, obtivemos como resultado inédito, a associação entre retinopatia e genótipo classe III : classe III em pacientes com diabetes mellitus tipo 1. Apesar de ausência de dados que concluam a verdadeira influência do alelo de classe III no desenvolvimento da doença em pacientes com DM1, esse resultado, aponta a influência da região promotora da insulina, em associação distintas daquela relacionada exclusivamente com a modulação da expressão da insulina.

Verificamos também, em comparação entre os genótipos e o sexo dos pacientes, ser mais frequente o genótipo de classe I : classe I em homens com DM1 quando comparado o genótipo de classe III : classe III, que é mais comum em mulheres com DM1, enquanto em pacientes com DM2, o genótipo de classe III : classe III apresentou frequência maior nas mulheres.

A associação diferencial em relação à cor da pele foi existente apenas no grupo de pacientes com DM1, sendo o genótipo de classe I : classe I mais frequente em 
indivíduos brancos do que em mulatos. Como reportado anteriormente, Mao et al.(2011), em estudo de expressão gênica diferencial entre dois grupos populacionais distintos, Caucasianos e Afro-Americanos, relataram a diversidade na modulação dos genes expressos. Os Caucasianos apresentaram 200 genes diferencialmente expressos, sendo significante a baixa expressão de genes envolvidos na sinalização do sistema complemento, enquanto, os Afro-Americanos apresentaram 574 genes diferencialmente expressos entre pacientes e controle, sendo significante a baixa expressão de genes envolvidos na via de sinalização de imunodeficiência primária. Esse resultado, demonstra a influência da ancestralidade no perfil de susceptibilidade à doenças. Sendo assim, de acordo com nosso resultado de associação, é provável serem os indivíduos brancos de genótipo classe I : classe I mais susceptíveis ao DM1.

Por fim, em pacientes diabéticas gestacionais a associação das classes genotípicas foi estabelecida com os dados de perfil glicêmico de jejum.

Concluindo, o estudo da associação entre o polimorfismo INS-VNTR com os diversos tipos de diabetes mostrou associações diferencias de acordo com o tipo de diabetes e também com variáveis clínicas e epidemiológicas. 
CONCLUSÕES 


\section{Conclusões}

Este é o primeiro estudo de associação avaliando as três principais formas de apresentação do diabetes mellitus com o polimorfismo INS-VNTR do gene da insulina, no mesmo grupo populacional, evidenciando associações diferenciais de acordo com o tipo de diabetes.

O alelo classe I e o genótipo classe I: classe I foi associado com a susceptibilidade ao DM1 e o alelo classe III e o genótipo classe III : classe III foram associados como fator de proteção contra o desenvolvimento de DM1, de forma semelhante ao observado em outras populações mundiais. O genótipo de classe I : classe III foi associado com susceptibilidade ao DM2, sendo esse achado observado apenas na população brasileira. Além da susceptibilidade diferencial aos diferentes tipos de diabetes, a retinopatia diabética esteve associada ao genótipo classe III : classe III em pacientes dom DM1, dado inédito na literatura. 
REFERÊNCIAS BIBLIOGRÁFICAS 


\section{Referências bibliográficas}

AMERICAN DIABETES ASSOCIATION. Diagnosis and classification of diabetes mellitus. Diabetes Care, v. 34 Suppl 1, p. S62-69, jan 2012.

AMERICAN DIABETES ASSOCIATION. Standards of Medical Care in Diabetes. Position Statement. Diabetes Care. v. 34 Suppl 1, p. S11-61, 2011.

AMYOT J.; SEMACHE M.; FERDAOUSSI M.; FONTE'S G.; POITOUT V. Lipopolysaccharides Impair Insulin Gene Expression in Isolated Islets of Langerhans via Toll-Like Receptor-4 and NF-kB Signalling. PLoS ONE, v.7, n.4., p. e36200, apr 2012.

ANDREOZZI F.; PRESTA I.; MANNINO GC.; SCARPELLI D.; DI SILVESTRE S. et al. A Functional Variant of the Dimethylarginine Dimethylaminohydrolase-2 Gene Is Associated with Insulin Sensitivity. PLoS ONE, v.7, n.4, p. e36224, abr 2012.

ANJOS S.; POLYCHRONAKOS C. Mechanisms of genetic susceptibility to type I diabetes: beyond HLA. Molecular Genetics and Metabolism, v.81, n.3, p.187-195, mar 2004.

ARCK P.; TOTH B.; PESTKA A.; JECHKE. Nuclear Receptors of the Peroxisome Proliferator-Activated Receptor (PPAR) Family in Gestational Diabetes: From Animal Models to Clinical Trials. Biology of Reproduction, v. 83, n.2, p. 168-176, aug 2010.

ASHCROFT F.M. \& RORSMAN P. Diabetes Mellitus and the b Cell: The Last Ten Years. Cell, v. 148, n. 6, p. 1160-1171, mar 2012.

AWATA T.; KAWASAKI E.; IKEGAMI H. et al.. Insulin Gene/IDDM2 locus in Japanese type 1 diabetes: Contribution of class I alleles and influence of class I subdivision in susceptibility to type 1 diabetes. Journal of clinical endrocrionolgy \& metabolism, v. 92, n. 5, p. 1791-5, Mar 2007.

BAROUKH N.; RAVIER M.A.; LODER M.K.; HILL E.V. et al. MicroRNA-124a regulates Foxa2 expression and intracellular signaling in pancreatic beta-cell lines, The Journal Biologic Chemistry, v.282, n. 27, p. 19575-19588, abr 2007.

BEIGUELMAN, B. Genética de populações humanas. Ribeirão Preto, SBG, p. 235, 2008.

BELL G. I.; HORITA S. and KARAM J. H.. A polymorphic locus near the human insulin gene is associates with insulin-dependent diabetes mellitus. Diabetes, v. 33, n. 2, p. 176 - 183. Fev 1984.

BENNETT, S.T.; LUCASSEN, A.M.; GOUGH, S.C.L. et al. Susceptibility to human type-1 diabetes at IDDM2 is determined by tandem repeat variation at the insulin gene minisatellite locus, Nature Genetics, v. 9, n.3, p. 284-292, Mar 1996. 
BENNETT A. J.; SOVIO U.; RUOKONEN A. et al.. Variation at the insulin gene VNTR (variable number tandem repeat) polymorphism and early growth. Diabetes, v. 53, n. 8, p. 2126-2131, Aug 2004.

BLUESTONE J.A.; HEROLDA K. \& EISENBARTH G. Genetics, pathogenesis and clinical interventions in type 1 diabetes. Nature, v. 464, n. 7293, p. 1293-1300, Abr 2010 .

BONNEFOND, A.; FROGUEL, P. \& VAXILLAIRE, M. The emerging genetics of type 2 diabetes. Trends in Molecular Medicine, v. 16, n. 9, p. 407-416, Aug 2010.

CHO Y.M.; KIM T.H.; LIM S.; CHOI S.H. et al., Type 2 diabetes-associated genetic variants discovered in the recent genome-wide association studies are related to gestational diabetes mellitus in the Korean population. Diabetologia, v. 52, n. 2, p. 253-261, Fev 2009.

CHUNG H.R.; YANG S. W., SHIN C. H. et al.. The association of variable number of tandem repeats of the insulin gene with susceptibility to type 1 diabetes among Korean subjects. Diabetes / Metabolism research and reviews, v. 26, n. 6, p. 474-480, Set 2010.

DEVENDRA D.; LIU E.\& EISENBARTH G. S. Type 1 diabetes: recent developments. BMJ, n. 328, n.7442, p. 750-754, Mar 2004.

DRIVER J.P.; SERREZE D.V.; CHEN Y.G. Mouse models for the study of autoimmune type 1 diabetes: a NOD to similarities and differences to human disease. Seminars in Immunopathology, v. 33, n. 1, p, 67-87, 2011.

ESAU C.; KANG X.; PERALTA E. et al. MicroRNA-143 regulates adipocyte differentiation, The Journal of Biological Chemistry, v.279, n. 50, p. 52361-52365, Out 2004.

FERNANDES A.P.M.; PACE A.E.; ZANETTI M.L.; FOSS M.C.; DONADI E.A. Fatores imunogenéticos associados ao diabetes mellitus do tipo 1. Revista LatinoAmericana de Enfermagem, v. 13, n. 5, p. 743-749, Set-Out 2005.

FERNANDEZ-VALVERDE S.L.; TAFT R.J.; MATTICK J.S. et al. MicroRNAs in bcell biology, insulin resistance, diabetes and its complications. Diabetes, v. 60, n.7, p. 1825-1831, Jul 2011.

FERREIRA, L. B.; MENDES-JUNIOR, C. T.; WIEZEL, C. E.; LUIZON, M.; SIMOES, A. L. Genomic ancestry of sample population from the state of São Paulo, Brazil. American journal of human biology, v. 18, n. 5, p. 702-5, Set - Out 2006.

FRANCISCO R.P.V.; TRINDADE T.C.; ZUGAIB, M. Gestational diabetes, what did change in the criteria for diagnosis. Revista Brasileira de Ginecologia e Obstetrícia, v. 33, n. 8, p.171-173, Aug 2011.

FREINKEL N.; METZGER B.E.; PHELPS R.L. et al. Gestational diabetes mellitus: a syndrome with phenotypic and genotypic heterogeneity. Hormone and Metabolic Research, v. 18, n. 7, p. 427-439, Jul 1986. 
FREEMAN J.S. A Physiologic and pharmacological basis for implementation of incretin hormones in the treatment of type 2 diabetes mellitus. Mayo Clinic Proceedings, v. 85, n. 12, p. S5-S14, Dez 2010.

FREEMARK M. Regulation of maternal metabolism by pituitary and placental hormones: roles in fetal development and metabolic programming. Hormone Research, v. 65, n. 3, p. 41-49, Abr 2006.

FREEMARK M. Placental hormones and the control of fetal growth. The Journal of Clinical Endocrinology and Metabolism, v. 95, n. 5, p. 2054-2057, Mai 2010.

GALTIER F. Definition, epidemiology, risk factors. Diabetes and Metabolism, v. 36, n. 6 Pt 2, p. 628-651, Dez 2010.

GOMES M.B.; LERARIO A.C. et al. Diretrizes da Sociedade Brasileira de Diabetes 2009. Sociedade brasileira de diabetes. Disponível em: < http://www.diabetes.org.br/attachments/diretrizes09_final.pdf $>$. Acesso em: 22 de jun. 2012.

GRAPHPAD SOFTWARE, I., EUA. San Diego California, USA, 2003.

GROSS J.L.; FERREIRA S.R.G.; FRANCO L.J.; et al.. Diagnóstico e classificação do Diabetes Mellitus e tratamento do Diabetes Mellitus Tipo 2. Recomendações da Sociedade Brasileira de Diabetes. Arquivo Brasileiro de Endocrinologia e Metabolismo, v. 44 Supl 1, p. S8-S27, 2000.

GUJA C.; GUJA L.; NUTLAND S. et al.. Strong association of insulin gene INSVNTR polymorphism with type 1 diabetes in the Romanian population. Romanian journal of internal medicine, v. 42, n. 2., p. 313 - 323, 2004.

GUO W.L.; TANG Y.; HAN X.Y.; JI L.N. Meta-analysis of the association of Pro12Ala polymorphism of peroxisome proliferator activated receptor gamma gene with type 2 diabetes in Chinese Han population. Zhongguo Yi Xue Ke Xue Yuan Xue Bao, v. 33, n. 6, p. 593-599, dez 2011.

GUO, S. W.; THOMPSON, E. A. Performing the exact test of Hardy-Weinberg proportion for multiple alleles. Biometrics, v. 48, n. 2, p. 361-72, Jun. 1992.

HALLER K, LAISK T, PETERS M, et al. VNTR I/I genotype of insulin gene is associated with the increase of follicle number independent from polycystic ovary syndrome. Acta Obstetricia et Gynecologica Scandinavica, v. 86, n. 6, p. 726-32, 2007.

HALIMI S. \& BENHAMOU P.Y. Diabetes, a worldwide disease. Presse Medicale, v. 33 Spec, p. Sp37-40, Jun 2004.

HAMZA M.S.; POTT M.; VEGA V.B. et al. De-novo identification of PPARC/RXR binding sites and direct targets during adipogenesis. PLoS ONE, v. 4, n. 3, p. e4907, Mar 2009. 
HANSEN S.K.; GJESING A.P.; RASMUSSEN S.K. et al Large-scale studies of the HphI insulin gene variable-number-of-tandem-repeats polymorphism in relation to Type 2 diabetes mellitus and insulin release. Diabetologia, v. 47, n. 6, p.1079-1087, Jun 2004.

HE A.; ZHU L.; GUPTA N.; CHANG Y.; FANG F.. Overexpression of micro ribonucleic acid 29, highly up-regulated in diabetic rats, leads to insulin resistance in 3T3-L1 adipocytes, Molecular Endocrinology, v. 21, n. 11, p. 2785-2794, Nov 2007.

INTERNATIONAL DIABETES FEDERATION. Global Guideline on Pregnancy and Diabetes. 2009. Disponível em: 〈(www.idf.org/)>. Acesso em: Junho de 2012.

INTERNATIONAL DIABETES FEDERATION. Disponível em: <(http://www.idf.org/diabetesatlas/)>.Acesso em: Junho 2012.

JENUN A.; MØRKRID K.; SLETNER L. et al. Impact of ethnicity on gestational diabetes identified with the WHO and the modified International Association of Diabetes and Pregnancy Study Groups criteria: a population-based cohort study. European Journal of Endocrinology, v. 166, n. 2, p. 317-324, Fev 2012.

KAROLINA D.S.; ARMUGAM A.; TAVINTHARAN S.; WONG M.T.K.; LIM S.C. et al. MicroRNA 144 Impairs Insulin Signaling by Inhibiting the Expression of Insulin Receptor Substrate 1 in Type 2 Diabetes Mellitus. PLoS ONE, v. 6, n. 8, p. e22839, Aug 2011.

KENNEDY C.G.; GERMAN M.S.; RUTTER W.J. The minisatellite in the diabetes susceptibility locus IDDM2 regulates insulin transcription. Nature Genetics, v. 9, n. 3, p.293-98, Mar 1995.

KLOOSTERMAN W.P.; LAGENDIJK A.K.; KETTING R.F.; MOULTON J.D.; PLASTERK R.H. Targeted inhibition of miRNA maturation with morpholinos reveals a role for miR-375 in pancreatic islet development. PLoS Biology, v. 5, n. 8, p. e203, Aug 2007.

KRECHLER T, JACHYMOVA M, PAVLIKOVA M, et al. Polymorphism -23HPhI in the promoter of insulin gene and pancreatic cancer: a pilot study. Neoplasma, v. 56, n. 1, p. 26-32, 2009.

KWAK S.H.; KIM T.H.;CHO Y.M. et al. Polymorphisms in KCNQ1 are associated with gestational diabetes in a Korean population. Hormone Research in Pediatrics, v. 74, n. 5, p. 333-338, Jul 2010.

LE STUNFF C, FALLIN D, BOUGNÈRES P. Paternal transmission of the very common class I INS VNTR alleles predisposes to childhood obesity. Nature Genetics, v. 29, n. 1, p. 96-99. Set. 2001.

LE STUNFF C.; FALLIN D.; SCHORK N. J.; BOUGNERES P. The insulin gene VNTR is associated with fasting insulin levels and development of juvenile obesity. Nature Genetics, v. 26, n. 4, p.444-446, Dez 2000. 
LEUNG H.T. \& LINSLEY P.S. The CD28 co-stimulatory pathway. Therapeutic Immunology, v. 1, n. 4, p. 217-228, Aug 1994.

LING V.; WU P.W.; FINNERTY H.F. et al. Assembly and annotation of human chromosome 2q33 sequence containing the CD28, CTLA4, and ICOS gene cluster: analysis by computational, comparative, and microarray approaches. Genomics, v. 78, n. 3, p. 155-168, Dez 2001.

LITOU H.; ANASTASIOU E.; THALASSINOU L. et al., Increased prevalence of VNTR III of the insulin gene in women with gestacional diabetes mellitus (GDM). Diabetes research and clinical practice, v. 76, n. 2, p. 223-228, Mai 2007.

LUCASSEN A.M.; SCREATON G.R.; JULIER C.; ELLIOT T.J.; LATHROP M.; BELL J.I. Regulation of insulin gene expression by IDDM associated, insulin gene locus haplotype. Human Molecular Genetics, v. 4, n. 4, p. 501-506, Abr 1995.

MAO J.; AI J.; ZHOU X.; SHENWU M. et al. Transcriptomic profiles of peripheral white blood cells in type II diabetes and racial differences in expression profiles. BMC Genomics, v. 12 Suppl 5, p.S12-S20, Dez 2011.

MCCARTHY, M.I. Genomics, type 2 diabetes, and obesity. The New England Journal of Medicine, v. 363, n. 24, p. 2339-2350, Dez 2010.

MEIGS J.B.; DUPUIS J.; HERBERT A.G.et al. The insulin gene variable number tandem repeat and risk of type 2 diabetes in a population-based sample of families and unrelated men and women. The Journal of Clinical Endocrinology and Metabolism, v. 90, n. 2, p. 1137-1143, Fev 2005.

METZGER B.E.; GABBE S.G.; PERSSON B. et al. International association of diabetes and pregnancy study groups recommendations on the diagnosis and classification of hyperglycemia in pregnancy. Diabetes and Care, v. 33, n. 3, p. 676682, Mar 2010.

MINISTÉRIO DA SAÚdE. CADERNOS DE ATENÇÃO BÁSICA - Diabetes Mellitus. Cadernos de Atenção Básica, A. Normas e Manuais Técnicos. n. 16, p. 64, 2006 .

MITCHELL S.M.; HATTERSLEY A.T.; KNIGHT B.; et al. Lack of support for a role of the insulin gene variable number of tandem repeats minisatellite (INS-VNTR) locus in fetal growth or type 2 diabetes-related intermediate traits in United Kingdom populations. The Journal of Clinical Endocrinology and Metabolism, v. 89, n. 1, p. 310-317, Jan 2004.

MUNIZ, Y. C.; FERREIRA, L. B.; MENDES-JUNIOR, C. T.; WIEZEL, C. E.; SIMOES, A. L. Genomic ancestry in urban Afro-Brazilians. Annals of human biology, v. 35, n. 1, p. 104-111, Jan - Fev 2008.

NEI, M. Molecular Evolutionary Genetics. Columbia University Press, New York, 1987 
NEJENTSEV S.; HOWSON J.M.; WALKER N.M. et al. Localization of type 1 diabetes susceptibility to the MHC class I genes HLA-B and HLA-A. Nature, v. 450, n. 7171, p. 887-892, Dez 2007.

NOBLE J.A.; VALDES A.M.; COOK M.; KLITZ W.; THOMSON G.; ERLICH H.A. The role of HLA class II genes in insulin-dependent diabetes mellitus: Molecular analysis of 180 Caucasian, multiplex families. American Journal of Human Genetics, v. 59, n. 5, p. 1134-1148, Nov. 1996.

NOKOFF N.J.; REWERS M.; CREE GREEN M. The interplay of autoimmunity and insulin resistance in type 1 diabetes. Discovery Medicine, v. 13, n. 69, p. 115-122, Fev 2012.

OLIVEIRA C.S.V.; FURUZAWA G.K.; REIS A.F.. Diabetes Mellitus do Tipo MODY, Arquivos Brasileiros de Endocrinologia \& Metabologia, v.46, n. 2, Abr 2002.

OLSSON A.H.; YANG B.T.; HALL E.; TANEERA J. et al. Decreased expression of genes involved in oxidative phosphorylation in human pancreatic islets from patients with type 2 diabetes. European Journal of Endocrinology, v. 165, n. 4, p. 589-595, Out 2011.

PECIOSKA S.; ZILLIKENS M.C.; HENNEMAN P.; SNIJDERS P.J.; OOSTRA B.A. et al. Association between Type 2 Diabetes Loci and Measures of Fatness. PLoS ONE v. 5, n. 1, p. e8541, Jan 2010.

PHILIP B. \& ISABEL W. Association of cytotoxic T lymphocyte-associated antigen 4 gene single nucleotide polymorphism with type 1 diabetes mellitus in Madurai population of Southern India. Indian Journal of Human Genetics, v. 17, n. 2, p. 8589, Mai 2011.

PLAISANCE V.; ABDERRAHMANI A.; PERRET-MENOUD V. et al. MicroRNA-9 controls the expression of Granuphilin/Slp4 and the secretory response of insulinproducing cells. The Journal of Biological Chemistry, v. 281, n. 37, p. 26932-26942, Jul 2006.

POY M.N.; ELIASSON L.; KRUTZFELDT J. et al. A pancreatic islet-specific microRNA regulates insulin secretion. Nature, v. 432, n. 7014, p. 226-230, Nov 2004.

POY M.N., SPRANGER M., STOFFEL M., MicroRNAs and the regulation of glucose and lipid metabolism. Diabetes, Obesity \& Metabolism, v. 9, n. 2, p. 67-73, Nov 2007.

PUGLIESE A.; AWDEH Z.L.; ALPER C.A. et al. The INS B allele (1,428 FokI) is associated with reduced IDDM incidence in autoantibodypositive first degree relatives despite the presence of autoantibodies and high-risk HLA alleles. Transplantation Proceeding, v. 27, n. 6, p.3392, Dez 1995.

PUGLIESE A.; ZELLER M.; FERNANDEZ A. et al. The insulin gene is transcribed in the human thymus and transcription levels correlated with allelic variation at the INS 
VNTR-IDDM2 susceptibility locus for type 1 diabetes. Nature Genetics, v. 15, n. 3, p. 293-297, Mar 1997.

PUGLIESE A. \& MICELI D. The insulin gene in diabetes. Diabetes / Metabolism research and reviews, v. 18, n. 1, p. 13-25, Jan-Fev 2002.

RAHA O.; SARKAR B. N.; BHASKAR L. V. K. S. et al.. Insulin (INS) promoter VNTR polymorphisms interactions and association with type 1 diabetes mellitus in Bengali speaking patients of Eastern India. Diabetologia Croatica, p. 40-44, Jul. 2011.

RASSI D. M.; JUNTA C. M.; FACHIN A. L. et al. Gene expression profiles stratified according to type 1 diabetes mellitus susceptibility regions. Annals of the New York Academy of Sciences, v. 1150, p. 282-289, Dez 2008.

RODRIGUEZ S., GAUNT T. R.; O'DELL S. D. et al. Haplotypic analyses of the IGF2-INS-TH gene cluster in relation to cardiovascular risk traits. Human Molecular Genetics, v. 13, n. 7, p. 715-725, Abr 2004.

RODRÍGUEZ S.; GAUNT T.R.; DENNISON E. et al.. Replication of IGF2-INS-TH*5 haplotype effect on obesity in older men and study of related phenotypes. European Journal of Human Genetics, v.14, n. 1, p. 109-116, Jan 2006.

ROUSSET, F. GENEPOP'007: a complete re-implementation of the GENEPOP software for Windowns and Linux. Mol Ecol Resour, v. 8, n. 1, p. 103-106, Jan. 2008.

SABATER L.; FERRER-FRANCESCH X.; SOSPEDRA M. et al.. Insulin alleles and autoimmune regulator (AIRE) gene expression both influence insulin expression in the thymus. Journal of Autoimmunity, v. 25, n. 4, p. 312 - 318, Dez. 2005.

SANTORO N.; CIRILLO G.; AMATO A.; LUONGO C. et al.. Insulin gene variable number of tandem repeats (INS VNTR) genotype and metabolic syndrome in childhood obesity. Journal of Clinical Endocrinology \& Metabolism, v. 91, n. 11, p. 4641-4. Jul 2006.

SHAAT N., EKELUND M., LEMMARK A. et al. Genotypic and phenotypic differences between Arabian and Scandinavian women with gestational diabetes mellitus. Diabetologia, v. 47, n. 5, p. 878-884, Abr 2004.

SHAAT N.; LERNMARK A.; KARLSSON E. et al. A variant in the transcription factor 7-like 2 (TCF7L2) gene is associated with an increased risk of gestational diabetes mellitus. Diabetologia, v. 50, n. 5, p. 972-979, Mai 2007.

SHU L.; SAUTER N.S.; SCHULTHESS F.T. et al. Transcription factor 7-like 2 regulates beta-cell survival and function in human pancreatic islets. Diabetes, v. 57, n. 3, p. 645-653, dez 2010.

STECK A. \& REWERS M. Genetics of type 1 diabetes. Clinical Chemistry, v. 57, n. 2, p. 176-185, fev 2011. 
STECHOVA K.; KOLAR M.; BLATNY R.; HALBHUBER Z. et al. Healthy first degree relatives of patients with type 1 diabetes exhibit significant differences in basal gene expression pattern of immunocompetent cells compared to controls: expression pattern as predeterminant of autoimmune diabetes. Scandinavian Journal of Immunology, v. 5, n. 2, p. 210-219, set 2011.

T2DB- T2D-Db an integrated data resource on type 2 diabetes. Disponível em: < http://t2ddb.ibab.ac.in/cgi-bin/statistics.cgi>. Acesso em: 20 jun. 2012.

UEDA H.; HOWSON J.M.; ESPOSITO L. et al. Association of the T-cell regulatory gene CTLA4 with susceptibility to autoimmune disease. Nature, v. 423, n. 6939, p. 506-511, mai 2003.

VAFIADIS P, BENNETT ST, COLLE E., et al.. Imprinted and genotype-specific expression of genes at the IDDM2 locus in pancreas and leucocytes. Journal Autoimmunity, v. 9, n. 3, p.397-403, Jun 1996.

VAN VLIET-OSTAPTCHOUK J.V.; VAN HAEFTEN T.W.; LANDMAN G.W.D. $e t$ al. Common Variants in the Type 2 Diabetes KCNQ1 Gene Are Associated with Impairments in Insulin Secretion During Hyperglycaemic Glucose Clamp. PLoS ONE, v. 7, n. 3, p. e32148, mar 2012.

VELD P.I. Insulitis in human type 1 diabetes. Islets, v. 3, n.4, p. 131-138. jul-aug 2011.

XU Y.; WEI Z.; ZHANG Z. et al. No association of the insulin gene VNTR polymorphism with polycystic ovary syndrome in a Han Chinese population. Reproductive Biology and Endocrinology, v. 1; n. 7, p. 141, Dez. 2009.

WALKER C.G.; GOFF L.; BLUCK L.J. et al. Variation in the FFAR1 Gene Modifies BMI, Body Composition and Beta-Cell Function in Overweight Subjects: An Exploratory Analysis. PLoS ONE, v. 6, n. 4, p. e19146, abr 2011.

WALTER M.; ALBERT E.;CONRAD M. et al.. IDDM2/insulin VNTR modifies risk conferred by IDDM1/HLA for development of Type 1 diabetes and associated autoimmunity. Diabetologia, v. 46, n. 5, p. 712-720, Mai 2003.

YANG B.; LIN H.; XIAO J.; LU Y. et al. The muscle-specific microRNA miR-1 regulates cardiac arrhythmogenic potential by targeting GJA1 and KCNJ2, Nature Medicine, v. 13, n. 4, p. 486-491, abr 2007.

YUN JH, GU BH, KANG YB et al. Association between INS-VNTR polymorphism and polycystic ovary syndrome in a Korean population. Gynecological and Endocrinology, .v. 28, n. 7, p.525-528. Jul 2012.

ZHAO Y.H.,WANG D.P., ZHANG L.L., ZHANG F. et al. Genomic expression profiles of blood and placenta reveal significant immune-related pathways and categories in Chinese women with gestational diabetes mellitus Diabetic Medicine, v. 28, n. 2, p. 237-246, fev 2011. 
ZHAO C.; DONG J.; JIANG T.; SHI Z.; YU B. et al. (2011) Early Second-Trimester Serum MiRNA Profiling Predicts Gestational Diabetes Mellitus. PLoS ONE, v. 6, n. 8, p. e23925, aug 2011. 
Anexos 


\title{
10. Anexos
}

\author{
ANEXO 1 \\ Termo de consentimento Livre e Esclarecido
}

HOSPITA DAS CLÍNICAS DA FACULDADE DE MEDICINA

DE RIBEIRÃO PRETO DA UNIVERSIDADE DE SÃO PAULO

Campus Universitário Monte Alegre, fone: 36366-1000, Fax: 3633-1144 CEP: 14048-900, Ribeirão Preto, São Paulo

TERMO DE CONSENTIMENTO LIVRE ESCLARECIDO

1) NOME DA PESQUISA: META-ANÁLISE DO PERFIL DE EXPRESSÃO GÊNICA DIFERENCIAL EM LINFÓCITOS DE PACIENTES COM DIABETES MELITUS TIPO 1, TIPO 2 E GESTACIONAL

2) PESQUISADOR RESPONSÁVEL: Dra. Diane Meyre Rassi

AS INFORMAÇÕES SUPRA-CITADAS DEVEM SER REDIGIDAS EM TERMOS SIMPLES, CONHECIDOS PELOS PACIENTES E DE FORMA QUE POSSAM ENTENDER:

No diabetes, ocorre diminuição da produção de insulina, fazendo com que o paciente necessite tomar insulina diariamente ou fazer dieta. Algumas pessoas desenvolvem a doença na infância (diabetes do tipo 1), outras na fase adulta (diabetes do tipo 2) e outras durante a gravidez (diabetes gestacional). Os motivos pelos quais os pacientes desenvolvem diabetes não são bem conhecidos. Para entender um pouco mais sobre os mecanismos associados com o desenvolvimento do diabetes, estamos propondo estudar os diversos tipos da doença (tipo 1, tipo 2 e gestacional), comparando algumas características, presentes no sangue, que são comuns a todos os tipos de diabetes, e outras que são observadas somente em cada tipo de diabetes. Para fazer este estudo, estamos pedindo ao Sr., Sra., ou responsável pelo paciente, a permissão para colher 10 $\mathrm{mL}$ de sangue (correspondente a 1 colher de sopa). O principal desconforto deste estudo e a picada da agulha, durante a colheita de sangue. Para evitar a colheita de sangue somente para este estudo, pretendemos colher o sangue em um dos seus retornos no hospital. Este estudo não traz benefício imediato ao doente, mas poderá, no futuro, trazer contribuições para os grupos de pacientes que vierem apresentar o diabetes, adotando medidas que poderão retardar ou impedir a progressão da doença. 
$\mathrm{Eu}$,

Registro Geral N ${ }^{\circ}$

, abaixo assinado, tendo recebido as informações acima, e ciente dos meus direitos abaixo relacionados, concordo em participar.

1 - A garantia de receber a resposta a qualquer pergunta ou esclarecimento a qualquer dúvida acerca dos procedimentos, riscos, benefícios e outros relacionados com a pesquisa e o tratamento a que serei submetido;

2 - A liberdade de retirar meu consentimento a qualquer momento e deixar de participar do estudo sem que isso traga prejuízo à continuação do meu cuidado e tratamento;

3 - A segurança de que não serei identificado e que será mantido o caráter confidencial da informação relacionada com a minha privacidade;

4 - O compromisso de me proporcionar informação atualizada durante o estudo, ainda que essa possa afetar minha vontade de continuar participando;

5 - A disponibilidade de tratamento médico e indenização que legalmente teria direito, por parte da Instituição de Saúde, em caso de danos que a justifiquem diretamente causados pela pesquisa e;

6 - Que se existirem gastos adicionais estes serão absorvidos pelo orçamento da pesquisa.

7 - Caso exista qualquer tipo de problema ou dúvidas gerais, questionamentos sobre a pesquisa, entrar em contato com a pesquisadora responsável, Dra. Diane Meyre Rassi, pelos telefones: (16) 3602-2566, (16) 3602-3246 ou (16) 8122-8949 ou e-mail: dianerassi@usp.br

Ribeirão Preto, de de 
ANEXO 2

Aprovação do Comitê de Ética em Pesquisa do HCRP e da FMRP-USP

HOSPITAL DAS CLÍNICAS DA FACULDADE DE MEDICINA DE RIBEIRÃO PRETO DA UNIVERSIDADE DE SÃO PAULO

Ribeirão Preto, 04 janeiro de 2012

Oficio $n^{\circ} 46 / 2012$

CEP/MGV

Prezados Senhores,

O trabalho intitulado "POLIMORFISMO DE GENES HLA E DA INSULINA EM PACIENTES COM DIABETES MELLITUS TIPO 1, TIPO 2 E GESTACIONAL", foi analisado "AD REFERENDUM" pelo Comitê de Ética em Pesquisa e enquadrado na categoria: APROVADO, bem como o Termo de Consentimento Livre e Esclarecido, de acordo com o Processo HCRP $n^{\circ}$ $12542 / 2011$.

Este Comitê segue integralmente a Conferência Internacional de Harmonização de Boas Práticas Clinicas (IGH-GCP), bem como a Resolução $n^{\circ}$ 196/96 CNS/MS.

Lembramos que devem ser apresentados a este CEP, o Relatório Parcial e o Relatório Final da pesquisa.

De acordo com Carta Circular $n^{\circ}$ 003/2011/CONEP/CNS, datada de 21/03/2011, o sujeito de pesquisa ou seu representante, quando for o caso, deverá rubricar todas as folhas do Termo de Consentimento Livre $e$ Esclarecido - TCLE - apondo sua assinatura na última do referido Termo; o pesquisador responsável deverá da mesma forma, rubricar todas as folhas do Termo de Consentimento Livre e Esclarecido - TCLE - apondo sua assinatura na última página do referido Termo.

Atenciosamente.

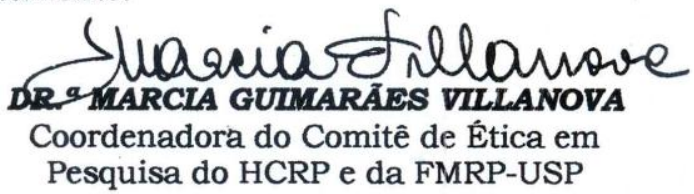

Ilustríssimos Senhores

DRa DIANE MEYRE RASSI

PROF. DR. EDUARDO ANTÔNIO DONADI (Supervisão)

Depto. de Clínica Médica 


\section{ANEXO 3}

Distribuição dos genótipos em associação com o sexo, pigmentação da pele e retinopatia em pacientes com DM1.

\begin{tabular}{ccccccccc}
\hline \multirow{2}{*}{ Genótipos } & \multicolumn{2}{c}{ Sexo } & \multicolumn{4}{c}{ Pigmentação da pele } & \multicolumn{2}{c}{ Retinopatia } \\
\cline { 2 - 8 } & F & M & Branco & Negro & Mulato & Amarelo & Presença & Ausência \\
\hline $\begin{array}{c}\text { classe I : } \\
\text { classe I }\end{array}$ & 20 & 38 & 78 & 2 & 4 & 2 & 3 & 67 \\
$\begin{array}{c}\text { classe I : } \\
\text { classe III } \\
\text { classe III : } \\
\text { classe III }\end{array}$ & 14 & 13 & 19 & 3 & 5 & 0 & 2 & 25 \\
\hline
\end{tabular}

Distribuição dos genótipos em associação com o sexo em pacientes com DM2.

\begin{tabular}{ccc}
\hline \multirow{2}{*}{ Genótipos } & \multicolumn{2}{c}{ Sexo } \\
\cline { 2 - 3 } & F & M \\
\hline classe I : classe I & 20 & 38 \\
classe I : classe III & 14 & 13 \\
classe III : classe III & 8 & 2 \\
\hline
\end{tabular}

Distribuição dos genótipos em associação com o perfil glicêmico de jejum em pacientes com DMG.

\section{Glicemia de jejum (mg/dL)}

\begin{tabular}{ccc}
\hline classe I : classe I & classe I : classe III & classe III : classe III \\
\hline 74 & 80 & 86 \\
81 & 67 & 97 \\
68 & 74 & 81 \\
82 & 65 & 102 \\
85 & 74 & 91 \\
96 & 86 & 95 \\
76 & 80 & 105 \\
78 & 78 & 105 \\
86 & 89 & 274,4 \\
59 & 80 & 145 \\
96 & 92 & 107 \\
74 & 85 & 111 \\
103 & 94 & 93 \\
69 & 105 & 80 \\
152 & 90 & 89 \\
108 & 99 & \\
70 & 132 & \\
86 & 96 & \\
\hline
\end{tabular}




115
94
148
89
104
71
91
92
96

